\title{
Global drivers of cryptocurrency infrastructure adoption
}

\author{
Ed Saiedi ( A Anders Broström • Felipe Ruiz
}

Accepted: 10 December 2019 / Published online: 2 March 2020

(C) The Author(s) 2020

\begin{abstract}
A vast digital ecosystem of entrepreneurship and exchange has sprung up with Bitcoin's digital infrastructure at its core. We explore the worldwide spread of infrastructure necessary to maintain and grow Bitcoin as a system (Bitcoin nodes) and infrastructure enabling the use of bitcoins for everyday economic transactions (Bitcoin merchants). Specifically, we investigate the role of legal, criminal, financial, and social determinants of the adoption of Bitcoin infrastructure. We offer some support for the view that the adoption of cryptocurrency infrastructure is driven by perceived failings of traditional financial systems, in that the spread of Bitcoin infrastructure is associated with low trust in banks and the financial system among inhabitants of a region, and with the
\end{abstract}

Electronic supplementary material The online version of this article (https://doi.org/10.1007/s11187-019-00309-8) contains supplementary material, which is available to authorized users.

E. Saiedi $(\bowtie) \cdot$ A. Broström

Department of Industrial Economics and Management, KTH

Royal Institute of Technology, Lindstedtsvägen 30, 114

28 Stockholm, Sweden

e-mail: ed.saiedi@indek.kth.se

A. Broström

e-mail: anders.brostrom@indek.kth.se

E. Saiedi · F. Ruiz

Department of Business Administration and Statistics, School of Industrial Engineering (ETSII), Universidad Politécnica de

Madrid, 28006 Madrid, Spain

F. Ruiz

e-mail: felipe.ruiz@upm.es occurrence of country-level inflation crises. On the other hand, our findings also suggest that active support for Bitcoin is higher in locations with well-developed banking services. Finally, we find support for the view that bitcoin adoption is also partly driven by cryptocurrencies' usefulness in engaging in illicit trade.

Keywords Bitcoin network · Digital currencies . Cryptocurrencies · Financial technology (Fintech) . Bitcoin nodes $\cdot$ Bitcoin merchants

JEL classifications $\mathrm{O} 3 \cdot \mathrm{P} 40 \cdot \mathrm{O} 57 \cdot \mathrm{L} 86 \cdot \mathrm{L} 17 \cdot \mathrm{D} 84$. L26

\section{Introduction}

Cryptocurrencies are proliferating. A decade on since their dawn with the invention of Bitcoin, the value of all cryptocurrencies reached $\$ 0.25$ trillion. To put that in perspective, there is $\$ 1.7$ trillion USD and \$1.4 trillion Euros in circulation today (European Central Bank 2019; U.S. Federal Reserve Board 2019). As of November 2019, bitcoin is the world's sixth largest currency in circulation. ${ }^{1}$ The average daily trading of cryptocurrencies has surpassed $1 \%$ of trading in foreign exchange markets, the world's largest market by trading volume. ${ }^{2}$ Bitcoin

\footnotetext{
${ }^{1}$ https://howmuch.net/articles/how-much-currencies-are-worth

2 In October 2019, daily trading in all cryptocurrencies varied between \$41.7B and \$15 6.3B (source: https://coinmarketcap.com/charts/), whereas daily trading in global foreign exchange was approximately \$6.6 T in April 2019 (Bank of International Settlements 2019).
} 
transactions and unique accounts alone have grown at nearly $60 \%$ per annum over the past 5 years. In short, cryptocurrencies are being adopted rapidly and broadly. While theoretical papers are emerging discussing why cryptocurrencies, or digital currencies in general, may be adopted by individuals or businesses (e.g., Cohen 2017; Dierksmeier and Seele 2018; Dodgson et al. 2015), there is a scarcity of global empirical studies on drivers of their adoption.

The emergence of cryptocurrencies has often been viewed as driven by the opportunity for radical innovation and entrepreneurship in financial solutions as created through the spread of new Internet-based technology (Iyidogan 2018; Teo 2015). However, recent studies have emphasized that in order to understand the historical growth and future prospect of fintech innovations, we must also understand the nature of the needs addressed by such innovations (Cohen 2017; Huang et al. 2019; Saiedi et al. 2017). The development and spread of technology is in this sense a prerequisite - but not a sufficient factor-for the spread of cryptocurrencies. In this paper, we focus on socio-economic and institutional factors related to potential drivers for interest in cryptocurrency development. Thereby, we seek to offer a novel and broader account for the growth of this type of financial technology.

Digital entrepreneurial ecosystems have two foundational pillars of digital infrastructure and users (Sussan and Acs 2017) and infrastructure facilitating connectivity, e.g., digital infrastructure, are found to particularly enhance startup activity (Audretsch et al. 2015). Digital infrastructures enable innovation (Henfridsson and Bygstad 2013; Sussan and Acs 2017), anchor open entrepreneurship (Ingram Bogusz and Morisse 2018), allow for fintech platforms to grow (Yermack 2018), and create decentralized work organizations (Tilson et al. 2010). While recent studies have shed light on determinants of fintech startup activity or fundraising using cryptocurrencies (Fisch 2019; Haddad and Hornuf 2019; Huang et al. 2019), there are, as of yet, no empirical studies exploring determinants of adoption of the infrastructure supporting cryptocurrencies. This study fills this gap.

We explore drivers behind the global uptake of digital infrastructure enabling the use of the most prominent digital currency to date; Bitcoin (spelled with capital B when referring to the system, and with lower-case $b$ when referring to the unit of account, in keeping with convention in the computer science literature.) We consider infrastructure necessary for Bitcoin's blockchain information dissemination and transaction verification, Bitnodes, as well as infrastructure necessary for the adoption of bitcoin as a means of payment in regular retail. We believe these types of Bitcoin infrastructure ${ }^{3}$ to provide an informative lens and context for exploring the drivers behind the recent growth of the cryptocurrency. In particular, we believe that that by studying patterns of adoption of these two different types of infrastructure, we obtain complimentary perspectives of the drivers behind the growth of Bitcoin as a system.

We chose to focus on Bitcoin since it is presently the most well-known and widespread cryptocurrency. ${ }^{4}$ Most cryptocurrencies are recorded as clones or as variations of the Bitcoin technology (e.g., Litecoin), build their blockchain as a fork of the Bitcoin blockchain (e.g., Bitcoin cash) or on nearly identical transaction ledgers (Gandal and Halaburda 2014; Wang et al. 2019). Bitcoin has the highest cryptocurrency trading volume, constitutes more than half of cryptocurrencies' market capitalization, provides much-needed liquidity to other cryptocurrencies, and enables a secondary market for the cryptocurrency ecosystem to thrive on. Bitcoin's decade-long dominating position is demonstrated by it being the only cryptocurrency whose price has causality effects on alternative cryptocurrencies or altcoins $^{5}$ (Svetlana et al. 2017).

Bitcoin has also been shown to play an important role for the emergence of new digital entrepreneurial ecosystems, consisting of Initial Coin Offering (ICO) issuers, payment processors, exchanges, wallets, financial services, mining hardware, and developers (Sameeh 2018). Bitcoin, or emulations of Bitcoin, play a central role in this development (The Economist 2008). For example, the first ICO was carried out in July 2013 by

\footnotetext{
$\overline{3}$ A review of these two types of technical infrastructure and their role for bitcoin as a currency is provided in the Appendix.

${ }^{4}$ See https://www.blockchain.com/en/charts/n-transactionstotal?timespan=all for bitcoin transactions and https://www.quandl. com/data/BCHAIN/NADDU-Bitcoin-Number-of-Unique-BitcoinAddresses-Used for unique accounts.

${ }^{5}$ Bitcoin constitutes $\sim 20-35 \%$ of all cryptocurrency trading volumes, and litecoin or bitcoin cash, which utilize Bitcoin's blockchain, are respectively the 4th and 7th largest cryptocurrency by volume as of January 3, 2019 (coinmarketcap.com/charts). Wei (2018) calculates Amihud-illiquidity ratios for 456 cryptocurrencies, listing Bitcoin as the most liquid. Hu et al. (2018) document average daily and monthly bitcoin price cross-correlation of respectively 0.174 and 0.21 with all altcoins with market values exceeding $\$ 1 \mathrm{M}$. Bitcoin's price crosscorrelation with ether, litecoin, and monero was 0.88 (Fisch 2019), 0.43 and 0.43 (Hu, Parlour, and Rajan 2018) respectively. ICO-bitcoin correlations have increased since January 2018's cryptocurrency price peaks (Fatás and Weder 2019).
} 
Mastercoin, a cryptocurrency built on the Bitcoin blockchain (Shin 2017). The central role of bitcoin is illustrated by the findings of Masiak et al. (2019), who find that shocks in bitcoin prices positively influence ether-the cryptocurrency underlying most ICOs' blockchain platforms - but not vice versa. In this light, the development of Bitcoin infrastructure might be expected to play a role in enabling the expansion of digital financing and entrepreneurship rapidly emerging through cryptocurrencies.

Our results provide some support for the view that bitcoin adoption is driven by perceived failings of traditional financial systems (see, e.g., Cohen 2017; Shiller 2019; Vigna and Casey 2015). In particular, we find more adoption where distrust in banks and the financial system are greater, as well as in countries experiencing inflation crises. Meanwhile, the spread of Bitcoin infrastructure seems to be complimentary to existing financial systems, as we observe less adoption where bank rents and share of the unbanked are highest. In line with expectations that interest in bitcoin as a speculative investment is a partial driver of adoption of bitcoin (e.g., Baur et al. 2018b), we find more Bitcoin infrastructure where the willingness to take risks are higher. We furthermore show that bitcoin adoption is greatest where the risk of narcotics-related money laundering is greatest, as well as where perceptions of the rule of law is strongest. This latter finding may hint at a shift to pseudonymous online cryptocurrency crime where offline law enforcement is strong.

While a number of studies make strides in researching the adoption of bitcoins - qualitatively by surveying experts (Ermakova et al. 2017) or users (Henry et al. 2018; Schuh and Shy 2016), anonymous online marketplaces (Böhme et al. 2015), archival data (Sadhya and Sadhya 2018), or quantitatively using the small de-anonymized fraction of an online forum (Athey et al. 2016) or within one continent solely (Yermack 2018), to the best of our knowledge, we provide the first global empirical study on the Bitcoin phenomenon. Our study is also the first to empirically analyze the growth of Bitcoin infrastructure. We thereby contribute to a nascent body of research that delves into exploring the adoption of financial technologies (Xue et al. 2011, Rau 2017, Haddad and Hornuf 2019, Huang et al. 2019, Yermack 2018, Higgins 2018, Estrin et al. 2018).

We improve upon current research on adoption of digital currencies by empirically examining actual digital currency support over time in a panel data set. We have location data, covering the entire world, enabling the use of geospatial data analysis to investigate the role of socio-economic and institutional factors, in parallel to technological and economic factors, in driving their adoption. Recent literature has emphasized the need to integrate the social, economic, and cultural elements when studying entrepreneurial ecosystems (Spigel 2017). As to the authors' best knowledge, there are no empirical studies yet that have simultaneously investigated the relevance of both types of factors for interest in Bitcoin on a global scale. Our unique context of cryptocurrency infrastructure allows us to do so.

By increasing our understanding of what socioeconomic and institutional factors that are associated with the adoption of the infrastructure behind virtual currencies, the study offers important insights to scholars seeking to understand the growth of cryptocurrencies to date. These results are also of potential interest to monetary authorities as well as for developers and entrepreneurs in the virtual currency ecosystem, including financial institutions, ecommerce payment system providers or technology companies, which are exploring or planning to issue or accept virtual currencies.

The remainder of this article is organized as follows. In section 2, we discuss a conceptual framework for our analyses. Section 3 provides a thorough description of our novel data, starting with an overview of the Bitcoin infrastructure studied. Sections 4 describes our methodology, and Section 5 explains our results. We conclude and discuss implications of our findings in Section 6.

\section{Conceptual framework}

In considering what socio-economic and institutional factors may be related to the intensity of Bitcoin infrastructure adoption, we build on a view of decisions to set up and operate Bitcoin infrastructure as being related to a combination of extrinsic and intrinsic motivations. The launch of the Bitcoin system was embedded in idealistic notions of providing means to replace existing financial structures, and nurturing an alternative monetary and financial system that would enable greater anonymity, privacy, and autonomy (Bashir et al. 2016; Böhme et al. 2015; Dodd 2018; Shiller 2019). Individuals setting up Bitcoin nodes to grow the peer-to-peer 
network would often do so as an expression of support for Bitcoin as a system and financial phenomenon. Meanwhile, those running a node do so to verify that their own transactions are secure, while it may also be related to bitcoin mining activities, where individuals seek to earn bitcoins. Merchants' willingness to adopt technology necessary to accept bitcoins as payment for their goods is clearly to a large extent driven by business motivations, while the customer preferences to which merchants react to, may considerably be driven by their support for Bitcoin on idealistic grounds. 'Support for Bitcoin' is thus in our study a central (albeit not directly observed) factor.

The growth of Bitcoin infrastructure can be expected to be directly linked not only to support and positive attitudes, but also to the actual use of bitcoin (e.g., in terms of the number of people holding bitcoins). We expect that in the relatively early stage of development that we are studying, the use of bitcoin as a currency and the support for the Bitcoin system are to be understood as interdependent entities. That is, we expect that positive attitudes towards the cryptocurrency will translate into more use, and we expect greater use to spread the interest for (and general awareness of) Bitcoin, i.e., to increase the number of people interested in supporting the Bitcoin network. In developing hypotheses about the adoption of Bitcoin infrastructure, we hence consider what set of socio-economic and institutional factors may be associated with greater support and use of the cryptocurrency.

\subsection{Bitcoin's differentiating technologies}

Cryptocurrencies such as bitcoins have been hailed as pioneering and potentially disruptive financial technologies. Bitcoin's blockchain technology allowed for a novel way of solving the "double spending problem" intrinsic to digital currencies, without relying on a central clearinghouse or trusted third party (Folkinshteyn et al. 2015; Böhme et al. 2015). Active support for Bitcoin may hence be understood as being fundamentally related to opportunities enabled from these differentiating technologies; making it an attractive substitute to traditional currencies for groups of users (Athey et al. 2016; Ermakova et al. 2017). Opportunities arising due to the differentiating technology underlying Bitcoin stem from its ability to remove the need for a trusted third party or disintermediation, and due to its cryptographic technology, that enables pseudonymity in online transactions (Cohen 2017). ${ }^{6}$

Preferences for remaining anonymous in financial transactions may be associated with entirely ideological views. In an empirical examination of the related phenomenon of ICOs, Fisch et al. (2019) find such ideological motives to be among the most important drivers behind the early development of ICOs. However, preferences for anonymity also arise due to specific intentions to evade legal authorities. Böhme et al. (2015) document that while consumer payments and buy-andhold purposes became important drivers of bitcoin adoption in later stages, in the early use of bitcoin, online sale of narcotics, and gambling transfers played a very important role.

Against this background, it would seem valid to expect that the global spread of bitcoin has been driven both by its potential role as a partial substitute role for traditional financial services and currencies, and by its potential role as facilitator of illicit activity. In what follows, we consider these two alternative accounts for what drives adoption of infrastructure for the supply and demand of bitcoins.

\subsection{Bitcoin as complement or substitute to established financial systems}

The nascent literature on the Bitcoin system and bitcoin currency indicates their financial potential as (a) a new exchange/payment system, (b) an investment, or (c) a speculative trading instrument. Bitcoin's novelty as a payment system is due to its relatively low foreignexchange transaction costs (Kim 2017), and its independence from monetary authorities, governments or processing via third-party financial intermediaries. Meanwhile, Glaser et al. (2014) find that uninformed bitcoin users are primarily interested in bitcoin as an alternative investment vehicle, rather than an alternative transaction

\footnotetext{
${ }^{6}$ Such opportunities were in line with influential factors at the very inception of the blockchain within the cyberpunk movement. Bitcoin's white paper outlines anonymity and decentralization as influential factors shaping the evolution of the blockchain sector (Iansiti and Lakhani 2017). While the developmental motives of the blockchain were anonymity and decentralization, the practical outcome can more exactly be described as it providing pseudonymity (Böhme et al. 2015) and disintermediation, not anonymity and decentralization. Eyal and Sirer (2014) state that "At this point, the currency is not decentralized as originally envisioned." In reality, blockchain has helped create a disintermediated payment system, as well as a disintermediated method of raising venture financing via ICOs.
} 
system. As an investment it increases opportunities for portfolio risk management owing to its very limited correlation with other asset returns such as fiat currencies, stocks, bonds and commodities such as gold (Baur et al. 2018a; Dyhrberg 2016) and hedging against economic uncertainty (Bouri et al. 2017a; 2017b).

While previous academic studies have attributed less (e.g., Blau 2018) or more weight (e.g., Baur et al. 2018 b) to speculative trading as the primary use of Bitcoin, it is clear that speculation is a factor behind the rising number of individuals holding bitcoin. To the extent that the adoption of Bitcoin infrastructure is related to the stock of bitcoin holders, geographical variation in Bitcoin infrastructure adoption may be related to geographical differences in the intensity of speculative trading. In this analysis, however, we are primarily concerned with analyzing support for Bitcoin infrastructure in relation to the cryptocurrency's potential as complement or substitute to more fundamental functions of the established financial system. This is since node infrastructure are primarily set up to support bitcoins as an exchange and payment system. Merchants' adoption of Bitcoin infrastructure may also be understood as driven by support for Bitcoin, both in regard to the merchants' own views and in regard to the views of customer groups that merchants would want to appeal to.

In the remainder of this section, we describe three sets of factors that may drive support for Bitcoin as a financial exchange/payment system. Bitcoin may substitute for (real or perceived) failings of established financial systems, due to opportunities of disintermediation and decentralization technologies. We first consider bitcoin as a substitute for fiat currencies in inflation crises. We subsequently consider less acute failings of established financial systems, in discussing whether Bitcoin can be considered a viable (potential) substitute to poorly functioning national banking markets. Finally, we consider a more ideological perspective of interest in Bitcoin as being driven by the spread of general attitudes of distrust in banks and the established financial system.

When discussing banking market development, we also acknowledge that financial development may also be expected to drive the interest in cryptocurrencies. If this mechanisms dominates, support for Bitcoin and the growth of Bitcoin infrastructure will be stronger-not weaker-in countries with well-developed banking markets.

\subsubsection{Inflation}

In its capacity as a global currency which is not tied to any particular economy, bitcoin has the potential to act as a hedging opportunity against country-specific risk. In particular, buying bitcoins offers a novel opportunity to hedge against (very) high inflation, in parallel to how gold and other assets have been known to function in the past (Arnold and Auer 2015). Luther (2016) finds that currency transitions have often occurred during episodes of hyperinflation, exemplified by many Bolivians and Peruvians who switched to US dollars, perceived to be safer, during such national episodes in the 1980s. People affected by very high inflation may therefore become more actively interested in holding and using bitcoin, and in supporting Bitcoin as an alternative financial system.

Cryptocurrencies have indeed been touted by advocates as a means to a less crisis-prone financial system (Maurer et al. 2013) and as a counterweight to (hyper)inflation (Dierksmeier and Seele 2018). There are also reports that countries experiencing high inflation have seen surges in interest in bitcoins. This is visible in the example of Venezuela, where inflation soared, trust in the national government policy and currency plummeted and interest in bitcoins increased, evidenced by the popularity of bitcoin mining (Kliber et al. 2019). Another noted example is Cyprus during its 2012-2013 financial crisis (Subramanian and Chino 2015). We hence expect that high inflation levels or inflation crises may systematically affect the adoption of the two types of Bitcoin infrastructure (bitnodes, bitcoin merchants).

Hypothesis 1: The occurrence of inflation crises is associated with increased adoption of Bitcoin infrastructure.

\subsubsection{Banking market development and competition}

There is a potential for financial technologies to substitute for deficient provision of traditional banking services, as evidenced, e.g., by the use of mobile money accounts to transfer money in Sub-Saharan Africa (Demirguc-Kunt et al. 2018). Digital currencies have been hailed as a promising means to reach businesses and people in remote and marginalized areas (Lagarde 2018). Around the world, most existing payment systems (e.g., credit and debit cards) rely on transactors to hold bank accounts. It is conceivable that digital currencies could serve as a payment system of choice for the 
unbanked (i.e., those without bank accounts). In fact, an extensive survey of the Bitcoin community finds that serving the unbanked is one of the foremost purported promises of this currency (Vigna and Casey 2015; see Chapter 8 entitled "Unbanked").

Whereas payment of a minor fee for access to services of an online trading platform is sufficient for a digital currency transaction (Dwyer 2015), banking systems impose fees on businesses and individuals, in the form of depository and transactional fees. Philippon (2016) finds that the unit cost of financial intermediation has remained consistently and surprisingly expensive from 1886 to 2012 . Conventional transactions impose costs ranging from a small percentage (e.g., 1-3\% for credit card purchases) up to highs of one fifth of transferred amounts (e.g., international remittances; see Beck and Martínez pería 2011).

By removing the intermediary, the development of Bitcoin has the potential to do away with these costs. Transaction fees for bitcoins are in the $0-1 \%$ range (Kaskaloglu 2014). Bitcoin offers a welcome alternative when high transaction costs of traditional transactions either disincentives the transaction altogether or diminish its benefits (Dierksmeier and Seele 2018). The ease of exchange via cryptocurrencies can extend much-needed liquidity to recipients of micropayments or loans in developing and underdeveloped countries, offering the world's 'unbanked' millions an unprecedented degree of convenience and security (Vigna and Casey 2015). Lacking access to a financial institution or the needed documentation to use one, such individuals have to rely on storing cash, endangering themselves and limiting them to transact with those within their physical reach (Dierksmeier and Seele 2018). As long as access to a mobile phone with SMS technologies or Internet connection exists on any device, a whole world of transaction and investment possibilities becomes available (Raymaekers 2015).

Besides the penetration of banking, underdeveloped competition in the banking market may be another factor driving interest in Bitcoin as a payment system. Low competition within the financial system is expected to be associated with high rents and limited innovation by incumbents, aggravating the frictions of traditional banking services in terms of costs, service availability, and service scope. Therefore, low competition may in principle drive consumers to adopt alternative financial technologies for reasons parallel to those developed above. Moreover, low competition in the banking market stimulates investment in fintech (Thakor 2019). Interest in Bitcoin may follow in the wake of such activity.
In summary, we suggest the following set of hypotheses:

Hypothesis 2a: The lower the population of financially included adults, the greater the adoption of Bitcoin infrastructure.

Hypothesis 2b: The lower the level of competition in banking markets, the greater the adoption of Bitcoin infrastructure.

On the other hand, it is also possible that financial development is a prerequisite for interest in cryptocurrencies. Lacking experience with traditional Internet banking services, people may not be prepared to deal in cryptocurrency. A lack of familiarity with financial intermediaries and their services may also lead to little interest in exploring their alternatives. Such a view would suggest that digital infrastructure aimed at disrupting banking may develop most strongly in environments with the most well-developed banking markets.

Financial literacy and sophistication is a pre-requisite for taking advantage of financial innovations (Campbell 2006) and engaging in complex financial products, such as stock market investments (van Rooij et al. 2011) or retirement planning (van Rooij et al. 2012). Financial literacy has been shown to underlie financial inclusion and increase the use of financial services (Grohmann et al. 2018) and hence, it is likely that a high level of financial literacy and inclusion is required for use of complex financial innovations such as bitcoins. The use of electronic payments has been found to be associated with financial inclusion (c.f. Thakor 2019). Emerging research points to complementarities between banking markets and fintech development (Hornuf et al. 2018; Klus et al. 2019). For example, Gazel and Schwienbacher (2018) find locations with more bank headquarters and financial competition attract more fintech clusters. Such a development can generate externalities in the form of greater know-how of financial technologies, and thereby also interest in cryptocurrencies such as bitcoin. It is also possible that in a more vibrant banking market, where competition drives banks to innovate, banking costumers become less risk-averse towards trying new electronic services.

Together, these arguments suggest that interest in bitcoin may be highest in countries with welldeveloped banking systems and high banking market competition. 
We consider the following two competing hypotheses:

Hypothesis 2c: The greater the population of financially-included adults, the greater the adoption of Bitcoin infrastructure.

Hypothesis 2d: The higher the level of competition in banking markets, the greater the adoption of Bitcoin infrastructure.

\subsubsection{Trust and social attitudes}

A prerequisite for economic exchange, trust has been found to be positively associated with financial development and investments. Researchers have explored its role in online markets such as e-commerce ( $\mathrm{Ba}$ and Pavlou 2002), peer-to-peer lending (Duarte et al. 2012), or crowdfunding (Liang et al. 2019; Rau 2017). While the blockchain technology may be perceived as reducing the need for direct trust in individuals, many important uses of bitcoin would seem to be positively associated with general trust. We therefore expect higher levels of trust in others to increase interest in Bitcoin, e.g., in the form of increased trade in bitcoins for investment, speculation and online or in-store commerce.

Cohen (2017) documents that bitcoins emerged as part of the $99 \%$ movement - initiated by the Occupy Wall Street protests - and frustrations with banks that had become too big to fail. ${ }^{7}$ The launch of the Bitcoin system was embedded in idealistic notions of providing means to replace existing financial structures, and nurturing an alternative monetary and financial system that enables greater anonymity, privacy, and autonomy (Bashir et al. 2016; Böhme et al. 2015; Dodd 2018; Shiller 2019). Via enabling cheap and automated verification on distributed ledgers, the blockchain technology underlying cryptocurrencies allows for trust in an intermediary to be replaced by trust in the devised code and rules that define how the network reaches consensus (Goldfarb and Tucker 2019). Desire for this replacement is likely greater where trust in financial intermediaries, whom traditionally verified payments, is lower, and can thus motivate the uptake of cryptocurrencies.

\footnotetext{
${ }^{7}$ Indeed, in the very first bitcoin mined, its founder, Satoshi Nakamoto, embedded the message "The Times 03/Jan/2009 Chancellor on brink of second bailout for banks," referring to the Times of London's sameday headline (Elliott and Duncan 2009).
}

While to the best of our knowledge no systematic investigation has been done regarding distrust to banks and financial institutions as a driver of support for Bitcoin, the role of trust to banks has started to be explored in other fintech settings. Saiedi et al. (2017) and Bertsch et al. (2017), show that a decline in trust in banks and financial institutions increases participation respectively, by lenders and borrowers, in online peer-to-peer (P2P) lending markets. Theoretical papers modeling trust-driven substitutions between intermediaries and fintech firms are also emerging (e.g., Thakor and Merton 2018). We thus posit that lower trust in banks and the financial system underlies the emergence and adoption of bitcoins. In our variable definitions, we use distrust to mean lack of trust for brevity.

Yermack (2015) reports that one of the major obstacles facing bitcoin in becoming an adopted currency is its extreme time-series volatility. This high volatility is a product of the highly speculative nature of the bitcoin market (Baek and Elbeck 2015). Yermack (2015) further reports that it is widely understood that most bitcoin transfers involve transactions between speculative investors. Empirical studies corroborate the use of bitcoins as a speculative investment (Baur et al. 2018b; Bouoiyour and Selmi 2015) and that it exhibits speculative bubbles (Cheah and Fry 2015; Fry 2018). It thus seems reasonable to assume that the interest to buy and hold bitcoins for speculative purposes, and the willingness to accept risk when holding bitcoin to be used for transactions, would require a certain level of risk-willingness. Regional differences in average willingness to take financial risks may therefore affect the use of bitcoin. We expect that the higher the willingness to take risk in a region, the greater the adoption of bitcoins for speculative trading.

In summary, we expect that active support for Bitcoin is associated with a lack of trust in the established financial system. Such support would be manifested, e.g., through the running of Bitcoin nodes, and may also affect merchants' willingness to accept bitcoin. Greater trust in other people and higher risk-willingness is expected to facilitate the use of bitcoin, and thereby the interest in adoption of Bitcoin infrastructure in a region - in particular in regard to merchants' adoption of bitcoin payments.

Hypothesis 3a: The greater the level of trust in others, the greater the adoption of Bitcoin infrastructure. 
Hypothesis 3b: The greater the level of distrust in banks and the financial system, the greater the adoption of Bitcoin infrastructure.

Hypothesis 3c: The higher the risk-willingness, the greater the adoption of Bitcoin infrastructure.

\subsection{Bitcoin as a facilitator of illicit activity}

Bitcoin's differentiating technology of pseudonymity makes the cryptocurrency interesting for actors pursuing activities of illegal trade such as drug trafficking, weapons trade, and prescription drug trade (Foley et al. 2019). Böhme et al. (2015) describe that the first notable adopters of bitcoin sought greater anonymity and a lack of regulation concerning what could be purchased using the currency. Bohannon (2016) states that bitcoin's purported anonymity made it popular among criminals. A recent study finds that around $25 \%$ of all bitcoin users and $44 \%$ of all transactions relate to trading in illegal activities (Foley et al. 2019).

The source of almost all bitcoins used for illicit purposes and laundered through exchange services are darknet marketplaces (Fanusie and Robinson 2018), i.e., marketplaces on encrypted websites that do not appear through conventional Internet browsing. Bitcoin is the primary means of payment on the dark-net (van Slobbe 2016) with estimates showing it accounts for nearly $95 \%$ of the transactions on some dark-net marketplaces (Smith 2019). Moreover, trading in bitcoin is also advantageous to sellers of illicit goods sold through such marketplaces. By allowing for pseudonymous exchange, digital currencies such as bitcoin have been identified as ideal money laundering vehicles (FATF 2014; NDIC 2008).

In view of these arguments, we expect the ceteris paribus interest in bitcoin to be higher in locations with high activity in trade of illegally acquired goods and services, and in locations where financial services related to such trade take place. In particular, bitcoin has an important role to play in the trade of illegal drugs online (Soska and Christin 2015). Bitcoins and online drug markets have made it possible to sell drugs to unknown customers, whereas for decades retail drug markets remained localized, i.e., dealers sold primarily to known customers (Aldridge and Décary-Hétu 2016a). Using cryptocurrencies to trade in drugs provides a means for circumventing state prohibition. Furthermore, the opportunity to shift drug trade online, with anonymity relatively well-preserved due to the use of bitcoins as means of payment, also allows greater personal security (threat of violence, etc.) than buying drugs directly from dealers or contacts (Barratt et al. 2016). Some sellers and buyers of drugs are therefore actively supporting bitcoin in view of its role in enabling on-line acquirement of drugs. It can also be expected that the use of bitcoin for drug purchases may spill over to other types of use, and thereby stimulate the general interest and familiarity with bitcoin as a means of payment.

Even though cryptocurrency markets create a potentially global platform for drug distribution, they tend to be used for local trade as opposed to cross-border trade (Demant et al. 2018). Hence, the adoption of Bitcoin infrastructure can be associated with the level of activity in on-line drug trade across locations. However, reliable measures for such activities are hard to come by. We suggest that the intensity of money-laundering activity and the effectiveness of law enforcement - two factors that are being measured with some reliability for a sufficiently large number of countries for our purpose - can be used as indicators for such demand.

Money-laundering refers to processes whereby the proceeds from illicit trade are being transacted through financial institutions so as to hide its origin in illicit activities. A substantial share of such activity is directly related to drug trade. While money laundering may take place across as well as within nations, locations with high levels of trade in drugs would typically rate high on measures of money-laundering activity.

The second factor that we consider, concerns to what extent drug trade would require the pseudonymity provided by on-line purchasing using bitcoins. We focus on the level of law enforcement in a country.

More effective law enforcement may in principle reduce bitcoin adoption for illicit intent. However, current research suggests that contemporary law enforcement does not possess the capacity to control much Internet-related crime (Holt et al. 2015). In most countries, no particular Internet-mediated drug trafficking investigations are carried out (Lavorgna 2014). Despite law enforcement efforts, such as the closure of Silk Road and Silk Road 2.0, crypto-markets continue to proliferate and have proven to be extraordinarily resilient (Aldridge and Décary-Hétu 2016b; Soska and Christin 2015). Drug buyers and sellers using the dark net perceive the likelihood of arrest to be much lower than alternative means (Aldridge and Décary-Hétu 2016b; Barratt et al. 2016; Ormsby 2016; Van Hout and Bingham 2014). 
We therefore would not expect that stricter law efforts may hamper Internet-based drug trade, but it should be expected to affect other forms of buying and selling drugs (e.g., openly on the street). Conditional on the level of demand for illegally acquired goods and services, greater perceptions of the quality of police, and courts could therefore drive illicit activity towards online anonymous (or pseudonymous) activities. ${ }^{8}$ In other words, we expect that the greater the likelihood of arrest on the streets for traditional drug trafficking, the greater the interest in selling drugs online using anonymitygranting technologies. And as argued above, we expect such interest to generate support for and interest in Bitcoin.

Therefore, we expect that the greater the enforcement of rule of law, the greater the use of bitcoins for illicit activity (conditional on the level of activity of a local drug market). We conclude that the level of drug trade activity in a location can be expected to be related to the extent of money-laundering and to law enforcement effectiveness. On the basis of our expectation that interest in bitcoin is partially driven by on-line drug trading activity, we thus suggest that both money-laundering and law enforcement are related to the adoption of Bitcoin infrastructure.

While we have emphasized above that the level of money-laundering constitutes a useful proxy for trades in illicit goods in a country, it should be noted that some locations may feature as prominent sites for money laundering activity without necessarily being centers of illicit trade. Even where this may be the case (primarily in countries where financial regulation is conducive to money laundering), we expect money-laundering to be associated with interest in bitcoin. Consistent with this expectation, $97 \%$ of direct bitcoin payments from identifiable criminal sources were received by exchanges in countries with weak anti-money laundering regulations (CipherTrace 2018). To the extent that they provide anonymity, bitcoins and other cryptocurrencies can be exploited for money-laundering purposes (Evans-Pughe et al. 2014; Moser et al. 2013), e.g., in the form of automated laundering operations (McGinn et al. 2016). With the rise of specialized bitcoin money laundering services on the dark-net, such opportunities are

\footnotetext{
${ }^{8}$ In fact, our rule of law variable has a 0.49 correlation with dark-net market drug purchase statistics in 26 countries, reported by Winstock et al. (2018).
}

becoming available to a broader audience (Albrecht et al. 2019; van Wegberg et al. 2018).

Together, the arguments outlined above can be summarized in the following two hypotheses:

Hypothesis 4: The more money-laundering activities taking place, the greater the adoption of Bitcoin infrastructure.

Hypothesis 5: The stronger the rule of law, the greater the adoption of Bitcoin infrastructure.

\section{Data}

\subsection{Dependent variables}

We utilize two global digital infrastructure datasets supporting the use of Bitcoins encompassing the fiveyear period from 2014 to 2018, one of computers that observably disseminate blockchain information, and validate and verify transactions on the Bitcoin network (known as Bitnodes; see Figure 1 for validation and verification actions in a bitcoin transaction life cycle), and one of merchants accepting bitcoins as payment. ${ }^{9}$

A Bitcoin node is any computer or data processor that connects to the Bitcoin network, in order to receive and send information relating to Bitcoin's blockchain (a growing list of records of bitcoin transactions). Each bitcoin user represents a node on the network. A subset of all nodes are Full Bitcoin nodes, which fully download every block and transaction and check them against all rules of Bitcoin (e.g., no double-spending of bitcoins). Any decentralized cryptocurrency depends on such full nodes to ensure its blockchain adheres to agreed-upon rules. Hence, Full Bitcoin nodes are essential to ensure security of Bitcoin's digital ecosystem and for full removal of a need for a trusted alternative node or third party. A user becomes a Full Bitcoin node by running a software, called Bitcoin Core, on her computer. By default, Full Bitcoin nodes accept incoming connections (in technical terms, are reachable or listening) and upload updated blockchain information to other peers or nodes on the network. These are termed Bitnodes, which are reachable full nodes on the network. Our data consists of all Bitnodes operating worldwide between 2014 and 2018. While there is no reliable

\footnotetext{
${ }^{9}$ Available at an open data repository associated with this publication.
} 


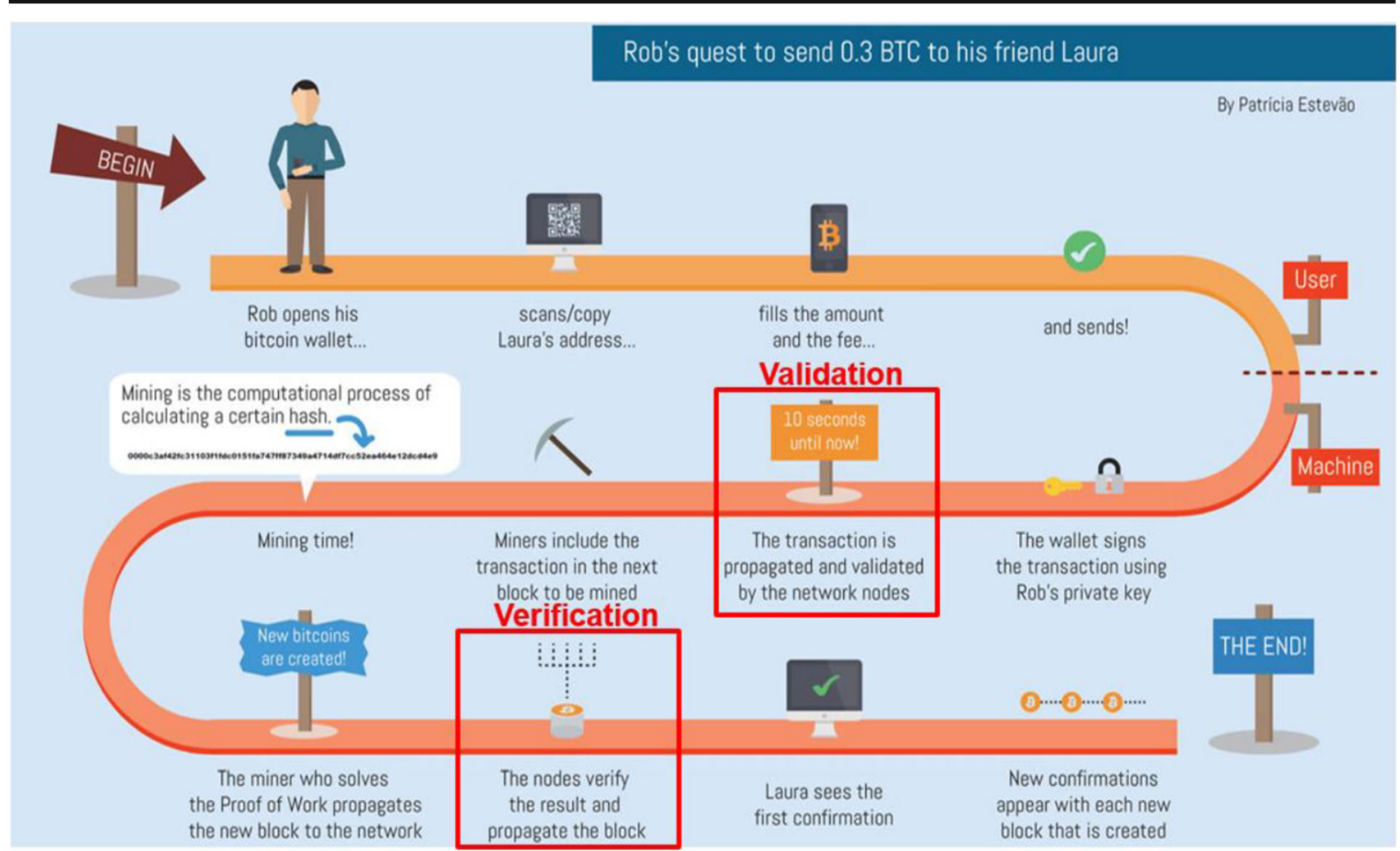

Fig. 1 Validation and verification role of nodes in the Bitcoin transaction life cycle (see red boxes). Infographic modified from original by Patrícia Estavão (printed with her permission under license CC BY-SA 4.0), available at patestevao.com/work/

method to determine if these Bitnodes are businesses, individuals, exchanges, bitcoin miners, or merchants, there are indications that they are users or businesses transacting in bitcoins or volunteers supporting the network (e.g., more nodes are online during US working hours). The Appendix describes Bitcoin nodes, Bitnodes, and our dataset preparation in greater detail.

Our dataset allows us to construct measures reflecting both the total intensity of Bitnode activity (Bitnode intensity) per country or region and year and the average number of Unique bitnodes by country or region and year. Figure 2 provides a global depiction of these variables. We also construct a measure of node availability by calculating for how many hours there is at least one Bitnode active in a country or region (Bitnode hours). For further details, see Table 1.

Our data for merchants accepting payments in bitcoin is from CoinMap.org. CoinMap is a website where either business owners or interested customers or users would add a business that accepts bitcoins (or bitcoins together with other cryptocurrencies) as payment in exchange for a service or good. Some of the businesses on these websites only accept bitcoins on their online websites. Soon after launching in 2013, CoinMap became the primary website worldwide, as referred to in online Bitcoin forums, to find businesses where bitcoin holders can spend them. Figure 3 depicts the global spread of merchants, whereas the Appendix describes the Bitcoin merchants dataset we use and our dataset preparation in greater detail.

The accumulated stock of merchants recorded on CoinMap may not, however, be an entirely accurate representation of the situation in that year, as there are numerous reported cases of merchants added to the database, who subsequently forego acceptance of bitcoins after months or years of low-demand (while there is no cost to offering this service other than training cashiers/personnel). In view of this, we choose to focus on annual inflow to the database. Our main dependent variable constructed from this database is hence the number of new bitcoin-accepting merchants in any given year in a country, or sub-country state, province or region. Our dataset does not suffer from survival bias, as even when merchants are removed from the map by users or the web admin, they are not dropped from our database.

Our dataset has the limitation that we only observe nonhidden Full Bitcoin nodes and merchants. Bitnodes, being reachable full nodes, are a subset of Full Bitcoin nodes keeping the network secure, as some nodes simply do not accept incoming connections, primarily due to installation 

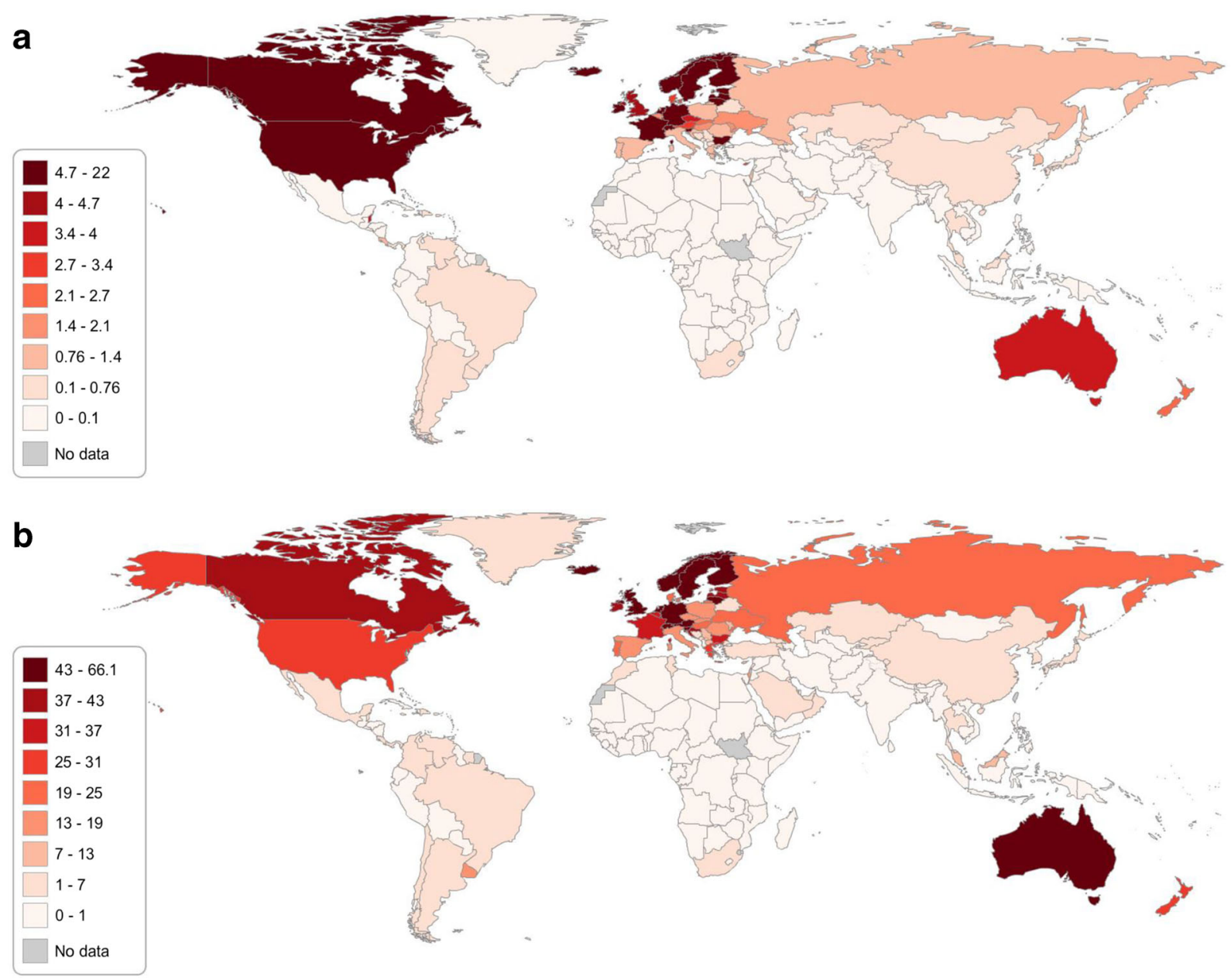

Fig. 2 a Global Map of Bitnode intensity (Monthly measure, averaged over 2014-2018; See Table 1 for variable definition). Top 15 countries are Monaco, Netherlands, Singapore, Lithuania, Luxembourg, Germany, Ireland, Switzerland, Sweden, Belize, Slovenia, Canada, Latvia, Finland, and Hong Kong. b. Global

of firewalls. Some estimates (e.g., Wang and Pustogarov 2017) indicate as many as 6 to 8 times more nodes on the network than our data includes. Similarly, Bitcoin merchants do not include merchants who hide their presence from CoinMap or only sell online. Hence, our study is focused on digital infrastructure providers who are openly and visibly supporting the Bitcoin network.

\subsection{Explanatory variables}

We construct a set of country-level variables related to Bitcoin's adoption potential given existing technological factors, its role as a potential substitute or complement to established financial institutions or to the
Map of Unique bitnodes (Averaged for every hour over 2014 2018; See Table 1 for variable definition). Top 15 countries are San Marino, Austria, Sweden, Germany, Luxembourg, Croatia, Switzerland, Netherlands, Slovenia, Lithuania, Monaco, Australia, Bulgaria, Finland, and UK

cryptocurrency's potential function as a facilitator of illicit activity.

\subsubsection{Financial characteristics}

In constructing an indicator for inflation as a driver for use of bitcoins, we utilize the concept of an Inflation Crisis, ${ }^{10}$ defined by Reinhart and Rogoff (2011) as depreciation in currency value of $20 \%$ per annum. For robustness tests, we also define alternative variables measuring such phenomena called 15\% Min Inflation and 25\% Min Inflation with

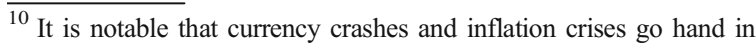
hand as shown by Reinhart and Rogoff (2011).
} 
Table 1 Variable description and data sources

\begin{tabular}{|c|c|c|c|}
\hline Variable & Description & Source & Source variable name \\
\hline \multicolumn{4}{|l|}{ Panel A } \\
\hline Bitnode intensity & $\begin{array}{l}\text { An intensity measure of the number of } \\
\text { active Bitnodes in a country multiplied } \\
\text { by how many hours each was active in a } \\
\text { month, standardized by the number of } \\
\text { hours in a month and averaged to } \\
\text { produce an annual measure (by taking } \\
\text { the mean of results for the first month of } \\
\text { each quarter). Standardized by dividing } \\
\text { it by the jurisdiction's population of } \\
\text { Internet users in millions (see Internet } \\
\text { variable). }\end{array}$ & $\begin{array}{l}\text { Bitcoin node data are from } \\
\text { bitnodes.com }\end{array}$ & $\begin{array}{l}\text { Constructed from } \\
\text { API-extracted data in JSON } \\
\text { format }\end{array}$ \\
\hline Unique bitnodes & $\begin{array}{l}\text { Number of unique Bitnodes in a country in } \\
\text { a month. This measure is then made into } \\
\text { an annual measure, by averaging its } \\
\text { value for the first month of each quarter } \\
\text { of a year. Standardized by dividing it by } \\
\text { jurisdiction's population of Internet } \\
\text { users in millions. }\end{array}$ & & $\begin{array}{l}\text { Constructed from } \\
\text { API-extracted data in JSON } \\
\text { format }\end{array}$ \\
\hline Bitnode hours & $\begin{array}{l}\text { Number of hours in a month where at least } \\
\text { one Bitnode from a country is active }\end{array}$ & & $\begin{array}{l}\text { Constructed from } \\
\text { API-extracted data in JSON } \\
\text { format }\end{array}$ \\
\hline Bitcoin merchants & $\begin{array}{l}\text { Number of new bitcoin merchants in a } \\
\text { country in a year, as per timing it was } \\
\text { added on CoinMap's map }\end{array}$ & $\begin{array}{l}\text { Bitcoin Merchant data are } \\
\text { from CoinMap.com }\end{array}$ & $\begin{array}{l}\text { Constructed from } \\
\text { API-extracted data }\end{array}$ \\
\hline Bitnode intensity $_{\mathrm{pc}}$ & $\begin{array}{l}\text { Similar to Bitnode intensity, but } \\
\text { standardized by population in millions }\end{array}$ & Bitnodes.com & \\
\hline Unique bitnodes $_{\mathrm{pc}}$ & $\begin{array}{l}\text { Similar to Unique bitnode, but } \\
\text { standardized by population in millions }\end{array}$ & Bitnodes.com & \\
\hline Bitcoin merchants $_{\mathrm{pc}}$ & $\begin{array}{l}\text { Similar to Bitnode Merchants, but } \\
\text { standardized by population in millions }\end{array}$ & CoinMap.com & \\
\hline GDP per capita & $\begin{array}{l}\text { Log of annual GDP per capita in a country. } \\
\text { GDP is at purchaser's prices converted } \\
\text { into current US dollars }\end{array}$ & World Bank WDI (2018) & NY.GDP.MKTP.CD \\
\hline Restrictive regulation & $\begin{array}{l}\text { An indicator variable equal to one in years } \\
\text { in which hostile or contentious } \\
\text { regulation against the use of bitcoins is } \\
\text { issued. Hostile regulation towards } \\
\text { bitcoin consists of regulatory authorities } \\
\text { imposing full prohibition of its use, or } \\
\text { partial prohibitions such as barring } \\
\text { financial institutions from dealing with } \\
\text { it. Contentious regulation towards } \\
\text { bitcoin consists of some legal } \\
\text { restrictions against use of bitcoin (incl. } \\
\text { Imposition of cumbersome compliance } \\
\text { requirements) or warnings against } \\
\text { bitcoin use by regulatory authorities } \\
\text { going beyond discouragement (incl. } \\
\text { Statements that bitcoin transactions may } \\
\text { cause violation of anti-money } \\
\text { laundering or terrorist financing rules). } \\
\text { Variable equals zero for countries that } \\
\text { have no regulatory framework or a } \\
\text { favorable regulatory framework for } \\
\text { bitcoins. }\end{array}$ & $\begin{array}{c}\text { Hand-collected data from Law } \\
\text { Library of Congress (2018), } \\
\text { bitlegal.io, and Wikipedia }\end{array}$ & \\
\hline
\end{tabular}


Table 1 (continued)

\begin{tabular}{|c|c|c|c|}
\hline Variable & Description & Source & Source variable name \\
\hline Population & $\begin{array}{l}\text { Total population in a country in millions. } \\
\text { Mid-year estimates. }\end{array}$ & World Bank WDI (2018) & SP.POP.TOTL \\
\hline Internet penetration & $\begin{array}{l}\text { Percentage of inhabitants using the Internet } \\
\text { in a year }\end{array}$ & $\begin{array}{l}\text { International } \\
\text { Telecommunications Unit }\end{array}$ & \\
\hline Broadband penetration & $\begin{array}{l}\text { Percentage of inhabitants with fixed } \\
\text { (wired)-broadband subscription in a } \\
\text { year }\end{array}$ & (ITU) (2018) & \\
\hline ICT market development & $\begin{array}{l}\text { A composite index of a nation's } \\
\text { development in ICT. The index includes } \\
\text { three aspects of digitalization: ICT } \\
\text { capability (skills and knowledge), } \\
\text { access to ICT infrastructure, and use of } \\
\text { intensity of ICT. }\end{array}$ & $\begin{array}{l}\text { Measuring the Information } \\
\text { Society Reports, ITU } \\
\text { (2015-2018) }\end{array}$ & ID (ICT Development Index) \\
\hline Latest technology & $\begin{array}{l}\text { National average of response to "In your } \\
\text { country, to what extent are the latest } \\
\text { technologies available? [1 = not } \\
\text { available; } 7=\text { widely available]" }\end{array}$ & $\begin{array}{l}\text { World Economic Forum, } \\
\text { Global Competitiveness } \\
\text { Report, Executive Opinion } \\
\text { Surveys (2014-2018) }\end{array}$ & EOSQ067 \\
\hline Internet servers & $\begin{array}{l}\text { Secure Internet servers per million people } \\
\text { using encryption technology in Internet } \\
\text { transactions }\end{array}$ & $\begin{array}{l}\text { World Bank and https://www. } \\
\text { netcraft.com }\end{array}$ & IT.NET.SECR.P6 \\
\hline Mobile subscriptions & $\begin{array}{l}\text { The variable measures the number of } \\
\text { mobile telephone subscriptions per } 100 \\
\text { adults in the population. A subscription } \\
\text { refers to a public mobile telephone } \\
\text { service that provides access to the } \\
\text { public-switched phone network using } \\
\text { cellular technology, including the count } \\
\text { of pre-paid SIM cards active in the final } \\
\text { three months of the year. }\end{array}$ & $\begin{array}{l}\text { World } \\
\text { Telecommunication/ICT } \\
\text { Development report and } \\
\text { database }\end{array}$ & \\
\hline Electricity cost & $\begin{array}{l}\text { Electricity cost is the total median cost in } \\
\text { percentage of income per capita } \\
\text { associated with completing procedures } \\
\text { to connect a warehouse to electricity. }\end{array}$ & $\begin{array}{l}\text { World Bank Doing Business } \\
\text { Reports (2014-2018) }\end{array}$ & \\
\hline Inflation crisis & $\begin{array}{l}\text { An indicator variable equal to one if in a } \\
\text { country the annual decline in the } \\
\text { average Consumer Price Index is greater } \\
\text { than } 20 \% \text { following Reinhart and } \\
\text { Rogoff (2011) }\end{array}$ & $\begin{array}{l}\text { Raw Data are from } \\
\text { International Monetary } \\
\text { Fund (IMF)'s World } \\
\text { Economic Outlook (2018) }\end{array}$ & \\
\hline Inflation & $\begin{array}{l}\text { The average annual change in Consumer } \\
\text { Price Index as a ratio. }\end{array}$ & & \\
\hline Unbanked & $\begin{array}{l}\% \text { aged } 15+\text { without account ownership at } \\
\text { a financial institution and without a } \\
\text { mobile-money-service provider }\end{array}$ & WB Global Findex Database & FX.OWN.TOTL.ZS \\
\hline Internet banking & $\begin{array}{c}\% \text { aged } 15+\text { who have used the Internet or } \\
\text { a mobile phone to access an account }\end{array}$ & & Fin5.d.1 \\
\hline Five-bank asset concentration & $\begin{array}{l}\text { Assets of five largest banks as a share of all } \\
\text { banking assets. These include all } \\
\text { earning assets, cash and due from banks, } \\
\text { foreclosed real estate, fixed assets, } \\
\text { goodwill, other intangibles, current tax } \\
\text { assets, deferred tax, discontinued } \\
\text { operations and other assets. }\end{array}$ & $\begin{array}{l}\text { World Bank's Global } \\
\text { Financial Development } \\
\text { Index (GFDI 2018); Raw } \\
\text { Data are from Bankscope } \\
\text { and Orbis Bank Focus, } \\
\text { Bureau van Dijk }\end{array}$ & GFDD.OI.06 \\
\hline $\begin{array}{c}\text { Three-bank asset } \\
\text { concentration }\end{array}$ & $\begin{array}{l}\text { Assets of three largest commercial banks } \\
\text { as a share of all commercial banking } \\
\text { assets. }\end{array}$ & & GFDD.OI.01 \\
\hline Rule of law & $\begin{array}{l}\text { Captures perceptions of the extent to which } \\
\text { agents have confidence in and abide by }\end{array}$ & & RQ.EST \\
\hline
\end{tabular}


Table 1 (continued)

\begin{tabular}{llll}
\hline Variable & Description & Source & Source variable name \\
\hline
\end{tabular}

Organized crime

Crime and violence costs

Money laundering

Panel B

Bitnode intensity

Unique bitnodes

Bitnode hours

Bitcoin merchants

High risk willingness

Trust in others the rules of society, and in particular, the World Bank Worldwide quality of contract enforcement, property rights, the police, and the courts, as well as the likelihood of crime and violence. This variable ranges from approximately -2.5 (weak) to 2.5 (strong) values for rule of law.

National average of response to "In your country, to what extent does organized crime (mafia-oriented racketeering, extortion) impose costs on businesses? [1 = not at all; $7=$ to a great extent $]$ "

National average of response to "In your country, to what extent does organized crime (mafia-oriented racketeering, extortion) impose costs on businesses? [ $1=$ to a great extent - imposes huge costs; 7 = not at all —imposes no costs]"

Countries identified as heavily engaged in "currency transactions involving significant amounts of proceeds from international narcotics trafficking."

An intensity measure of the number of active bitnodes in a region multiplied by how many hours each was active in a month, divided by the number of hours in a month and averaged to produce an annual measure (by taking the mean of results for the first month of each quarter). Standardized by dividing it by the jurisdiction's population of Internet users in millions (see Internet users variable).

Number of unique bitnodes in a statistical region in a month made into an annual measure, by averaging its value for the first month of each quarter of a year. Standardized by dividing it by jurisdiction's population of Internet users in millions.

Number of hours in a month in which at least one bitnode from a region is active.

Number of new bitcoin merchants in a statistical region in a year, as per timing it was added on CoinMap's map

A region's average of an indicator variable for each LiTS III's survey respondent, equal to one if response to this question, is above 8: "Please, rate your willingness to take risks, in general, on a scale from 1 to 10 , where 1 means that you are not willing to take risks at all, and 10 and means that you are very much willing to take risks."
Governance Indicators

(2018)

World Economic Forum, Global Competitiveness Report, Executive Opinion Surveys (2014-2018)

EOSQ034

US Dept. of State Bureau for International Narcotics and Law Enforcement Affairs (2018)

Bitcoin node data are from bitnodes.com

Constructed from API-extracted data

Constructed from API-extracted data

Constructed from API-extracted data

Bitcoin Merchant data are from CoinMap.com

EBRD (2016) Life in Transition Societies (LiTS) Survey III; US Data are complemented with same question in FINRA (2015)‘s National Financial Capabilities Study in 2015
EOSQ055
Constructed from
API-extracted data

Q4.28 in LiTS III; J2 in NFCS 
Table 1 (continued)

\begin{tabular}{|c|c|c|c|}
\hline Variable & Description & Source & Source variable name \\
\hline & $\begin{array}{l}\text { A region's average of an index } \\
\text { standardized to run from }-1 \text { to } 1 \text {, in } \\
\text { answering to "Generally speaking, } \\
\text { would you say that most people can be } \\
\text { trusted, or that you cannot be too careful } \\
\text { in dealing with people? Please answer } \\
\text { on a scale of } 1 \text { to } 5 \text {, where } 1 \text { means that } \\
\text { you have complete distrust and } 5 \text { means } \\
\text { that you have complete trust." }\end{array}$ & $\begin{array}{l}\text { EBRD (2016) LiTS Survey } \\
\text { III; US Data are } \\
\text { complemented using the } \\
\text { same question's response } \\
\text { using NORC (2016)‘s } \\
\text { General Social Survey } \\
\text { (GSS) Geo-sensitive data }\end{array}$ & $\begin{array}{l}\text { Q4.03 in LiTS III; TRUST in } \\
\text { GSS }\end{array}$ \\
\hline $\begin{array}{l}\text { Distrust in banks \& financial } \\
\text { system }\end{array}$ & $\begin{array}{l}\text { A statistical region's average of an index } \\
\text { standardized to run from }-1 \text { to } 1 \text {, in } \\
\text { answering to "To what extent do you } \\
\text { trust banks and the financial system? } \\
\text { Please answer on a scale of } 1 \text { to } 5 \text {, where } \\
1 \text { means that you have complete distrust } \\
\text { and } 5 \text { means that you have complete } \\
\text { trust." }\end{array}$ & & $\begin{array}{l}\text { Q4.04j in LiTS III; } \\
\text { CONFINAN in GSS }\end{array}$ \\
\hline Distrust in other institutions & $\begin{array}{l}\text { A region's average of indices standardized } \\
\text { to run from }-1 \text { to } 1 \text {, in answering to, } \\
\text { similar to that above, on the following } \\
\text { institutions, other than banks and the } \\
\text { financial system: The } \\
\text { Government/Cabinet of Ministers, the } \\
\text { Parliament, Courts, the Military, The } \\
\text { police, Unions and Religious } \\
\text { Institutions. }\end{array}$ & & $\begin{array}{l}\text { Q4.04b, e, f, h, I, } \mathrm{m} \& \mathrm{n} \text { in } \\
\text { LiTS III; Trust in the same } \\
\text { institutions in GSS }\end{array}$ \\
\hline Bitcoin price & $\begin{array}{l}\text { Annually-averaged price of Bitcoin in } \\
\text { thousands of USD, from quotes on four } \\
\text { large Bitcoin exchanges of 2014-2018, } \\
\text { namely Bitstamp, Kraken, Coinbase and } \\
\text { Gdax }\end{array}$ & $\begin{array}{l}\text { www.cryptodatadownload. } \\
\text { com/; Accessed on } \\
\text { September 3, } 2018\end{array}$ & $\mathrm{BTC} / \mathrm{USD}$ \\
\hline
\end{tabular}

corresponding alternative thresholds. In further robustness tests, we utilize a continuous measure of Inflation along with the square root of Inflation. Inflation data is collected from the International Monetary Fund.

Data on the proportion of unbanked adults is collected from the World Bank's Financial Inclusion Index. Following Gross et al. (2012), we define the unbanked as individuals older than 15 years without a checking, saving or money market account. A subset of those holding bank accounts, are those with access to the Internet and mobile banking, which can serve as another proxy of financial inclusion in a digital age. From the same source, we obtain an Internet banking variable for robustness of results.

We extract data on concentration in the banking industry from the World Bank Global Financial Development Index. We primarily use Five-bank asset concentration, the asset concentration of the largest five banks in each country. For use in robustness testing, we also use Three-bank asset concentration, which is the asset concentration of the largest three banks in each country.

\subsubsection{Criminality characteristics}

The US' Bureau of International Narcotics and Law Enforcement Affairs performs an annual assessment of the risk of money laundering in 200 countries and jurisdictions. The bureau identifies "major money laundering countries" as those whose "financial institutions engage in transactions involving significant amounts of proceeds from international narcotics trafficking". The definition

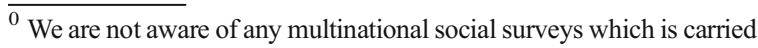
out annually, and even if such a survey existed, social characteristics typically do not change much 1 year to another (e.g., see Hoffman et al. 2009 for an explanation of how general trust changes over intermediate time horizons).
} 
of "financial institutions" employed by the bureau in the period we study includes digital currencies and "other value transfer systems." We introduce an indicator variable (money laundering) that takes the value one if a country is included in the bureau's list in a given year.

As an indicator for the level of law enforcement, we obtain from the Worldwide Governance Indicators of the World Bank a rule of law variable. This variable captures the likelihood of crime and violence, and the extent to which agents abide by and have confidence in the rules of society, in particular the quality of police, courts, contract enforcement and property rights.

\subsubsection{Social characteristics}

We obtain social characteristic variables of general risktaking, general trust, and trust in banks and the financial system from the Life in Transition (LITS III) survey which was carried out in 34 countries from 2014 to 2016. While data used to create most of the independent variables described previously was only available on the level of countries, LITS data can be broken down to the (subnational) regional level, corresponding to states, provinces or administrative regions in the 34 countries where this survey was carried out. The LITS survey was, however, only carried out once during the period that we investigate in this paper, ${ }^{11}$ meaning that we have no time variation to exploit for this analysis. In order to utilize as much of the variation in the data as possible, exploring the role of these social characteristics is carried out at the regional rather than national level. This has the consequence that analyses investigating the role of social characteristics are restricted to regions in 34 countries (294 regions) predominantly in Europe, instead of our full set of countries, and these variables are cross-sectional.

\subsection{Control variables}

We furthermore construct a number of control variables related to fundamental economic and legal prerequisites for the growth of Bitcoin infrastructure.

Participation in any financial system is strongly tied to the availability of economic resources. In our analysis of global adoption of Bitcoin infrastructure, variations in economic strength across countries and regions is therefore a natural first factor to consider. We control for GDP utilizing data from the World Bank.

Alongside economic strength, we also expect technological development to be strongly related to the spread of Bitcoin infrastructure. It is therefore important that our modeling exercise takes the level of technological development into account. In particular, as an Internet-enabled technology, bitcoin adoption is only feasible for users who have regular access to the Internet. We are, however, reluctant to introduce separate control variables for such factors in order to avoid overfitting our models, and in order to avoid introducing multicollinearity issues (the level of technological development across countries is well-known to co-vary with, e.g., economic and institutional variables (Czernich et al. 2011; Greenstein and Spiller 1996) and our main control variable of GDP per capita is highly correlated $(0.89)$ with Internet penetration in our dataset). Instead, all our main dependent variables measuring the penetration of Bitcoin infrastructure are normalized by Internet penetration, i.e., the percentage of Internet users in a country.

As a virtual currency with the potential to disrupt existing payment systems and possibly even monetary systems (Böhme et al. 2015), bitcoin aims to rival fiat currencies issued by central banks. Barriers to adoption in each jurisdiction for bitcoins are largely enforced by regulation. Most regulation vis-à-vis bitcoins are issued by a country's financial regulatory authorities (Law Library of Congress 2018). As suggested by public choice theory (Stigler 1971), incumbents may lobby for regulation to keep out competitors and create rents for themselves. To the extent that bitcoin rivals government-issued currencies, regulatory barriers on bitcoins by governments can hamper their adoption. We create a longitudinal indicator variable, Restrictive regulation, equal to one in a country and for all the years in which restrictive (i.e., contentious or hostile) regulation is in effect in a country by its financial regulator on either transacting in bitcoin or buying and selling goods or services in exchange for bitcoins. Hostile regulation towards bitcoin consists of regulatory authorities imposing full prohibition of its use, or partial prohibitions such as barring financial institutions from dealing with it. Contentious regulation towards bitcoin consists of some legal restrictions against use of bitcoin (incl. imposition of cumbersome compliance requirements) or warnings against bitcoin use by regulatory authorities going beyond discouragement (incl. statements that bitcoin transactions may cause violation of anti-money laundering or terrorist 
Table 2 Summary statistics for panels A and B

\begin{tabular}{|c|c|c|c|c|c|c|}
\hline \multicolumn{7}{|c|}{ Panel A: Country-year level dataset (2014--2018; 137 countries) } \\
\hline \multicolumn{7}{|l|}{ Dependent variables } \\
\hline Bitnode intensity & 685 & 2.02 & 4.07 & 0.0 & 0.2 & 34.9 \\
\hline Unique bitnodes & 685 & 15.12 & 23.45 & 0.0 & 3.6 & 123.4 \\
\hline Bitnode hours & 685 & 431.46 & 334.30 & 0.0 & 608.8 & 750.0 \\
\hline Bitcoin merchants & 685 & 1.32 & 5.05 & 0.0 & 0.2 & 114.0 \\
\hline Bitnode intensity $\mathrm{pc}_{\mathrm{p}}$ & 685 & 1.65 & 3.52 & 0.0 & 0.1 & 30.8 \\
\hline Unique bitnodes $_{\mathrm{pc}}$ & 685 & 11.70 & 19.40 & 0.0 & 1.9 & 114.2 \\
\hline Bitcoin merchants $\mathrm{pc}_{\mathrm{p}}$ & 685 & 0.98 & 3.99 & 0.0 & 0.1 & 90.9 \\
\hline \multicolumn{7}{|l|}{ Control variables } \\
\hline GDP per capita & 685 & 8.80 & 1.46 & 5.7 & 8.8 & 11.7 \\
\hline Restrictive regulation & 685 & 0.11 & 0.32 & 0.0 & 0.0 & 1.0 \\
\hline Population & 685 & 51.22 & 166.39 & 0.1 & 11.2 & 1394.1 \\
\hline \multicolumn{7}{|l|}{ Technological variables } \\
\hline Internet penetration & 685 & 54.68 & 27.71 & 3.3 & 59.1 & 97.6 \\
\hline Broadband penetration & 685 & 14.45 & 13.79 & 0.0 & 9.9 & 55.7 \\
\hline ICT market development & 685 & 5.27 & 2.23 & 1.2 & 5.3 & 8.9 \\
\hline Latest technology & 685 & 4.84 & 0.94 & 2.3 & 4.8 & 6.6 \\
\hline Internet servers & 685 & 4.07 & 11.24 & 0.0 & 0.2 & 123.1 \\
\hline Mobile subscriptions & 685 & 113.39 & 34.07 & 25.0 & 115.4 & 259.4 \\
\hline \multicolumn{7}{|l|}{ Financial variables } \\
\hline Inflation crisis & 685 & 0.04 & 0.20 & 0.0 & 0.0 & 1.0 \\
\hline Inflation & 685 & 0.05 & 0.07 & -0.0 & 0.0 & 0.4 \\
\hline Unbanked & 685 & 38.56 & 27.59 & 0.0 & 37.9 & 93.6 \\
\hline Internet banking & 685 & 27.89 & 21.89 & 0.4 & 23.5 & 85.1 \\
\hline Five-bank asset concentration & 685 & 78.84 & 16.19 & 27.5 & 80.9 & 100.0 \\
\hline Three-bank asset concentration & 685 & 63.94 & 18.47 & 18.4 & 64.0 & 100.0 \\
\hline \multicolumn{7}{|l|}{ Criminality variables } \\
\hline Rule of law & 685 & 0.06 & 0.99 & -2.3 & -0.1 & 2.1 \\
\hline Organized crime & 665 & 4.77 & 1.02 & 1.5 & 4.8 & 6.9 \\
\hline Crime and violence costs & 685 & 4.45 & 1.07 & 1.5 & 4.5 & 6.8 \\
\hline Money laundering & 685 & 0.36 & 0.48 & 0.0 & 0.0 & 1.0 \\
\hline \multicolumn{7}{|l|}{ Alternative variables } \\
\hline Shadow economy & 670 & 30.22 & 12.76 & 8.1 & 30.2 & 63.3 \\
\hline Taxation & 580 & 25.82 & 12.49 & -1.3 & 24.7 & 65.0 \\
\hline Tax burden & 665 & 77.62 & 12.00 & 37.2 & 79.2 & 99.9 \\
\hline Tax haven & 685 & 0.06 & 0.23 & 0.0 & 0.0 & 1.0 \\
\hline Stock market return & 440 & 0.67 & 25.77 & -72.1 & -1.9 & 282.9 \\
\hline Crisis stock market return & 460 & -2.77 & 19.70 & -51.7 & -4.6 & 52.5 \\
\hline Bitcoin mining country & 685 & 0.07 & 0.26 & 0.0 & 0.0 & 1.0 \\
\hline Bitcoin mining MWs & 670 & 1.85 & 11.28 & 0.0 & 0.0 & 111.0 \\
\hline Electricity price & 685 & 21.98 & 76.11 & 0.7 & 14.3 & 1038.0 \\
\hline Electricity cost & 685 & 1329.8 & 3006.7 & 0.0 & 308.2 & $28,965.9$ \\
\hline
\end{tabular}


Panel B: Region-year level dataset (2014-2018; 294 NUTS2 or equivalent regions in 34 countries)

Dependent variables

\begin{tabular}{|c|c|c|c|c|c|c|}
\hline Bitnode intensity & 1470 & 2.17 & 4.71 & 0.0 & 0.4 & 59.7 \\
\hline Unique bitnodes & 1470 & 17.37 & 33.31 & 0.0 & 5.9 & 486.5 \\
\hline Bitcoin merchants & 1470 & 2.03 & 6.90 & 0.0 & 0.0 & 109.7 \\
\hline \multicolumn{7}{|l|}{ Social variables } \\
\hline High risk willingness & 1470 & 0.16 & 0.12 & 0.0 & 0.1 & 0.7 \\
\hline Trust to Others & 1470 & -0.05 & 0.26 & -0.8 & -0.1 & 1.0 \\
\hline Distrust in banks \& financial system & 1470 & 0.09 & 0.31 & -0.9 & 0.1 & 1.0 \\
\hline Distrust in other institutions & 1470 & 0.01 & 0.24 & -0.9 & 0.0 & 0.8 \\
\hline \multicolumn{7}{|l|}{ Interaction variable } \\
\hline Bitcoin price & 1470 & 2.76 & 3.21 & 0.3 & 0.6 & 8.5 \\
\hline
\end{tabular}

financing rules). This is a longitudinal measure. Information about regulation on bitcoin trade is hand collected from the US Library of Congress, bitlegal.io, and Wikipedia.

A list of all dependent and explanatory variables used in the analysis and their definitions are described in Table 1, where Panel A documents our country-level analysis and Panel B the regional-level analysis. Summary statistics for all our variables are presented in Table 2 and a correlation matrix is available in the Appendix (Table A.I).

\section{Estimation methodology}

\subsection{Country-level analyses}

We construct a panel-data structured database of countries and years for adoption of non-hidden Bitcoin nodes and Bitcoin merchants, as well as our independent variables. We limit our database to 2014 to 2018, the period for which full Bitcoin node and merchant data are available. We regress our measures of infrastructure adoption over two baseline variables of GDP per capita and restrictive regulationscapturing fundamental economic and legal countrylevel characteristics - as well as our independent variables.

In our country-level analyses, we limit our analysis to 137 countries in which all our explanatory variables are available from their respective data sources for all years in our database. The variable with the most limited global coverage, $\%$ of unbanked, was restricted due to the breadth of coverage of the World Bank's Financial Inclusion survey. We refer to the resulting database as Panel A, for which summary statistics are available in Table 2. Having reduced our sample from 201 countries respectively for which we have Bitnode and CoinMap data $^{12}$ to 137 countries may introduce a sample selection bias. While this choice was driven by a need to have values for all independent variables used in the analysis, it is justifiable as the excluded nations are smaller in size by orders of magnitude and often reliable statistics on financial and criminal characteristics unavailable for them. ${ }^{13}$

Our dependent variables take the value 0 for a non-trivial share of our observations (i.e., for countries and years in which no Bitcoin infrastructure is detected), and can thus be thought of as censored variables. In our country-year analyses, we therefore run random-effects Tobit models lower-censored at zero with panel-data adjusted bootstrapped standard errors. ${ }^{14}$ We employ the following model specification, where the subscripts $i$ and $t$, refer to countries and years respectively:

\footnotetext{
$\overline{12} 147$ countries have been reported to have at least one Bitcoin merchant, with 28 having only one. We have coded the countries without reported merchants on CoinMap as having no merchants. Given that the median GDP per capita of these countries is below $\$ 1000$, it is reasonable to assume that no merchants existed in these nations.

${ }^{13}$ In fact, the median population of the excluded 60 countries is less than 0.3 million while for those included in the analyses it is 11.7 million.

${ }^{14}$ This entails blocked bootstrapping with countries as blocks, for the bootstrapped clustering.
} 
Bitcoin Infrastructure Adoption Variable $_{i t}$

$$
\begin{aligned}
& =\beta_{0}+\beta_{1} \times \ln (G D P)_{i t}+\beta_{2} \\
& \times \text { Restrictive regulation }_{i t}+\beta_{3} \\
& \times \text { Inflation }_{\text {crisis }_{i t}}+\beta_{4} \times \text { Unbanked }_{i t} \\
& +\beta_{5} \times \text { Five bank asset concentration }{ }_{i t} \\
& +\beta_{6} \times \text { Money laundering }{ }_{i t} \\
& +\beta_{7} \times \text { Rule of } \operatorname{law}_{i t}+W R_{i}+\zeta_{t}+W R_{i} \times \zeta_{t} \\
& +\varepsilon_{i t}
\end{aligned}
$$

Our Bitcoin infrastructure adoption variables are bitnode intensity, unique bitnodes, bitnode hours and Bitcoin merchants. The world region fixed effects $\left(W R_{i}\right)$ and year fixed effects $\left(\zeta_{t}\right)$, respectively control for systematic differences across world regions, ${ }^{15}$ and for changes in the price of bitcoin and in global macroeconomic conditions over time. Our interactions of world region and year fixed effects $\left(W R_{i} \times \zeta_{t}\right)$ absorb the effect of world region-specific shocks or time trends in adoption of bitcoins. Given the countryyear level variation of our Panel A data, these controls are stringent enough to tease out the effect of our country-level variables. The limited variation of our country-level characteristics during the five years of observation does not allow for the inclusion of country-level fixed effects. ${ }^{16} \mathrm{We}$ cluster all regression standard errors at the country level. In robustness tests, we cluster our results at the country and the year level, and results do not significantly change.

\subsection{Regional level analysis}

Our region-year analyses are meant to investigate the effect of social variables such as general and institutional trust, and risk willingness on the adoption of Bitcoin infrastructure. Our social variables are derived from the Life in Transition Societies (LiTS III) Survey carried out between 2014 and 2016 of 51,000 households in 34 countries. To this end, we construct a database of averages of social variables for the 294 statistical regions surveyed, which are primarily located in nations in Eastern Europe

\footnotetext{
${ }^{15}$ Defined using the World Bank's division of nations into world regions of North America, Europe \& Central Asia, East Asia \& Pacific, Latin America \& Caribbean, Middle East \& North Africa, Sub-Saharan Africa, and South Asia

${ }^{16}$ Upon their inclusion, many of our country-level variables would be omitted, due to their limited time-series variation from 2014 to 2018 in variables such as Restrictive regulation.
}

and Central Asia, as well as Germany, Italy, and Greece. We make adjustments to ensure our dependent variable database regions match statistical regions from the LiTS III survey, and then calculate region-level dependent variables of bitnode intensity, unique bitnodes and bitnode hours. We complement this data with population statistics from European or national statistics agencies for these 34 countries. Hence, we have effectively restricted our analysis from 137 countries in the country-year level database in Panel A, to a subset of 34 countries in the region-year level database in panel B (with 294 regions). Summary statistics for Panel B are available in Table 2.

Our region-level analyses use the following randomeffects Tobit regression model, where subscripts $j$ and $t$, refer respectively to sub-national administrative or statistical regions and years:

$$
\begin{aligned}
& \text { Bitcoin Infrastructure Adoption } \text { Variable }_{j t} \\
& =\beta_{8}+\beta_{9} \times \ln (G D P)_{i t}+\beta_{10} \\
& \times \text { Restrictive regulation }_{i t}+\beta_{11} \\
& \times \text { High risk willingness }_{j t}+\beta_{12} \\
& \times \text { Trust to others }_{j t}+\beta_{13} \\
& \times \text { Distrust in banks and the financial } \text { System }_{j t} \\
& +\beta_{14} \times \text { Distrust in other institutions }_{j t}+c_{i} \\
& +\zeta_{t}+\varepsilon_{i t}
\end{aligned}
$$

This equation involves our baseline characteristics of logged $G D P$ and restrictive regulation to control for the heterogeneity specific to the economic and legal conditions, with our social characteristic variables following. Our region-level empirical models using eq. 2 control for systematic differences across nations using country fixed effects $\left(c_{i}\right)$ and for macro-economic conditions using year fixed effects $\left(\zeta_{t}\right)$. Similar to Giannetti and Wang (2016), we control for distrust (lack of trust) in other institutions unrelated to banks and the financial system, to separate the specific effect of distrust to banks from any idiosyncratic relationship between general institutional sentiments and Bitcoin infrastructure adoption. In additional tests, we interact high risk willingness with bitcoin price to examine how this social characteristic varies with price increases. 
Table 3 Financial and criminality drivers of Bitcoin nodes (Panel A; Country-year level)

\begin{tabular}{|c|c|c|c|c|c|c|}
\hline Dependent variables & $\begin{array}{l}(1) \\
\text { Bitnode inte }\end{array}$ & $(2)$ & (3) & (4) & $\begin{array}{l}\text { (5) } \\
\text { Unique bitnodes }\end{array}$ & $\begin{array}{l}(6) \\
\text { Bitnode hours }\end{array}$ \\
\hline \multicolumn{7}{|l|}{ Financial characteristics } \\
\hline Inflation crisis & & $\begin{array}{l}0.338 \\
(0.386)\end{array}$ & & $\begin{array}{l}0.530+ \\
(0.306)\end{array}$ & $\begin{array}{l}7.038^{* * *} \\
(2.596)\end{array}$ & $\begin{array}{l}50.642 \\
(65.208)\end{array}$ \\
\hline Unbanked & & $\begin{array}{l}-0.006 \\
(0.013)\end{array}$ & & $\begin{array}{l}0.008 \\
(0.009)\end{array}$ & $\begin{array}{l}-0.189^{*} \\
(0.078)\end{array}$ & $\begin{array}{l}-2.309 \\
(1.421)\end{array}$ \\
\hline Five-bank asset concentration & & $\begin{array}{l}-0.004 \\
(0.015)\end{array}$ & & $\begin{array}{l}0.003 \\
(0.013)\end{array}$ & $\begin{array}{l}0.011 \\
(0.069)\end{array}$ & $\begin{array}{l}-5.080^{* *} \\
(1.676)\end{array}$ \\
\hline \multicolumn{7}{|l|}{ Criminality characteristics } \\
\hline Money laundering & & & $\begin{array}{l}1.302^{*} \\
(0.568)\end{array}$ & $\begin{array}{l}1.347^{*} \\
(0.604)\end{array}$ & $\begin{array}{l}6.916^{* * *} \\
(2.381)\end{array}$ & $\begin{array}{l}176.344^{\text {**** }} \\
(53.490)\end{array}$ \\
\hline Rule of law & & & $\begin{array}{l}1.343^{* *} \\
(0.424)\end{array}$ & $\begin{array}{l}1.445^{* *} \\
(0.474)\end{array}$ & $\begin{array}{l}9.323^{\text {**** }} \\
(2.557)\end{array}$ & $\begin{array}{l}88.669+ \\
(45.858)\end{array}$ \\
\hline \multicolumn{7}{|l|}{ Baseline controls } \\
\hline GDP per capita & $\begin{array}{l}1.425^{* * *} \\
(0.363)\end{array}$ & $\begin{array}{l}1.338^{* * * *} \\
(0.378)\end{array}$ & $\begin{array}{l}0.617 \\
(0.415)\end{array}$ & $\begin{array}{l}0.681 \\
(0.457)\end{array}$ & $\begin{array}{l}0.039 \\
(2.209)\end{array}$ & $\begin{array}{l}72.001^{*} \\
(34.734)\end{array}$ \\
\hline Restrictive regulation & $\begin{array}{l}-0.574^{+} \\
(0.314)\end{array}$ & $\begin{array}{l}-0.581^{*} \\
(0.291)\end{array}$ & $\begin{array}{l}-0.553^{+} \\
(0.290)\end{array}$ & $\begin{array}{l}-0.529 \\
(0.324)\end{array}$ & $\begin{array}{l}3.069^{*} \\
(1.347)\end{array}$ & $\begin{array}{l}32.565 \\
(39.446)\end{array}$ \\
\hline Constant & $\begin{array}{l}-11.455^{* * *} \\
(3.123)\end{array}$ & $\begin{array}{l}-10.185^{* *} \\
(3.616)\end{array}$ & $\begin{array}{l}-5.464 \\
(3.573)\end{array}$ & $\begin{array}{l}-6.624 \\
(4.347)\end{array}$ & $\begin{array}{l}19.808 \\
(20.597)\end{array}$ & $\begin{array}{l}382.419 \\
(431.859)\end{array}$ \\
\hline Year FEs & Yes & Yes & Yes & Yes & Yes & Yes \\
\hline World Region FEs & Yes & Yes & Yes & Yes & Yes & Yes \\
\hline Year-World Region FEs & Yes & Yes & Yes & Yes & Yes & Yes \\
\hline Panel Data Specifications & Tobit & Tobit & Tobit & Tobit & Tobit & Tobit \\
\hline Observations & 685 & 685 & 685 & 685 & 685 & 685 \\
\hline Number of Countries & 137 & 137 & 137 & 137 & 137 & 137 \\
\hline Pseudo R-Squared & 0.34 & 0.4 & 0.34 & 0.41 & 0.62 & 0.22 \\
\hline Log-likelihood & -1314.9 & -1314.6 & -1306.7 & -1306.1 & -2268.1 & -2386.8 \\
\hline RHO & 0.74 & 0.74 & 0.72 & 0.72 & 0.54 & 0.62 \\
\hline
\end{tabular}

All models are Tobit random effects models lower-censored at 0 and their associated pseudo R-squared are reported. Panel-data adjusted bootstrapped standard errors, clustered at the country level, are reported in parentheses. The symbols $* * *, * *, *,+$ mean that the reported coefficients are statistically different from zero, respectively, at the $0.1,1,5$, and $10 \%$ level. Model 6 is additionally upper-censored at 750 (upper limit of active bitnode hours in a month)

\section{Estimation results}

\subsection{Financial and criminality drivers}

Our first set of analyses focus on associations between use and running of bitnodes or merchants and the criminality and financial characteristics discussed previously. We first report results on bitnodes and subsequently on Bitcoin merchants.

Table 3 reports results of our random effects regressions for three dependent variables measuring the frequency of bitnode activity in a country, relative to the number of Internet users. These dependent variables are standardized measures described in Table 1, namely bitnode intensity, unique bitnodes, and bitnode hours. In all regression models (1) to (4), our primary dependent variable of bitnode intensity is regressed against a baseline of controls, GDP per capita and a dummy variable for restrictive regulation being in effect. Models (2) and (3) add financial characteristics and criminality characteristics, respectively, and model (4) expands the baseline estimation to include both sets of financial and 
criminality characteristics. The magnitude and standard deviations of coefficients for either sets of variables do not alter in a significant way and are robust to inclusion of both. Models (5) and (6) respectively regress unique bitnodes and bitnode hours on the full set of countrylevel characteristics. The Internet Appendix Tables IA.I to IA.III show the effect of each individual variable being added separately to the baseline model, for each of our dependent variables.

Model 1 is our baseline model. Fixed effects for years, world regions and their interactions together with our two basic controls account for a substantial fraction of the variation in Bitnode intensity, corresponding to a pseudo $R^{2}$ of 0.34 . As expected, more restrictive regulations vis-à-vis bitcoins are associated with belowaverage total intensity of Bitnode activity (models 1 to 4), but with the occurrence of an above-average number of unique bitnodes. The effect of restrictive regulation is clearly driven by differences on the intensive margin (i.e., how many hours a month Bitnodes are available) rather than difference on the extensive margin (i.e., how many unique Bitnodes are being run in a country). This may indicate that while restrictive regulation reduces the actual use of bitcoins, primarily by making the exchange of bitcoins to fiat currencies illegal and secondarily by forbidding the trade of cryptocurrencies, it does not effectively suppress the general interest in Bitcoin as a phenomenon, and to contributing to its infrastructure. ${ }^{17}$

The occurrence of an inflation crisis is associated with an increase in the number of unique bitnodes in a country $(p<0.01)$. The coefficient estimate indicates that the onset of an inflation crisis in a country is associated with an uptake of $47 \%$ of the average and $30 \%$ of the standard deviation of the number of unique bitnodes in a country. We run robustness tests by altering the inflation crisis cut-off to a minimum of $15 \%$ or $25 \%$ of annual inflation and find similar results (see Internet Appendix Table IA.IV). This speaks to bitcoins being utilized for financial hedging where currency devaluations greatly erode the value of a national currency, consistent with hypothesis 1 .

While a greater fraction of unbanked in a country is not found to be associated with the intensity of use of Bitnodes (models 2, 4), it is negatively associated with the number of unique Bitnode users (model $5, p<0.05$ ). This result goes against the

\footnotetext{
${ }^{17}$ Plausibly, this increase in the extensive margin may result from greater publicity of bitcoins following national restrictions.
}

notion that Bitcoin infrastructure is being set up as a substitute to the financial system in countries where financial inclusion and penetration is low, but rather that Bitcoin infrastructure emerge where the penetration of the financial system is greater. This result goes against our hypothesis $2 \mathrm{a}$, in favor of our counter-hypothesis $2 \mathrm{c}$.

The coefficient on Five-bank asset concentration in model 6 is negative and significant at $1 \%$, indicating that greater concentration in the financial sector reduces the intensity of use of Bitnodes. This result goes against our hypothesis $2 \mathrm{~b}$ assertion, in favor of the opposing hypothesis $2 \mathrm{~d}$. Together with the findings for unbanked populations, results point to the penetration of Bitcoin infrastructure increasing in well-developed banking systems (hypotheses $2 \mathrm{c}$ and $2 \mathrm{~d}$ ), where the general familiarity with online finance is greater and the related digital entrepreneurial ecosystem is more vibrant.

Countries with high risk of drug-related money laundering tend to exhibit greater Bitnode intensity of activity (model $4, p<0.05$ ) and Bitnode adopters (model 5, $p<0.01$ ) and provide significantly more active hours of supply of Bitcoin nodes (model $6, p<0.001$ ). This latter coefficient estimate for money laundering is significant at the $1 \%$ level and suggests that countries that have a highrisk of money laundering, all else equal, run Bitcoin nodes for $\sim 7$ days more in a month $(=176.3 / 24)$ than other countries. Our hypothesis 4 is therefore validated.

The variable rule of law pertains to society's perception of the likelihood of crime and violence, as well as their confidence in the quality of the police, courts, contract enforcement, and property rights in each country. It is strongly associated with increases in Bitnode use intensity (model $4, p<0.05$ ) and the number of unique bitnodes (model $5, p<0.001$ ). These are in agreement with our hypothesis 5 . We note, however, that our Rule of law measure could be thought of as having two distinct components: the dependability of law enforcement, as well as the likelihood of crime and violence. Our hypothesized relationship relates to the former of these aspects. We therefore undertake further analysis in order to ensure that our estimates on rule of law are not driven by the Bitcoin infrastructure penetration being greater in countries with more crime and violence.

We use costs to businesses associated with crime and violence, the sub-index crime and violence costs of the World Economic Forum's Global Competitiveness Index, as a proxy for the intensity of crime and violence in nations. A related variable from the same source, the 
degree of Organized crime, is also investigated. Inserting these variables into our main models yields insignificant estimates throughout. We interpret these results (reported in Internet Appendix, Table IA.V) to indicate that the association between rule of law and our dependent variables is, as argued in the corresponding hypothesis, driven by country-level differences in the reliability and effectiveness of police and the legal system.

Table 4 presents the results of our analyses on determinants of adoption of Bitcoin merchants globally on the same countries and using the same Panel A database on which our Table 3 results are based on. Similar to Table 3, models 2 and 3 progressively add national financial and criminality characteristics to our baseline model (1). We expand the baseline estimation in model (4) to include both sets of characteristics.

Model 4 seems to indicate that national financial characteristics dominate criminality explanations in acceptance of bitcoins by merchants. Our coefficient estimates on the unbanked fraction $(\beta=-0.048)$ in model 4 is statistically significant at the $10 \%$ level, suggesting that adoption of bitcoins by merchants is more popular in locations where adults have bank accounts to a greater extent in agreement with hypothesis $2 \mathrm{c}$ rather than $2 \mathrm{a}$. Together with the results in the same direction in Table 3 and contrary to a widely purported promise of bitcoins

Table 4 Financial and criminality drivers of Bitcoin merchants (Panel A; Country-year level)

\begin{tabular}{|c|c|c|c|c|}
\hline Dependent variable & $\begin{array}{l}\text { (1) } \\
\text { Bitcoin merchants }\end{array}$ & $(2)$ & (3) & (4) \\
\hline \multicolumn{5}{|l|}{ Financial characteristics } \\
\hline Inflation crisis & & $\begin{array}{l}-0.418 \\
(1.175)\end{array}$ & & $\begin{array}{l}0.639 \\
(1.807)\end{array}$ \\
\hline Unbanked & & $\begin{array}{l}-0.059+ \\
(0.031)\end{array}$ & & $\begin{array}{l}-0.048+ \\
(0.029)\end{array}$ \\
\hline Five-bank asset concentration & & $\begin{array}{l}-0.041 \\
(0.032)\end{array}$ & & $\begin{array}{l}-0.037 \\
(0.037)\end{array}$ \\
\hline \multicolumn{5}{|l|}{ Criminality characteristics } \\
\hline Money laundering & & & $\begin{array}{l}1.163^{*} \\
(0.560)\end{array}$ & $\begin{array}{l}0.761 \\
(0.867)\end{array}$ \\
\hline Rule of law & & & $\begin{array}{l}1.448^{*} \\
(0.712)\end{array}$ & $\begin{array}{l}1.303^{*} \\
(0.628)\end{array}$ \\
\hline \multicolumn{5}{|l|}{ Baseline characteristics } \\
\hline GDP per capita & $\begin{array}{l}1.401^{*} \\
(0.552)\end{array}$ & $\begin{array}{l}0.481 \\
(0.495)\end{array}$ & $\begin{array}{l}0.368 \\
(0.531)\end{array}$ & $\begin{array}{l}-0.234 \\
(0.579)\end{array}$ \\
\hline Restrictive regulation & $\begin{array}{l}-0.020 \\
(0.997)\end{array}$ & $\begin{array}{l}-0.667 \\
(0.922)\end{array}$ & $\begin{array}{l}0.111 \\
(0.736)\end{array}$ & $\begin{array}{l}-0.388 \\
(0.908)\end{array}$ \\
\hline Constant & $\begin{array}{l}-12.041^{*} \\
(5.301)\end{array}$ & $\begin{array}{l}1.336 \\
(4.511)\end{array}$ & $\begin{array}{l}-3.980 \\
(4.916)\end{array}$ & $\begin{array}{l}6.166 \\
(5.096)\end{array}$ \\
\hline Year FEs & Yes & Yes & Yes & Yes \\
\hline World Region FEs & Yes & Yes & Yes & Yes \\
\hline Year-World Region FEs & Yes & Yes & Yes & Yes \\
\hline Panel Data Specification & Tobit & Tobit & Tobit & Tobit \\
\hline Observations & 685 & 685 & 685 & 685 \\
\hline Number of Countries & 137 & 137 & 137 & 137 \\
\hline Log-likelihood & -1418.2 & -1415.8 & -1415.1 & -1413.7 \\
\hline RHO & 0.23 & 0.23 & 0.22 & 0.22 \\
\hline
\end{tabular}

All models are Tobit random effects models lower-censored at 0 . Panel-data adjusted bootstrapped standard errors, clustered at the country level, and are reported in parentheses. The symbols $* * *, * *, *,+$ mean that the reported coefficients are statistically different from zero, respectively, at the $0.1,1,5$, and $10 \%$ level 
(see, e.g., Vigna and Casey 2015), this points to a picture of Bitcoin infrastructure serving the banked population more than the unbanked. It is noteworthy that our Bitcoin merchants variable is more concentrated in certain countries, especially in the earlier years of the sample. This has the effect that the broad and stringent set of fixed effects interacting world regions and year dummies, and our baseline characteristics, account for a great deal of the variation in our data, reducing the variation that can be attributed exclusively to our exploratory variables.
The coefficient estimate on rule of law is significant $(p<0.05)$ in models (3) and (4) where we control for other covariates and money laundering is only statistically significant in model (3), in agreement with our hypothesis 5 .

\subsection{Social drivers}

Table 5 presents the results of our region-level analyses. This set of analysis uses regional-level versions of the dependent variables and baseline

Table 5 Social drivers of adoption of Bitcoin infrastructure (Panel B; Region-year level)

\begin{tabular}{|c|c|c|c|c|c|c|}
\hline Dependent variables & $\begin{array}{l}(1) \\
\text { Bitnode } \\
\text { intensity }\end{array}$ & $\begin{array}{l}(2) \\
\text { Unique } \\
\text { bitnodes }\end{array}$ & $\begin{array}{l}(3) \\
\text { Bitcoin } \\
\text { merchants }\end{array}$ & $\begin{array}{l}(4) \\
\text { Bitnode } \\
\text { intensity }\end{array}$ & $\begin{array}{l}(5) \\
\text { Unique } \\
\text { bitnodes }\end{array}$ & $\begin{array}{l}(6) \\
\text { Bitcoin } \\
\text { merchants }\end{array}$ \\
\hline \multicolumn{7}{|l|}{ Social characteristics } \\
\hline High risk willingness & $\begin{array}{l}4.848 \\
(3.421)\end{array}$ & $\begin{array}{l}27.595 \\
-23.031\end{array}$ & $\begin{array}{l}17.267^{* * * *} \\
(4.552)\end{array}$ & $\begin{array}{l}6.309^{+} \\
(3.400)\end{array}$ & $\begin{array}{l}38.307 \\
(23.387)\end{array}$ & $\begin{array}{l}20.057^{* *} \\
(6.603)\end{array}$ \\
\hline $\begin{array}{l}\text { High risk willingness } \mathrm{x} \text { Bitcoin } \\
\text { price }\end{array}$ & & & & $\begin{array}{l}-0.581^{* *} \\
(0.000)\end{array}$ & $\begin{array}{l}-4.928^{*} \\
(0.002)\end{array}$ & $\begin{array}{l}-1.824^{*} \\
(0.911)\end{array}$ \\
\hline Trust in others & $\begin{array}{l}1.804 \\
(1.229)\end{array}$ & $\begin{array}{l}17.246^{+} \\
-9.43\end{array}$ & $\begin{array}{l}-0.819 \\
(2.561)\end{array}$ & $\begin{array}{l}1.945 \\
(1.186)\end{array}$ & $\begin{array}{l}17.833^{+} \\
(9.374)\end{array}$ & $\begin{array}{l}0.441 \\
(2.713)\end{array}$ \\
\hline $\begin{array}{l}\text { Distrust in banks \& financial } \\
\text { system }\end{array}$ & $\begin{array}{l}4.383^{* *} \\
(1.638)\end{array}$ & $\begin{array}{l}25.271^{*} \\
-12.525\end{array}$ & $\begin{array}{l}-0.942 \\
(3.210)\end{array}$ & $\begin{array}{l}4.266^{* *} \\
(1.581)\end{array}$ & $\begin{array}{l}24.855^{*} \\
(12.449)\end{array}$ & $\begin{array}{l}2.581 \\
(3.310)\end{array}$ \\
\hline Distrust in other institutions & $\begin{array}{l}-2.827 \\
(2.311)\end{array}$ & $\begin{array}{l}-18.204 \\
-16.9\end{array}$ & $\begin{array}{l}-8.955^{*} \\
(4.354)\end{array}$ & $\begin{array}{l}-2.632 \\
(2.248)\end{array}$ & $\begin{array}{l}-17.708 \\
(16.809)\end{array}$ & $\begin{array}{l}-3.834 \\
(4.351)\end{array}$ \\
\hline Bitcoin price & & & & $\begin{array}{l}0.011 \\
(0.038)\end{array}$ & $\begin{array}{l}-2.985^{\text {**** }} \\
(0.391)\end{array}$ & $\begin{array}{l}0.269 \\
(0.169)\end{array}$ \\
\hline \multicolumn{7}{|l|}{ Baseline characteristics } \\
\hline GDP per capita & $\begin{array}{l}-1.886^{*} \\
(0.869)\end{array}$ & $\begin{array}{l}-33.543^{* * * *} \\
-8.313\end{array}$ & $\begin{array}{l}-6.211 \\
(4.548)\end{array}$ & $\begin{array}{l}-1.884^{*} \\
(0.821)\end{array}$ & $\begin{array}{l}-33.558^{* * * *} \\
(8.239)\end{array}$ & $\begin{array}{l}-6.341 \\
(4.225)\end{array}$ \\
\hline Restrictive regulation & $\begin{array}{l}-0.139 \\
(0.422)\end{array}$ & $\begin{array}{l}3.468 \\
-4.051\end{array}$ & $\begin{array}{l}-0.441 \\
(2.254)\end{array}$ & $\begin{array}{l}0.049 \\
(0.401)\end{array}$ & $\begin{array}{l}5.212 \\
(4.036)\end{array}$ & $\begin{array}{l}0.240 \\
(2.133)\end{array}$ \\
\hline Constant & $\begin{array}{l}8.381 \\
(7.710)\end{array}$ & $\begin{array}{l}239.257^{* * *} \\
-71.928\end{array}$ & $\begin{array}{l}35.253 \\
(38.691)\end{array}$ & $\begin{array}{l}8.424 \\
(7.301)\end{array}$ & $\begin{array}{l}239.675^{* * * *} \\
(71.287)\end{array}$ & $\begin{array}{l}32.577 \\
(35.990)\end{array}$ \\
\hline Year FEs & Yes & Yes & Yes & Yes & Yes & Yes \\
\hline Country FEs & Yes & Yes & Yes & Yes & Yes & Yes \\
\hline Panel Data Specifications & Tobit & Tobit & Tobit & Tobit & Tobit & Tobit \\
\hline Observations & 1470 & 1470 & 1470 & 1470 & 1470 & 1470 \\
\hline Number of Statistical Regions & 294 & 294 & 294 & 294 & 294 & 294 \\
\hline Number of Countries & 34 & 34 & 34 & 34 & 34 & 34 \\
\hline Log-likelihood & -2800.7 & -5221.2 & -2742.9 & -2796.7 & -5218.4 & -2740.9 \\
\hline RHO & 0.78 & 0.59 & 0.24 & 0.78 & 0.59 & 0.24 \\
\hline
\end{tabular}

Notes: All models are Tobit random effects models, lower censored at 0 and their associated overall R-squared is reported. Their standard errors are reported in parentheses. The symbols $* * *, * *, *,+$ mean that the reported coefficients are statistically different from zero, respectively, at the $0.1,1,5$ and $10 \%$ level 
characteristics of Table 3, and in addition includes social variables and country-level fixed effects in order to control for unobserved country-level heterogeneity. Country-level differences in financial and criminality factors are absorbed by these fixed effects and are not included individually in this analysis. Dependent variables are standardized by the number of Internet users. Year fixed effects control for unobserved year-specific events.

Models 1 and 2 present estimates of the model specification in Eq. (2) for bitnode intensity and unique bitnodes. In regressing the trust in others variable against unique bitnodes, the coefficient estimate of model (1) is insignificant. In model (2), the coefficient of $\beta=17.2$ is significant at the $10 \%$ level. In terms of magnitude, these suggest that a one standard deviation decrease in trust in others is associated with 4.5 fewer unique bitnode adopters per million Internet users or $31.3 \%$ of average adopters of bitnodes in statistical regions. We thus find only weak and partial support for hypothesis $3 \mathrm{a}$.

The coefficient estimate for our variable distrust in banks and the financial system is statistically significant in models (1) to (2), respectively at the $1 \%$ and $5 \%$ level. In terms of magnitude, a one standard deviation increase in distrust in banks and the financial system equivalent to $31 \%$ more distrustful people ${ }^{18}$ is associated with an increase of 8 unique bitnode adopters per million Internet users (equivalent to $54 \%$ of mean adopters in statistical regions), or an increase equivalent to $34 \%$ of the standard deviation of bitnode intensity. These effects are fairly large, and corroborate the role of crisis-related factors and distrust in banks being a factor in the early use of other peer-to-peer fintech technologies (see, e.g., Saiedi et al. 2017; Thakor and Merton 2018), in agreement with hypothesis $3 \mathrm{~b} .{ }^{19}$

Model 3 documents region-level social determinants of the adoption of bitcoin by merchants. Our hypothesized trust variables do not yield any statistically significant association to merchants' rate of adoption of

\footnotetext{
${ }^{18}$ Equivalent to $115 \%$ of the time-wise increase in Americans' distrust in banks seen from 2006 till 2010 (which was $26.7 \%$ based on the Gallup survey), the year this distrust peaked at the height of the financial crisis.

${ }^{19}$ Given Bitcoin's origins in the cypherpunk and crypto-anarchist subcultures (Swartz 2018), it is possible that distrust in government may be have greater association with the adoption of bitcoin. We explored this, by substituting for distrust in banks with a similarlyconstructed distrust in government variable from the same sources, and do not find any explanatory power to this latter variable in regressing either of our Bitcoin infrastructure variables.
}

bitcoin. However, our measure of self-reported willingness to take risks by individuals is found to be significant at the $0.1 \%$ level consistent with our hypothesis $3 \mathrm{c}$. This suggests that adoption of bitcoins by merchants occurs more where the population have a higher tendency to engage in risky and speculative behavior.

We conduct a further test regarding the hypothesis $3 \mathrm{c}$. In developing this hypothesis, we argued that riskwillingness can be expected to be associated with the penetration of Bitcoin infrastructure since the level riskwillingness could be expected to influence how many people that are interested in holding bitcoin. If this is the case, we should be able to observe signs of Countercyclical Risk Aversion. Such behavior, which has been identified as explaining behavior on the stock market (Cohn et al. 2015; Guiso et al. 2018), would imply that when prices go down, generally risk-averse individuals are even less willing than before to take on risks. While riskwillingness would generally be associated with greater participation in financial markets, this association would hence in the presence of countercyclical risk aversion be strengthened in periods when assets trade at a relatively lower price. We test this prediction in models 4 to 6 which use the same variables used respectively in models 1 through 3, but add an interaction term of the annuallyaveraged bitcoin price variable with high risk willingness. The estimates on these interaction terms are consistently and significantly negative. We interpret these findings as providing relatively strong support for hypothesis $3 \mathrm{c}$, and for the notion that there is greater interest to hold bitcoins - both by merchants themselves and by their costumers - in regions with higher levels of risk-taking.

\subsection{Robustness tests}

We consider a range of robustness tests to lend empirical support to our findings, with respect to (i) alternative definitions of variables utilized to test our hypotheses, (ii) an alternative modeling approach, and (iii) alternative strategies for choosing the reference sample (e.g., restricting analysis to geographies with non-zero infrastructure).

We investigate the construct validity of our financial variables by constructing alternative measures relating to the relevant hypotheses. These alternative variables are listed along with the original variables in Table 1. Each alternative measure is significantly correlated, at below $1 \%$ significance, with the original variable.

The results of this exercise are shown in Table 6 . Models 1 and 4 are provided for easy reference and are 
Table 6 Robustness tests with alternative measures for financial variables (Panel A; Country-year level)

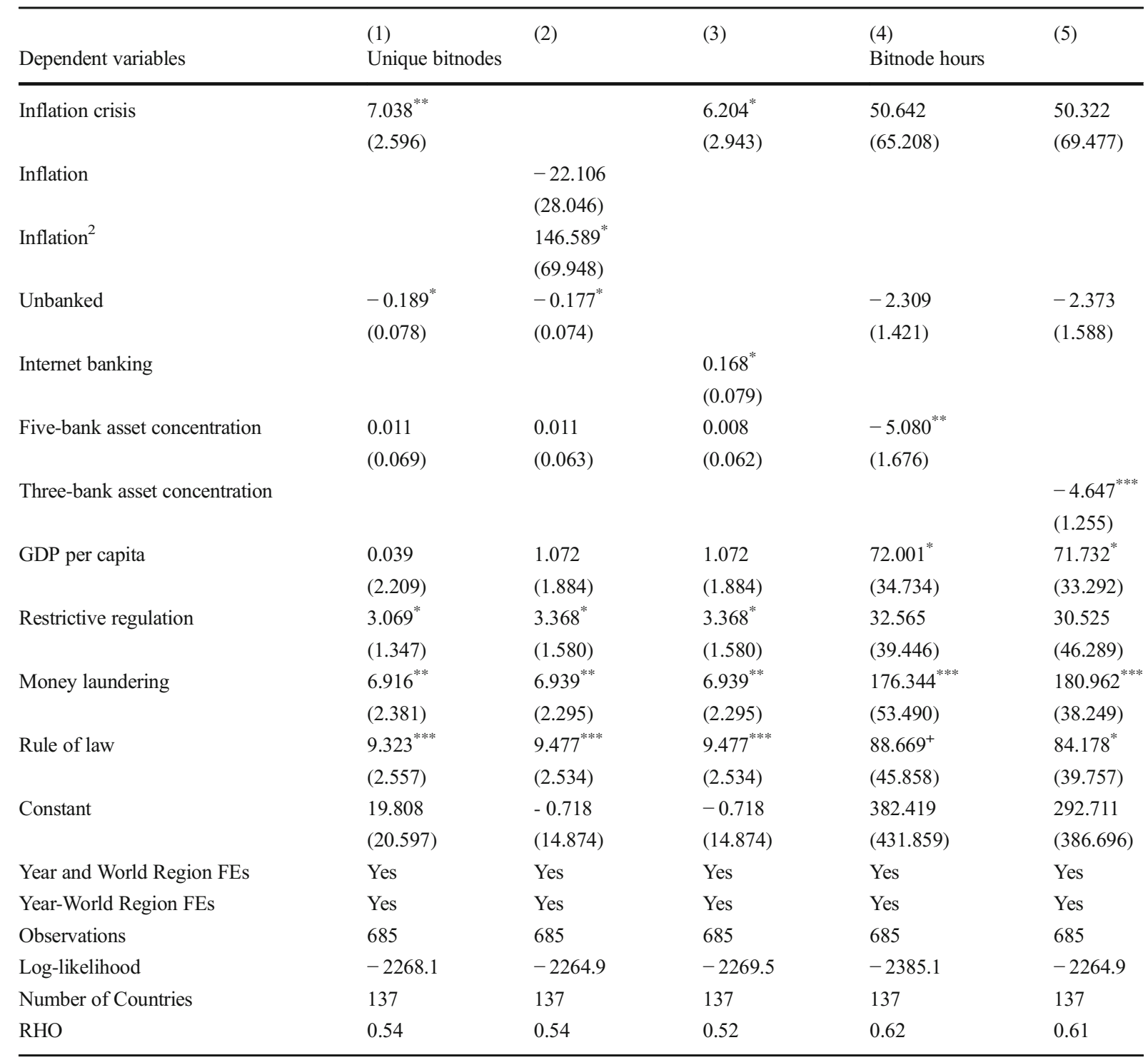

All models are Tobit random effects models lower-censored at 0 and their associated pseudo R-squared are reported. Panel-data adjusted bootstrapped standard errors, clustered at the country level, are reported in parentheses. The symbols $* * *, * *, *,+$ mean that the reported coefficients are statistically different from zero, respectively, at the $0.1,1,5$, and $10 \%$ level. Models 4 and 5 are additionally upper-censored at 750 (upper limit of active Bitnode hours in a month)

duplicates of models 5 and 6 in Table 3. In model 2, a linear and quadratic combination of the continuous measure inflation are replacing the indicator variable inflation crisis. A non-linear specification is used since our Hypothesis 1 states that it is very high inflation levels which are expected to be associated with greater uptake of Bitcoin infrastructure. In agreement with such hypothesizing, the estimate on the quadratic component is positive and significant at
$5 \%$. Moreover, inflation and inflation ${ }^{2}$ are jointly significant at less than $0.1 \%$. The coefficients imply that on average, starting at inflation values of $15.1 \%$ increases in inflation contribute to broadening the population of bitcoin adopters. In further work, reported in Table IA.IV of the Internet Appendix, we confirm that using indicator variables for $>15 \%$ or $>$ $25 \%$ inflation, instead of the $>20 \%$ indicator used in our main analysis yields qualitatively similar results. 
In model 3, we replace unbanked for the proportion of those with Internet banking. We find a positive and significant coefficient on this variable, which as before supports our hypothesis $2 \mathrm{c}$ that greater financial inclusion leads to greater adoption of Bitcoin infrastructure. In model 5 we replace five-bank asset concentration with another measure for the concentration in the banking industry of three-bank asset concentration. Also, with this alternative measure, we find support for our hypothesis $2 \mathrm{~d}$ in that greater competition in the banking sector is associated with greater uptake of Bitcoin infrastructure.

Next, we consider an alternative modeling approach. While we have presented our two sets of analyses of
Bitnodes and merchants in parallel, our separate econometric models for these two could be under-utilizing our related dependent variables. Since there may be unobserved factors (e.g., the number of bitcoin users in a country) which are related to both the intensity of bitnode operations and the number of Bitcoin merchants, the error terms (or unaccounted part) of each model could be expected to be positively correlated. Running these two sets of analysis as a system is therefore of interest. We implement a generalized simultaneous equation model (GSEM). Table 7 reports results of a Tobit model fitted with GSEM for three possible pairings of our three bitnode dependent variables with

Table 7 Robustness tests using generalized simultaneous equation modeling (Panel A; country-year level)

\begin{tabular}{|c|c|c|c|c|c|c|}
\hline \multirow[b]{2}{*}{ Dependent variables } & \multicolumn{2}{|l|}{ (1) } & \multicolumn{2}{|l|}{ (2) } & \multicolumn{2}{|l|}{ (3) } \\
\hline & $\begin{array}{l}\text { Bitnode } \\
\text { intensity }\end{array}$ & $\begin{array}{l}\text { Bitcoin } \\
\text { merchants }\end{array}$ & $\begin{array}{l}\text { Unique } \\
\text { bitnodes }\end{array}$ & $\begin{array}{l}\text { Bitcoin } \\
\text { merchants }\end{array}$ & $\begin{array}{l}\text { Bitnode } \\
\text { hours }\end{array}$ & $\begin{array}{l}\text { Bitcoin } \\
\text { merchants }\end{array}$ \\
\hline \multicolumn{7}{|l|}{ Financial characteristics } \\
\hline Inflation crisis & $\begin{array}{l}1.534^{+} \\
(0.852)\end{array}$ & $\begin{array}{l}1.149 \\
(1.120)\end{array}$ & $\begin{array}{l}11.008^{* *} \\
(3.806)\end{array}$ & $\begin{array}{l}1.149 \\
(1.120)\end{array}$ & $\begin{array}{l}87.005 \\
(77.197)\end{array}$ & $\begin{array}{l}1.149 \\
(1.120)\end{array}$ \\
\hline Unbanked & $\begin{array}{l}0.010 \\
(0.011)\end{array}$ & $\begin{array}{l}-0.049 \\
(0.032)\end{array}$ & $\begin{array}{l}-0.129^{*} \\
(0.061)\end{array}$ & $\begin{array}{l}-0.049 \\
(0.032)\end{array}$ & $\begin{array}{l}-1.585 \\
(1.349)\end{array}$ & $\begin{array}{l}-0.049 \\
(0.032)\end{array}$ \\
\hline $\begin{array}{l}\text { Five-bank asset } \\
\text { concentration }\end{array}$ & $\begin{array}{l}0.011 \\
(0.018)\end{array}$ & $\begin{array}{l}-0.038 \\
(0.036)\end{array}$ & $\begin{array}{l}0.010 \\
(0.068)\end{array}$ & $\begin{array}{l}-0.038 \\
(0.036)\end{array}$ & $\begin{array}{l}-5.084^{* * *} \\
(1.244)\end{array}$ & $\begin{array}{l}-0.038 \\
(0.036)\end{array}$ \\
\hline \multicolumn{7}{|l|}{ Criminality characteristics } \\
\hline Money laundering & $\begin{array}{l}1.481^{*} \\
(0.635)\end{array}$ & $\begin{array}{l}0.594 \\
(0.653)\end{array}$ & $\begin{array}{l}6.942^{* *} \\
(2.454)\end{array}$ & $\begin{array}{l}0.594 \\
(0.653)\end{array}$ & $\begin{array}{l}111.079^{* *} \\
(37.625)\end{array}$ & $\begin{array}{l}0.594 \\
(0.653)\end{array}$ \\
\hline Rule of law & $\begin{array}{l}1.937^{\text {**** }} \\
(0.457)\end{array}$ & $\begin{array}{l}1.173^{*} \\
(0.566)\end{array}$ & $\begin{array}{l}9.693^{* * * *} \\
(1.942)\end{array}$ & $\begin{array}{l}1.173^{*} \\
(0.566)\end{array}$ & $\begin{array}{l}73.946^{*} \\
(34.603)\end{array}$ & $\begin{array}{l}1.173^{*} \\
(0.566)\end{array}$ \\
\hline \multicolumn{7}{|l|}{ Baseline characteristics } \\
\hline GDP per capita & $\begin{array}{l}0.552^{+} \\
(0.329)\end{array}$ & $\begin{array}{l}-0.162 \\
(0.504)\end{array}$ & $\begin{array}{l}1.147 \\
(1.514)\end{array}$ & $\begin{array}{l}-0.162 \\
(0.504)\end{array}$ & $\begin{array}{l}43.281 \\
(31.870)\end{array}$ & $\begin{array}{l}-0.162 \\
(0.504)\end{array}$ \\
\hline Restrictive regulation & $\begin{array}{l}-0.122 \\
(0.404)\end{array}$ & $\begin{array}{l}-0.692 \\
(0.772)\end{array}$ & $\begin{array}{l}0.024 \\
(1.781)\end{array}$ & $\begin{array}{l}-0.692 \\
(0.772)\end{array}$ & $\begin{array}{l}19.883 \\
(49.044)\end{array}$ & $\begin{array}{l}-0.692 \\
(0.772)\end{array}$ \\
\hline Constant & $\begin{array}{l}-6.473^{*} \\
(3.257)\end{array}$ & $\begin{array}{l}5.854 \\
(5.702)\end{array}$ & $\begin{array}{l}7.629 \\
(15.480)\end{array}$ & $\begin{array}{l}5.854 \\
(5.702)\end{array}$ & $\begin{array}{l}493.289 \\
(318.059)\end{array}$ & $\begin{array}{l}5.854 \\
(5.702)\end{array}$ \\
\hline Year FEs & Yes & Yes & Yes & Yes & Yes & Yes \\
\hline World Region FEs & Yes & Yes & Yes & Yes & Yes & Yes \\
\hline Year-World Region FEs & Yes & Yes & Yes & Yes & Yes & Yes \\
\hline Observations & 685 & & 685 & & 685 & \\
\hline Log-likelihood & -2960.1 & & -3814.1 & & -5410.2 & \\
\hline Number of Countries & 137 & & 137 & & 137 & \\
\hline
\end{tabular}

All models are Generalized Simultaneous Equation Models fitted with Tobit models lower-censored at 0 and their associated log-likelihoods are reported. Standard errors, clustered at the country level, are reported in parentheses. The symbols $* * *, * *, *,+$ mean that the reported coefficients are statistically different from zero, respectively, at the $0.1,1,5$ and $10 \%$ level 
our Bitcoin merchant variable. Our results are highly similar to those found using single equation models (models 4 to 6 in Table 3; model 4 in Table 4). In model 1 , rule of law is more significant in explaining bitnode intensity at $0.1 \%$ with a greater coefficient magnitude, while other variables retain their significance. Meanwhile, rule of law is similarly significant in explaining Bitcoin merchants. Results for unique bitnodes and bitnode hours in models 2 and 3 are very similar to our previous findings in our main analysis in Table 3 and confirm our previous findings.

Finally, we repeat our main analyses excluding countries in which no bitnode activity ( 7 countries) or Bitcoin merchants (24 countries) exist during our sample period. Tables IA.VII and IA.VIII of the Internet Appendix, present these results respectively for our financial and criminality variables analysis (Panel A; Country-Years) and for our social variables analysis (Panel B; RegionYear). This is to investigate to what extent our results are driven by countries that do not have any Bitcoin infrastructure at any time of observation. Our coefficient magnitudes are very similar and statistical significances remain largely unchanged from our main findings presented earlier.

\subsection{Additional analysis}

In this section, we perform additional analysis in order to set our main analysis into context. Specifically, we investigate a set of factors beyond the main variables and controls used in the main model, which may drive the diffusion of Bitcoin infrastructure. In a first set of analysis, we explore a wider set of measures of technological development. Thereafter, we seek to rule out the following alternative explanations: (i) shadow economy and tax evasion, (ii) rewards in cryptocurrency mining of bitcoins, and (iii) hedging of equity markets.

\subsubsection{Technological/infrastructural characteristics}

In our main models, we account for the role of technological development by normalizing the dependent variables by the number of Internet users. In further work, we construct a range of variables to explore further nuances in the relationship between technological development and the penetration of Bitcoin infrastructure.

Since Information and Communication Technology (ICT) is an enabler and prerequisite for financial technologies (Haddad and Hornuf 2019; Huang et al. 2019), as first order tests, we explore measures accounting for more advanced types of Internet use. Beyond the previously used Internet penetration, we also extract measures of broadband penetration and mobile telephone subscriptions from the International Telecommunications Unit (ITU)'s World Telecommunication/ICT Development reports, respectively defined as percentage of households with access to broadband, and the number of mobile telephone transactions per 100 adults in the population. We obtain ICT capabilities and ICT market development from the ITU's Measuring the Information Society Reports; the former measures user sophistication as a composite index of adult literacy, and secondary and tertiary education, and the latter measures Information and Communication Technology (ICT) development as a composite index of ICT infrastructure, ICT capabilities (skills and knowledge) and ICT use of intensity. We measure the extent to which the latest technology is available, using the Executive Opinion Survey of the World Economic Forum's Global Competitiveness Report. We obtain Internet servers data from the World Bank and netcraft.com, as the number of servers using encryption technology in Internet communication per one million people. We utilize electricity cost and electricity price data from the World Bank's Doing Business datasets, respectively measuring the median cost in percent terms relative to income per capita of connecting and running a warehouse with electricity, and the price in US cents per kWH of monthly electricity consumption for a warehouse based in the largest business city of a country for the month of March.

Table 8 shows the effect of these variables on per-capita standardized dependent variables. Model 1 shows, for reference, the relationship between GDP per capita and bitnode intensity. In all other models, we do not include GDP per capita due to very high correlations - as high as 0.91 - with the technology variables (see Appendix, Table A.I). Models 2 and 3 respectively show that the Internet and broadband penetration are significant (at $0.1 \%$ and $5 \%$ respectively) in explaining bitnode intensity. Models 4 through to 7 examine the effect of each explanatory variable in Eq. (1) independently on bitnode intensity. ICT market development and latest technology are highly significant (at $0.1 \%$ ), while secure Internet servers and mobile subscribers are significant at $10 \%$ and $5 \%$ respectively. While not reported, we also tested ICT capabilities separately which was highly significant at $0.1 \%$. Models 9 through to 12 represent the results of Eq. (1), by progressively regressing all infrastructural variables onto our three per-capita dependent variables. ICT market development 


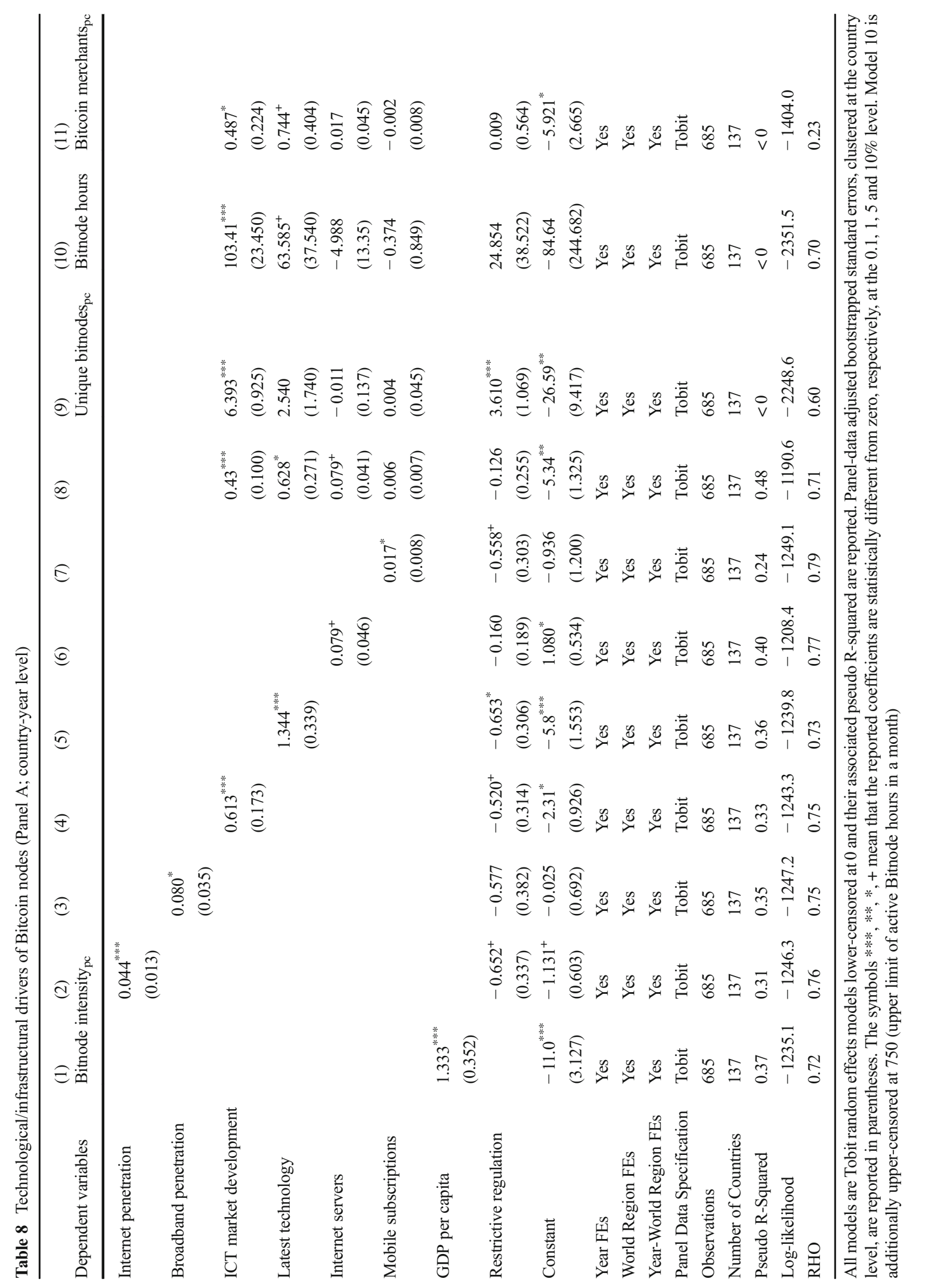


and latest technology remain positive and significance in most regressions at $0.1 \%$ and below $10 \%$ respectively. This aligns with the expectation that Bitcoin infrastructure are more likely to appear in countries where ICT is more advanced. Still, analysis of the pseudo- $R^{2} \mathrm{~S}$ suggest that economic strength (GDP per capita) is a more efficient predictor of Bitcoin infrastructure penetration than ICT market development. This supports our choice to anchor our main analysis in models controlling for this factor.

\subsubsection{Alternative explanations for bitcoin adoption}

We additionally test a range of other variables argued for in the emerging literature to drive the use of cryptocurrencies. $^{20}$ Since they enable global transactions, digital assets can be used for shadow banking and tax evasion (Van Alstyne 2014). Currently, many national governments and their tax administrations are in the process of penning legislation on assets held in cryptocurrencies, while international task forces are devised to combat cryptocurrency-enabled tax crime (J5 2018). Most countries, however, have still not imposed any regulation or indeed effective regulation (Akins et al. 2015; Marian 2013). Hence, it is conceivable that bitcoins and Bitcoin infrastructure would find the greatest use and support where incentives for tax avoidance and evasion are highest. To test this, in Tables 9 and 10 we separately regress our dependent variables of bitnode intensity and Bitcoin merchants, on measures for the size of the shadow economy relative to the GDP (shadow economy), an indicator variable for whether a jurisdiction is a tax haven (tax haven), tax rates on income, and capital gains (taxation), and a measure of tax burden across countries (tax burden). We maintain the baseline controls, but omit other controls to avoid confounding of variables. We do not find an indication to support the shadow economy and taxation drivers (Tables 9 and 10; Models 1 to 4). This could be attributed either to more hidden uses of bitcoins in such nations or that the new potentials that cryptocurrencies enable for tax evasion and shadow economy, are not yet extensive enough to constitute a large part of bitcoin use.

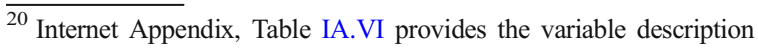
and data sources for these variables. Our analyses of these additional characteristics, reported in Tables 9 and 10, are restricted to fewer than all 137 countries in Panel A, as certain variable sources do not report values for all countries in our sample.
}

It is possible that use of Bitcoin infrastructures (esp. Bitcoin nodes) are primarily being driven by cryptocurrency miners vying to reap the financial rewards associated with mining bitcoins. Hence, we explore if bitcoin mining is a major driver of adoption of our variables, by regressing a bitcoin mining country indicator variable for countries identified by the Cambridge Centre for Alternative Finance's two versions of the Global Cryptocurrency Benchmarking Study (Hileman and Rauchs 2017; Rauchs et al. 2018) as having medium-to-large scale mining operations, and additionally find no significant effect in our robustness tests (Tables 9 and 10, Model 5). We include estimates of mining intensity (in MW) and do not find any significant effect in our robustness tests (Tables 9 and 10, Model 6). We attribute this to operation of Bitcoin nodes being driven by other than purely financial incentives and rewards to mine bitcoins, while this may still be a contributing factor. Bitcoin mining facilities are highly concentrated in certain countries with cheap and reliable electricity, cold climate and friendly regulatory environment (e.g., Rauchs et al. 2018 identify only 128 mining facilities worldwide, where only 7 countries are mining more than $40 \mathrm{MW}$ whereas $1.7 \mathrm{GW}$ have been identified worldwide), whereas nodes are less concentrated. In fact, Miller et al. (2018) find only $2 \%$ of nodes on the Bitcoin network to account for three quarters of the mining power. We additionally test electricity prices in USD per $\mathrm{kWh}$ in different countries and years and similarly find no effect (Tables 9 and 10, Model 7).

One of the touted benefits of cryptocurrencies in the financial literature has been in enabling diversification (Bouri et al. 2019a) or as a hedge against equity markets (Bouri et al. 2019b), although some studies have found them to be a weak hedge for stock markets (Kliber et al. 2019; Shahzad et al. 2019). Certainly bitcoins are held due to their speculative nature (Rauchs et al. 2018; Baur et al. 2018b), in congruence with the reported effects of our high-risk willingness variable, in addition to serving as an alternative investment (Glaser et al. 2014). We test to see if Bitcoin infrastructure has seen an uptick worldwide as a hedge for low returns in national stock markets. Model 8 in Tables 9 and 10 presents results of that and does not show evidence for hedging as a main driver of bitcoin use. In Model 9 of these tables, we additionally test to see if purely low returns during the global financial crisis can be attributable to an upsurge in adoption, and similarly do not find statistically significant effects on our crisis stock market return variable. 
Table 9 Additional analysis on the role of alternative potential drivers (Panel A; country-year level)

\begin{tabular}{ll}
\hline Dependent variable & $(1)$ \\
& Bitnode in \\
\hline Shadow economy & -0.037 \\
& $(0.031)$
\end{tabular}

Tax haven

(2)

(3)

(4)

(5)

(6)

(7)

(8)

(9)

9)

(0.665)

Taxation

0.011

(0.021)

Tax burden

-0.011
$(0.027)$

Bitcoin mining
country

0.374

(0.996)

Bitcoin mining MWs

$-0.013$

Electricity price

$-0.002$

(0.035)

Stock market return

$-0.002$

(0.005)

Crisis stock market

0.005

return

\begin{tabular}{|c|c|c|c|c|c|c|c|c|c|}
\hline GDP per capita & $\begin{array}{l}1.173^{* * *} \\
(0.373)\end{array}$ & $\begin{array}{l}1.452^{\text {**** }} \\
(0.377)\end{array}$ & $\begin{array}{l}1.735^{\text {**** }} \\
(0.421)\end{array}$ & $\begin{array}{l}1.640^{\text {**** }} \\
(0.334)\end{array}$ & $\begin{array}{l}1.420^{* * * *} \\
(0.333)\end{array}$ & $\begin{array}{l}1.408^{\text {**** }} \\
(0.351)\end{array}$ & $\begin{array}{l}1.425^{\text {**** }} \\
(0.334)\end{array}$ & $\begin{array}{l}1.680^{\text {**** }} \\
(0.370)\end{array}$ & $\begin{array}{l}1.384^{* *} \\
(0.477)\end{array}$ \\
\hline \multirow[t]{2}{*}{ Restrictive regulation } & -0.500 & $-0.579^{*}$ & -0.474 & $-0.570^{+}$ & $-0.582^{*}$ & -0.466 & $-0.582^{*}$ & -0.636 & -0.744 \\
\hline & $(0.348)$ & $(0.279)$ & $(0.363)$ & $(0.331)$ & $(0.295)$ & $(0.293)$ & $(0.283)$ & $(0.439)$ & $(0.490)$ \\
\hline \multirow[t]{2}{*}{ Constant } & $-8.222^{*}$ & $-11.567^{* * * *}$ & $-14.639^{* * *}$ & $-12.552^{* *}$ & $-11.480^{* * *}$ & $-11.260^{* * *}$ & $-11.281^{* * * *}$ & $-13.802^{* * *}$ & $-10.959^{* *}$ \\
\hline & $(3.646)$ & $(3.065)$ & $(3.731)$ & $(4.325)$ & $(2.869)$ & $(2.936)$ & $(3.366)$ & $(3.326)$ & $(4.252)$ \\
\hline Year FEs & Yes & Yes & Yes & Yes & Yes & Yes & Yes & Yes & Yes \\
\hline World Region FEs & Yes & Yes & Yes & Yes & Yes & Yes & Yes & Yes & Yes \\
\hline $\begin{array}{l}\text { Year-World Region } \\
\text { FEs }\end{array}$ & Yes & Yes & Yes & Yes & Yes & Yes & Yes & Yes & Yes \\
\hline Observations & 670 & 685 & 580 & 665 & 685 & 670 & 685 & 440 & 460 \\
\hline Log-likelihood & -1291.6 & -1314.4 & -1131.3 & -1267.2 & -1314.8 & -1269.2 & -314.6 & -975.1 & -1023.1 \\
\hline Number of Countries & 134 & 137 & 116 & 134 & 137 & 134 & 137 & 92 & 92 \\
\hline RHO & 0.74 & 0.74 & 0.77 & 0.75 & 0.74 & 0.75 & 0.74 & 0.76 & 0.75 \\
\hline
\end{tabular}

Notes: All models are Tobit random effects models lower-censored at 0 and their associated pseudo R-squared are reported. Panel-data adjusted bootstrapped standard errors, clustered at the country level, are reported in parentheses. The symbols ***, **, *, + mean that the reported coefficients are statistically different from zero, respectively, at the $0.1,1,5$ and $10 \%$ level

\section{Discussion and limitations}

To date, bitcoin is clearly the most prominent and widespread cryptocurrency. A decade on from the first bitcoin transaction, this paper studies the determinants of adoption of infrastructure supporting bitcoin's use as a digital currency. Infrastructure supporting Bitcoin's peer-to-peer network (the hosting of bitnodes, which are infrastructure meant to validate and verify transactions) as well as infrastructure facilitating the integration of bitcoin into the regular economy (merchants' acceptance of bitcoins as payment) has been explored. The results are summarized in Table 11. 
Table 10 Additional analysis (continued) on the role of alternative potential drivers (Panel A; Country-year level)

\begin{tabular}{|c|c|c|c|c|c|c|c|c|c|}
\hline Dependent variable & $\begin{array}{l}\text { (1) } \\
\text { Bitnode m }\end{array}$ & $\begin{array}{l}\text { (2) } \\
\text { rchants }\end{array}$ & (3) & (4) & $(5)$ & (6) & (7) & (8) & (9) \\
\hline Shadow economy & $\begin{array}{l}-0.003 \\
(0.033)\end{array}$ & & & & & & & & \\
\hline Tax haven & & $\begin{array}{l}-0.431 \\
(1.276)\end{array}$ & & & & & & & \\
\hline Taxation & & & $\begin{array}{l}0.003 \\
(0.038)\end{array}$ & & & & & & \\
\hline Tax burden & & & & $\begin{array}{l}-0.071 \\
(0.047)\end{array}$ & & & & & \\
\hline Bitcoin mining country & & & & & $\begin{array}{l}1.003 \\
(1.283)\end{array}$ & & & & \\
\hline Bitcoin mining MWs & & & & & & $\begin{array}{l}0.002 \\
(0.031)\end{array}$ & & & \\
\hline Electricity price & & & & & & & $\begin{array}{l}0.020 \\
(0.025)\end{array}$ & & \\
\hline Stock market return & & & & & & & & $\begin{array}{l}0.020 \\
(0.019)\end{array}$ & \\
\hline Crisis stock market return & & & & & & & & & $\begin{array}{l}-0.010 \\
(0.025)\end{array}$ \\
\hline GDP per capita & $\begin{array}{l}1.343^{*} \\
(0.648)\end{array}$ & $\begin{array}{l}1.413^{* *} \\
(0.492)\end{array}$ & $\begin{array}{l}1.550^{*} \\
(0.633)\end{array}$ & $\begin{array}{l}1.137^{* *} \\
(0.438)\end{array}$ & $\begin{array}{l}1.387^{* *} \\
(0.535)\end{array}$ & $\begin{array}{l}1.474^{* *} \\
(0.557)\end{array}$ & $\begin{array}{l}1.372^{*} \\
(0.588)\end{array}$ & $\begin{array}{l}0.590 \\
(0.364)\end{array}$ & $\begin{array}{l}0.689^{+} \\
(0.362)\end{array}$ \\
\hline Restrictive Bitcoin Regulation & $\begin{array}{c}-0.024 \\
(0.821)\end{array}$ & $\begin{array}{c}-0.024 \\
(0.750)\end{array}$ & $\begin{array}{l}0.461 \\
(0.941)\end{array}$ & $\begin{array}{l}-0.129 \\
(0.793)\end{array}$ & $\begin{array}{l}-0.109 \\
(0.725)\end{array}$ & $\begin{array}{l}-0.132 \\
(1.040)\end{array}$ & $\begin{array}{l}-0.053 \\
(0.970)\end{array}$ & $\begin{array}{l}-0.035 \\
(0.708)\end{array}$ & $\begin{array}{l}-1.203 \\
(1.315)\end{array}$ \\
\hline Constant & $\begin{array}{l}-11.121^{+} \\
(6.577)\end{array}$ & $\begin{array}{l}-12.096^{*} \\
(4.786)\end{array}$ & $\begin{array}{l}-13.596^{*} \\
(5.954)\end{array}$ & $\begin{array}{l}-3.933 \\
(4.898)\end{array}$ & $\begin{array}{l}-12.092^{*} \\
(5.281)\end{array}$ & $\begin{array}{l}-12.620^{*} \\
(5.213)\end{array}$ & $\begin{array}{l}-11.805^{*} \\
(5.633)\end{array}$ & $\begin{array}{l}-4.499 \\
(3.641)\end{array}$ & $\begin{array}{l}-5.190 \\
(3.540)\end{array}$ \\
\hline Year FEs & Yes & Yes & Yes & Yes & Yes & Yes & Yes & Yes & Yes \\
\hline World Region FEs & Yes & Yes & Yes & Yes & Yes & Yes & Yes & Yes & Yes \\
\hline Year-World Region FEs & Yes & Yes & Yes & Yes & Yes & Yes & Yes & Yes & Yes \\
\hline Observations & 670 & 685 & 580 & 665 & 685 & 670 & 685 & 440 & 460 \\
\hline Log-likelihood & -1382.1 & -1418.2 & -1278.1 & -1407.8 & -1418.0 & -1377.5 & -1417.8 & -1151.0 & -1195.8 \\
\hline Number of Countries & 134 & 137 & 116 & 134 & 137 & 134 & 137 & 92 & 92 \\
\hline RHO & 0.23 & 0.23 & 0.21 & 0.20 & 0.23 & 0.23 & 0.23 & 0.18 & 0.19 \\
\hline
\end{tabular}

All models are Tobit random effects models lower-censored at 0 and their associated pseudo R-squared are reported. Panel-data adjusted bootstrapped standard errors, clustered at the country level, are reported in parentheses. The symbols $* * *, * *, *,+$ mean that the reported coefficients are statistically different from zero, respectively, at the $0.1,1,5$, and $10 \%$ level

Our results offer some support for the view that bitcoin adoption is driven by perceived failings of traditional financial institutions and systems (see, e.g., Cohen 2017; Shiller 2019; Vigna and Casey 2015). In particular, we find more activity in the running of Bitcoin nodes in regions with low trust in banks and the financial system. These corroborate the role of distrust in banks, which spread widely in the aftermath of the financial crisis of 20072009 , being a factor in the early use of other peer-to-peer fintech technologies (see, e.g., Saiedi et al. 2017; Bertsch et al. 2017; Thakor and Merton 2018). We also find greater supply of and demand for Bitcoin infrastructure in years in which countries undergo inflation crises, potentially indicative of a loss of faith in central-bank issued currencies or using bitcoin as an investment or store of value. Our findings suggest that the ideological motives for use of cryptocurrencies in entrepreneurial financing (e.g., Fisch et al. 2019) extend to sentiments of infrastructure adopters, 
Table 11 Summary of hypotheses and results of hypothesis tests

\begin{tabular}{|c|c|c|c|}
\hline Hypothesis number & Hypothesis & Results & $\begin{array}{l}\text { Support for nodes and/or } \\
\text { merchants? }\end{array}$ \\
\hline H1 & $\begin{array}{l}\text { The occurrence of inflation crises is associated } \\
\text { with increased adoption of Bitcoin infrastructure. }\end{array}$ & Supported & Nodes \\
\hline H2a (vs. countering H2c) & $\begin{array}{l}\text { The lower (for } \mathrm{H} 2 \mathrm{c} \text { : greater) the population of } \\
\text { financially included adults, the greater the } \\
\text { adoption of Bitcoin infrastructure. }\end{array}$ & $\begin{array}{l}\mathrm{H} 2 \mathrm{a} \text { rejected in } \\
\text { favor of } \mathrm{H} 2 \mathrm{c}\end{array}$ & Nodes and partially merchants \\
\hline $\mathrm{H} 2 \mathrm{~b}$ (vs. countering H2d) & $\begin{array}{l}\text { The lower (for } \mathrm{H} 2 \mathrm{~d} \text { : higher) the level of competition } \\
\text { in banking markets, the greater the adoption of } \\
\text { Bitcoin infrastructure. }\end{array}$ & $\begin{array}{l}\mathrm{H} 2 \mathrm{~b} \text { rejected in } \\
\text { favor of } \mathrm{H} 2 \mathrm{~d}\end{array}$ & Nodes \\
\hline $\mathrm{H} 3 \mathrm{a}$ & $\begin{array}{l}\text { The greater the level of trust in others, the greater the } \\
\text { adoption of Bitcoin infrastructure. }\end{array}$ & Partially supported & Nodes \\
\hline $\mathrm{H} 3 \mathrm{~b}$ & $\begin{array}{l}\text { The greater the level of distrust in banks and the } \\
\text { financial system, the greater the adoption of } \\
\text { Bitcoin infrastructure. }\end{array}$ & Supported & Nodes \\
\hline $\mathrm{H} 3 \mathrm{c}$ & $\begin{array}{l}\text { The higher the risk-willingness, the greater the } \\
\text { adoption of Bitcoin infrastructure. }\end{array}$ & Supported & Merchants and partially nodes \\
\hline $\mathrm{H} 4$ & $\begin{array}{l}\text { The more money-laundering activities taking place, } \\
\text { the greater the adoption of Bitcoin infrastructure. }\end{array}$ & Supported & Nodes and partially merchants \\
\hline H5 & $\begin{array}{l}\text { The stronger the rule of law, the greater the adoption } \\
\text { of Bitcoin infrastructure. }\end{array}$ & Supported & Nodes and merchants \\
\hline
\end{tabular}

who are active supporters of the cryptocurrency ecosystem.

Furthermore, we find that lower industry concentration in the banking market - which we take to indicate higher banking competition - are positively associated with running of Bitcoin nodes. This finding is in line with contrary to findings for certain peer-to-peer financial technologies (e.g., crowdfunding by Rau 2017), but in line with studies finding complementarities between banking markets and fintech development (Hornuf et al. 2018; Klus et al. 2019). Our data also indicate that contrary to expectations put forth by some (e.g., Killeen 2015; Vigna and Casey 2015), greater Bitcoin infrastructure adoption has not yet emerged in countries with a larger unbanked population. Together, these results paint a picture of bitcoins being used as a complement to existing financial institutions, rather than a substitute. It is likely that, as a recent study by Yermack (2018) of fintech adoption in Africa suggests, a lack of information technology infrastructure underlies failures of fintech platforms to succeed in countries with low financial inclusion.

Geographical variation in self-reported willingness to take risks is found to be correlated to the acceptance of bitcoins by merchants, suggesting that the high volatility of bitcoins and uncertain regulatory environment reduces its appeal in more risk-averse societies.

Our results also support the view that bitcoin adoption is driven partly by the cryptocurrency's usefulness in allowing illicit business activity. Greater rule of law increases the adoption of both types of Bitcoin infrastructure we have analyzed. Higher rule of law may plausibly spur those desiring to engage in illicit activity in countries with high quality of police and courts to turn to online trade as a safer means of procuring illegal drugs (Barratt et al. 2016). Results suggest that countries home to a greater risk of money laundering are more likely to host infrastructure for bitcoin transaction verification and validation, being in line with evidence that bitcoins are utilized greatly for drug trade and other illicit activities (Athey et al. 2016; Böhme et al. 2015; Foley et al. 2019).

Finally, our results lend support for Bitcoin node infrastructure being driven, to a greater extent, by banking market development, crime, and societal distrust in banks and the financial system, while they lend support for Bitcoin merchants being driven more by risk willingness and criminality measures (specifically rule of law). While the emergence of these infrastructures coincides across geographies (c.f. Figs. $2 b$ and 3 ) and time (c.f. Figs. 4 and 5), results suggest they may be subject to different mechanisms. A possible interpretation is that the pattern for nodes reflects attitudes to a greater extent (or active support for Bitcoin), whereas the pattern for merchants reflects the user base more (or interest in Bitcoin) (Fig. 5).

Our study has certain limitations relating to the availability of data. One such limitation is that we do 


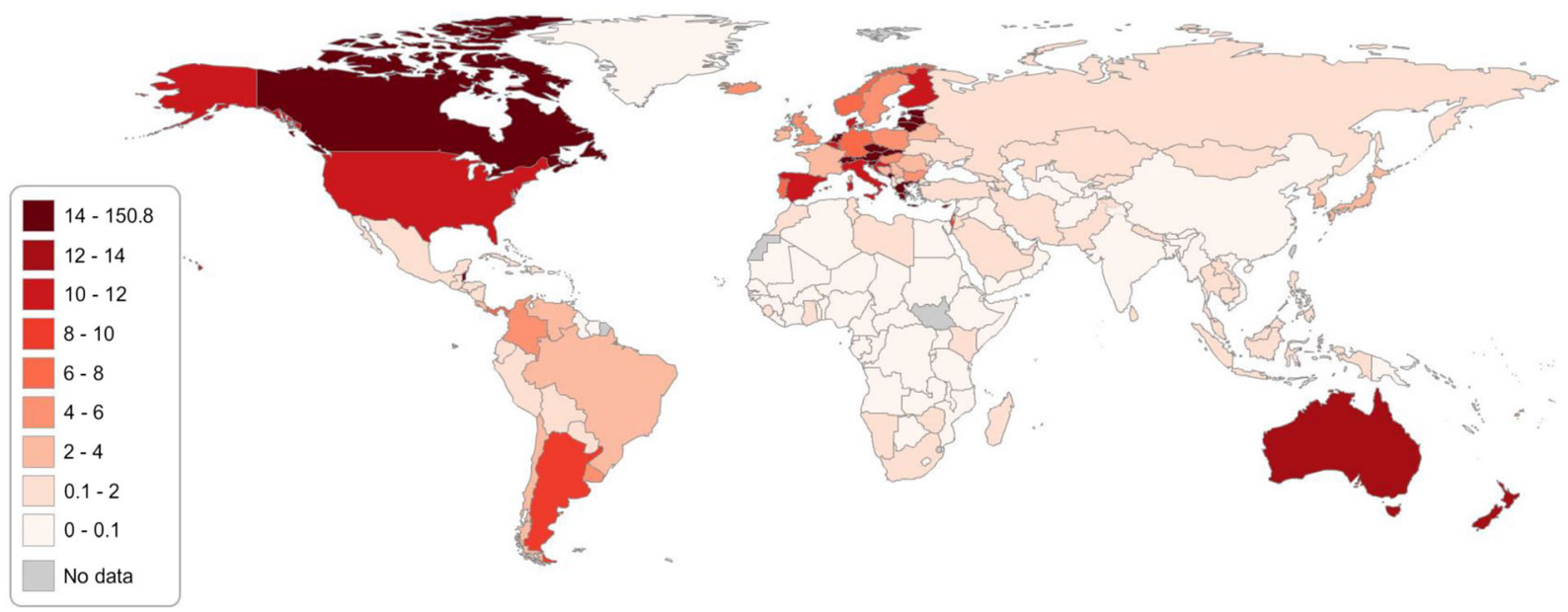

Fig. 3 Total Bitcoin merchants per million users (see Table 1 for variable definition). Top 15 countries are San Marino, Liechtenstein, Slovenia, Czech Republic, Montenegro, Belize, Estonia, Lithuania, Austria, Switzerland, Slovakia, Monaco, Latvia, Malta, and Greece

not directly observe the use of bitcoin as a currency (e.g., in the number of people holding bitcoin in a country). We are therefore not able to explore to what extent the associations that our study uncovers are driven by country-level differences in bitcoin adoption, or by other related factors. A further limitation of our study that is in measuring the penetration of Bitcoin infrastructure across space and time, we are only capturing nodes and merchants who do not hide their location. We believe such open support for Bitcoin's network to provide a proxy for the adoption of Bitcoin infrastructure. Nevertheless, our inability to observe hidden infrastructure can result in underweighting the role of certain characteristics in assessing drivers of cryptocurrency infrastructure. In particular, more sophisticated users and criminals using bitcoins are more likely to use firewalls to avoid revealing their network presence. We therefore suggest that the size of the effect we attribute to such technological or criminality characteristics can be seen as a lower-bound to their true effect. Hence, by directly measuring open support for the digital currency ecosystem, this study determines the effect of financial characteristics on bitcoin adoption, while ascribing lower-bound for the effects of technological, criminality, and social drivers.

In choosing appropriate variables to specify and test hypotheses about illicit activities as drivers of interest in
Fig. 4 Monthly time-series variation of addition of Bitcoin merchants worldwide on CoinMap

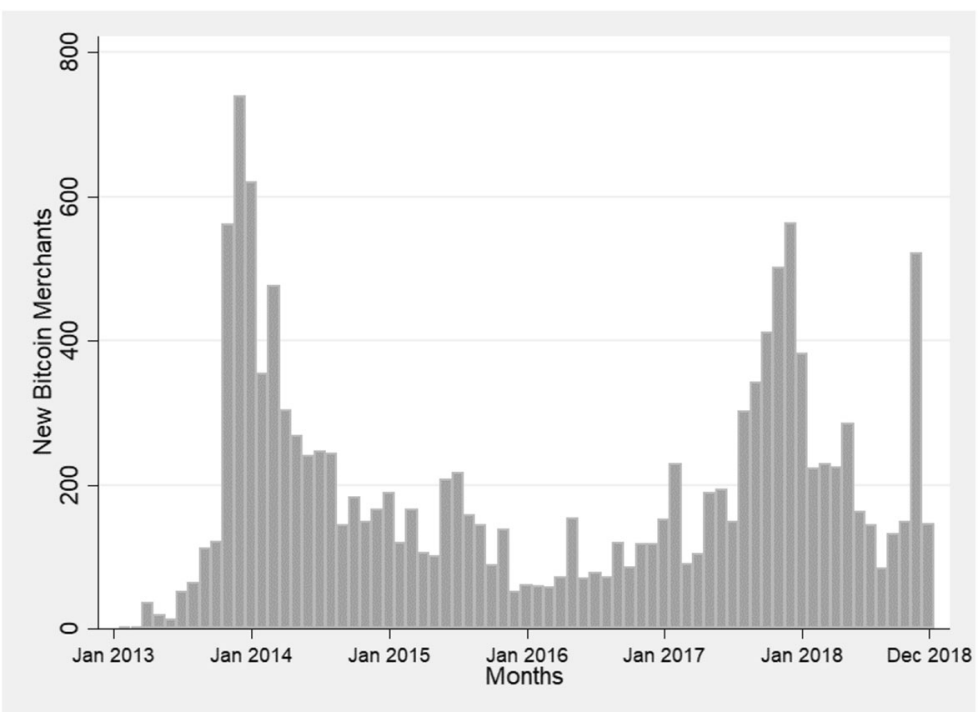


Fig. 5 Quarterly time-series variation of Bitnode intensity worldwide

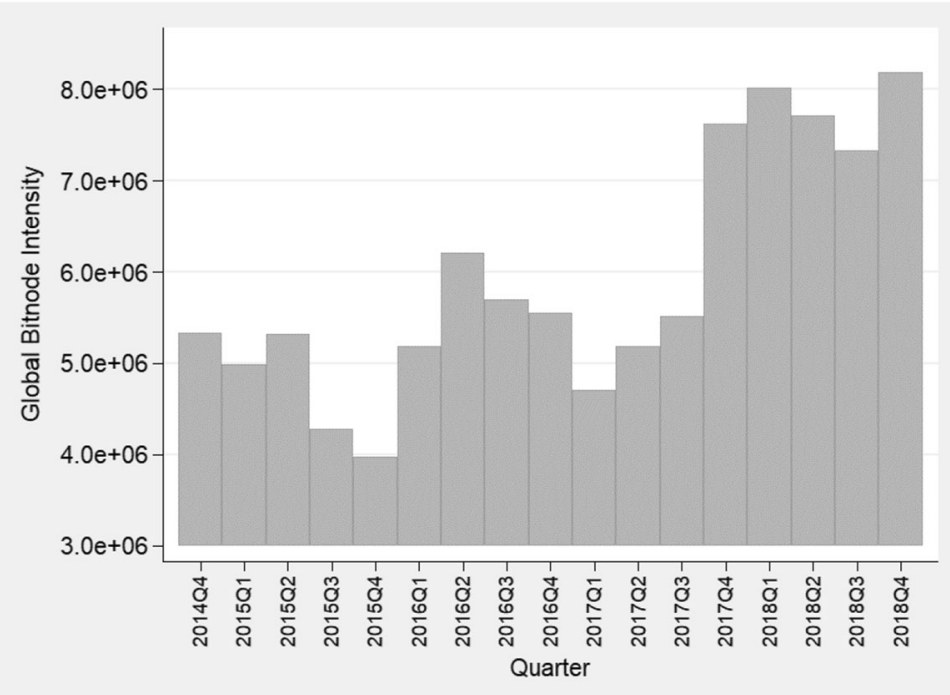

Bitcoin, we had to resort to measures that we expect to proxy for illicit activities, since more direct measures were not available with sufficient global comparability. We did not, for example, use actual dark-net drug sales or drug-trade statistics (e.g., the Global Drug Survey; see UNODC 2019), as they are currently only available for a limited subset of countries, and with varying degrees of reliability. Another limitation is the lack of appropriate proxies for certain relevant constructs related to attitudes towards cryptocurrencies and their potential advantages over fiat currencies. For example, cultural preferences for privacy is a potentially relevant factor, and data is available from surveys. However, recent research casts doubts as to their reliability due to the Digital Privacy Paradox, in that stated privacy preferences are different from observed privacy preferences (Athey et al. 2017). Certain relevant national characteristics were also omitted as they underlie utilized variables, as is for instance the case of financial literacy (not included as a separate variable; Grohmann et al. 2018) and financial inclusion (included in our models).

\section{Conclusions and implications}

The global spread of the use of cryptocurrencies is a notable feature of the twenty-first century economy. Already an important locus of entrepreneurial activity, cryptocurrencies can alter the business models of existing actors within entrepreneurial finance (Block et al. 2018) and are expected to have significant consequences for business in the relatively near future (e.g., see Dierksmeier and Seele 2018). Understanding the drivers behind their spread thus far is therefore important to scholars studying digital currencies and their role in present and future digital entrepreneurial ecosystems.

While papers on potential risks and opportunities posed by cryptocurrencies are flourishing (e.g., Choo 2015; Dierksmeier and Seele 2018; Kethineni and Cao 2019; Tasca 2015), as well as those posed by blockchains and ICOs (e.g., Kewell et al. 2017; Martino et al. 2019), little is empirically known about the spread, growth, and patterns of use of these innovations. To the best of our knowledge, this paper is the first academic empirical inquiry with global geographic coverage of the emergence of Bitcoin as an alternative financial system. A significant contribution of this study is therefore analyzing large global cryptocurrency databases and providing the annualized data online ${ }^{21}$ for further empirical studies in this nascent and emerging field. The study also offers important insights to scholars seeking to understand the growth of cryptocurrencies through a grounded global analysis, not least to separate a great deal of myth from facts.

While descriptive in nature, our results paint a picture of the adoption of cryptocurrencies as being related to its usefulness as a complement to traditional financial services. Such usefulness derives on the one hand from

\footnotetext{
${ }^{21}$ Data is included as supplementary material, accessible from this journal's webpage.
} 
inefficiencies and failings (e.g., inflation crises) of traditional economic or financial systems, and on the other hand on the opportunity to conduct illegal or shady transactions using cryptocurrencies.

We now turn to the implications of our study for various scholars, as well as for institutions which may shape, regulate, or lend oversight to digital currencies now or in the future.

\subsection{Implications for scholars of digital currency}

With the support for cryptocurrency infrastructure and interest in making financial transactions using cryptocurrencies expected to keep growing over time, further research should seek to explore further what drives participation, and what consequences such support may have on incumbent financial structures. This study has demonstrated that institutional and social factors had important roles to play in the growth of the Bitcoin system to date, which suggests that such factors should also be carefully considered in future research on digital currency development.

The study shows that despite the much-touted promise of bitcoins (e.g., Dierksmeier and Seele 2018; Killeen 2015; Vigna and Casey 2015) and blockchain technologies (e.g., Larios-Hernández 2017) in increasing financial inclusion and poverty reduction, it is the countries where such issues are less poignant that have the strongest penetration of Bitcoin infrastructure. On the one hand, this finding calls for further research on barriers to adoption of digital currencies in less developed settings, and how these may be overcome. On the other hand, our results may be seen as fuel for a broader discussion about the role of cryptocurrencies. While clearly potentially helpful for citizens of countries beset by hyperinflation, evidence on the strong connection to illicit activity and the, as of yet, unrealized promise of providing a means to increase financial inclusion would seem to weigh in with arguments that the cryptocurrency's growth is to be seen as cause for concern-e.g., in the light of price manipulation (Griffin and Shams 2019), heavy electricity use associated with Bitcoin mining (Krause and Tolaymat 2018) and the increased occurrence of cybercrimes and frauds involving cryptocurrencies (Corbet et al. 2019; Kamps and Kleinberg 2018; Li et al. 2018; Su 2019).
7.2 Implications for actors in digital ecosystems

This paper depicts how a decentralized infrastructural system grows organically and offers indirect evidence of motives that underlie the fast-growing and evolving digital currency ecosystem. Our findings indicating that interest in Bitcoin thus far is strongest in the most financially well-developed locations may spur entrepreneurs in the digital currency ecosystem to develop new means to simplify the process of using bitcoins for it to have a chance of reaching the unbanked, or integrating their products on more widespread communication technologies (e.g., mobile phones). Some efforts, such as the integration of bitcoin on the popular M-Pesa system in Kenya (Vigna and Casey 2015) have been made, while of greater use towards poverty reduction could be focusing on, e.g., reducing persistently high international remittance fees (Beck and Martínez Pería 2011).

Technology firms planning or exploring to issue their own digital currencies, such as Facebook's Libra project (Libra Association 2019), can draw lessons from the historical patterns of adoption of bitcoins depicted in this paper. In particular, the findings indicating that interest in Bitcoin is associated with distrust in banks and established financial institutions, would seem to point to an advantage that can be exploited in marketing new currencies. The greater trust of consumers in technology companies than in banks (Bain and Company 2019; Forbes 2015) could provide an edge in harnessing fintech technologies, albeit if they can retain such trust (Nair 2019).

7.3 Implications for central banks and public authorities

The debate on the risk and opportunities of central banks issuing cryptocurrencies, or more broadly central bank digital currencies (CBDC), is intensifying (Borio et al. 2017; Conti-Brown et al. 2018; Engert and Fung 2017; Niepelt 2020). Many central banks currently conduct research on digital currency issuance (Cœuré 2018). The real-world uptake and support for bitcoins can be seen as a case study for the risks and demand for preserving anonymity in digital transactions, as alluded to in Acquisti et al.'s (2016) survey on the economics of privacy. The history of bitcoin use so far can help inform CBDC-design as regulators weigh trade-offs between the need to control transaction fraud and the desire to avoid invasive or costly monitoring of individuals. Some economic theorists suggest that this trade-off will exist despite any technological progress (Kahn et al. 2005; Kahn and Roberds 2008). 
The correlation of distrust in banks with bitcoin adoption should be of concern to financial regulators for whom financial stability and transactions through legitimate monetary channels is tantamount. Nowhere is this more a concern than in countries experiencing very high inflation. Low faith in the currency's stability, coupled with a distrust in the national financial system, can drive the populace into digital currencies, rendering a monetary authorities' monetary supply less effective.

Law enforcement agencies must react to the use of digital assets for narcotics-related money laundering. Finally, there is cause for concern for tax administrations and revenue agencies in use of digital currencies for tax evasion, as evidenced by formation of international task forces (J5 2018). Further studies could shed more light on empirically establishing the extent of use of cryptocurrencies for money laundering and tax evasion.

Acknowledgments We owe thanks to Silvio Vismara (the editor), the anonymous referees, Gustav Martinsson, Per Strömberg, Christopher Baum, Sergio Correia, Andreas Stephan, David Yermack, Ali Mohammadi, Mariassunta Giannetti, Matthew Stogsdill, Zheng Xiaochen, Mike van Rossum, Carolin Bock, Yury Kucheev, Joaquin Ordieres, and seminar participants at the 4th EntFin Conference, Swedish House of Finance and Royal Institute of Technology, for helpful comments and discussions. We owe thanks to Addy Yeow, the SatoshiLabs, and NORC at the University of Chicago for the databases utilized and Patrícia Estavão for an infographic. All remaining errors are our own.

Funding information Open access funding provided by Royal Institute of Technology. We would also like to thank two anonymous reviewers whose comments greatly improved this manuscript. This paper is produced as part of the EMJD Program, European Doctorate in Industrial Management (EDIM), funded by the European Commission, Erasmus Mundus Action 1.

\section{Appendix}

\section{Bitcoin infrastructure}

\section{Bitcoin nodes}

Relating to the supply-side of global bitcoin infrastructure, we focus our study on Bitcoin nodes, i.e., bitnodes. Bitcoin relies on a decentralized network of nodes, which use computational proofs-of-work to reach consensus on the bitcoin blockchain (Nakamoto 2008). To validate and relay transactions, the Bitcoin network must broadcast messages using nodes (see Fig. 1 for validation and verification actions in a bitcoin transaction life cycle). To ensure security and to prevent circumvention of consensus rules such as double-spending (i.e., when a user attempts to spend the same bitcoin twice), each node uses a randomized protocol to select eight peers with which it establishes long-lived outgoing connections, and exchange views of the state of the blockchain with their incoming and outgoing peers in order to verify and validate new transactions (Heilman, Kendler, and Zohar 2015).

If a node fully validates every block and transaction, by independently checking them against all consensus rules of Bitcoin, it is termed a full node. Some of the primary consensus rules of Bitcoin, verified by full nodes, are: (a) Spent transactions require correct signatures, (b) Blocks may only release a limited number of bitcoins as a block reward, (c) Blocks and transactions are to follow the consensus format and (d) A transaction output cannot be double-spent. Such full nodes would require a bitcoin core client installed on a computed connected to the Internet. A full note contains the entire record of bitcoin's blockchain, a distributed public ledger of all transactions. ${ }^{22}$ Archival or listening nodes (also called reachable nodes) are a subset of full nodes that accept incoming connections and upload or "relay" complete copies of archival bitcoin blocks and transaction data to peers on the bitcoin network. They are useful for bootstrapping new full node peers or helping light-weight nodes discover their balance. Light-weight nodes are meant for market participants who do not want to run full nodes and use a Simplified Payment Verification method to verify transactions by downloading only a part of the blockchain (e.g., only block headers and partial blocks).

Running a full node is the only way for a bitcoin market participant to independently ascertain that all consensus rules are followed and for full removal of a need for a trusted alternative node or third party. Running full nodes also much increases a market participants' security as many attacks against lightweight nodes do not affect full nodes, and they offer the most privatized and anonymized way to transact in bitcoins, hiding addresses belonging to the full node operator. It is, hence, in the interest of market participants to run a full node. ${ }^{23}$

\footnotetext{
${ }^{22}$ The size of the entire blockchain has exponentially increased, from 21.7GB to $176.5 \mathrm{~GB}$ from Sept 2014 to 2018 . Through the same time period the price of storage has decreased by $\sim 45 \%$ (http://jcmit. net/diskprice.htm).

$23 \mathrm{https} / /$ en.bitcoin.it/wiki/Clearing_Up_Misconceptions_About Full_Nodes\#Myth:_There_is_no_incentive_to_run_nodes_so_the network_relies_on_altruism
} 
Bitcoin nodes contribute to bitcoin's aim to serve as a medium of exchange, and contribute to bitcoin's goal to serve as a store of value. Nodes are critical to the functioning of the entire bitcoin ecosystem and were a core part of the functioning of Bitcoin's blockchain from its design inception. Figure 2a shows a global map of the revealed intensity of bitcoin node adoption, averaged for the five years from 2014 to 2018. Figure $2 \mathrm{~b}$ shows a map of the number of non-hidden unique bitcoin nodes per month, averaged for the same period.

\section{Bitnodes dataset preparation}

We obtain data on reachable (aka listening) full nodes on the Bitcoin network from Bitnodes.earn.com. ${ }^{24}$ Our database contains all reachable nodes running Bitcoin protocol version 70,001 (i.e., Bitcoin core 0.8.x), which was introduced on February $2013,{ }^{25}$ or later versions. These nodes may or may not be full nodes; however, they have been set up to be reachable. Reachable nodes have port 8333 , or a port they have configured the software to, open for incoming connections. The default configuration in node software is to have listening enabled. However, home connections are usually filtered by a modem or router. Bitcoin core will request automatic configuration of your router to allow incoming connections. Unfortunately, many routers do not allow automatic configuration and require manual configuration. Moreover, firewalls may also need to be configured to allow inbound connections to port 8333 . Hence, it is conceivable that there are as many as 6 to 8 times more nodes on the network than our database could reach (Wang and Pustogarov 2017). However, our database can be assumed to provide a reasonable proxy for the total geographical distribution of nodes in the bitcoin network.

From the extensive Bitnode database ( $\sim 1$ Terabyte), location-specific measures for the adoption of Bitcoin nodes was constructed through the following procedure:

\footnotetext{
${ }^{24}$ Network snapshots are taken every few minutes in JSON format, and have been compressed and stored in monthly Tarball files from September 2014 onwards. The python crawler implementation of this website is made available by Addy Yeow on GitHub, https://github. com/ayeowch/bitnodes.

${ }^{25}$ To illustrate speed of adoption of a protocol, a year on from release of the following protocol, nearly $98 \%$ of nodes had updated to the newer protocol.
}

(a) Downloading ultra-compressed files containing thousands of JSON files for first month of each quarter, with each JSON file being a pythoncrawled database snapshot taken nearly every 6 min containing such information as IP addresses, city, country, and coordinate information relating to nodes

(b) Retaining every 10th file corresponding to nearly hourly records of all crawled non-hidden Bitcoin nodes

(c) Re-structuring the hourly files to form monthly databases

(d) Calculating all variables separately for countries and administrative regions of 34 countries included in LITS III survey. The region-level analysis consisted of:

i. Matching world cities to NUTS-2 regions of 34 countries in Life in Transition Societies' Social Survey

ii. Geo-locating regions of unidentified IP addresses, using geo-location tools of IP addresses meant for the STATA software, specifically the SSC package geocode_ip, written by Correia (2017), yet modified to use the API service from ipgeolocation.io.

(e) Creating country-year and region-year data of nonhidden bitcoin node use, in a panel data structure. There are 201 countries worldwide for which in at least one year between 2014 and 2018 a Bitnode is operated.

The Bitnodes' database uses Python's GeoIP2 geo-locating package to identify countries of nodes. Also the geolocation we use to locate unidentified IP addresses uses two alternative and independent IP databases. These IP address geolocation services state the accuracy of IP geolocation to be are around $95 \%$ to $99 \%$ at the country-level, and $55 \%$ to $80 \%$ at the region level (See https://www. iplocation.net/geolocation-accuracy). Poese et al. (2011), Komosny et al. (2017) and Shavitt and Zilberman (2011) find that the main geolocation databases are accurate at the country level. Hence, our Bitnode analyses at the country and region level, while providing a best-estimate of location of bitcoin nodes, is limited by the accuracy of geolocation. 


\section{Bitcoin merchants}

We also study bitcoin infrastructure driving the demand for bitcoins, using data on how many merchants that accept bitcoin as a currency for selling their goods or services. By adopting bitcoin payment technology, merchants contribute to bitcoin serving as a medium of exchange. They also facilitate bitcoin's adoption as a unit of account, by enabling the quotation of prices in bitcoins.

Merchants' adoption of technology to accept bitcoins as payment should largely be driven by perceived demand for such services among its customers. A certain amount of computer savviness would be expected for merchants to start accepting bitcoins; businesses would need to download a bitcoin client and give customers a bitcoin address where payments can be sent. However, bitcoin payment service providers such as Bitpay, Bitgo, or Coinbase.com offer web and mobile apps that simplify the process of becoming a bitcoin-accepting merchant.

It has been reported that merchants reported satisfaction with bitcoin payment processing due to its strikingly lowcost (Böhme et al. 2015). As an example, Coinbase (the largest bitcoin payment processing firm) currently charges zero fees on incoming payments, greatly reduced from the fees they bear when credit card are used for payment. Compared with other payment forms, however, bitcoin payments expose the merchants to a new type of volatility risk, since the exchange rate of any bitcoins that is received in payment may vary substantially over time. Payments can be accepted using hardware terminals, touch screen apps or simple wallet addresses using QR codes. Most bitcoin merchants prefer to minimize the volatility risk of holding bitcoins by offloading or selling bitcoins as soon as possible after the sale of their service or product.

While this study is focused on infrastructure supporting Bitcoin, many infrastructure providers for Bitcoins simultaneously extend support to other cryptocurrencies, as it has become prevalent with multi-currency platforms payment service providers used by cryptocurrency merchants. Figure 3 shows the worldwide of the number of merchants per country, averaged by the nation's population.

\section{Bitcoin merchants dataset preparation}

Our data for merchants accepting payments in bitcoin is extracted from data stored using CoinMap's API (The data is available at https://coinmap.org/api/v1/venues/, whereas an R-code was written to convert the JSON format data to a Stata-readable format). CoinMap is a website where either business owners or interested customers or users would add a business that accepts bitcoins (or bitcoin and other cryptocurrencies) as payment in exchange for a service or good. Some of the businesses on these websites only accept bitcoins on their online websites.

CoinMap started in early 2013 with self-reporting of venues on an OpenStreetMap ${ }^{26}$ map, being done by adding a tag of bitcoin =yes (or selecting bitcoin as a payment type in a pre-defined drop-down list) to venues on its extensive interactive map. One would have needed to sign up and enter in edit mode and use OpenStreetMap's user-friendly editor interface to select a building or business and tag it as accepting bitcoins. CoinMap would synchronize with any such entries made into OpenStreetMap up until the middle of 2017, after which OpenStreetMap integration stopped and adding venues on CoinMap's own interface by logging in via Google/ Facebook/etc. and right-clicking, became the only way to add a bitcoin-accepting merchant. Soon after launching in 2013, CoinMap became the primary website worldwide, as referred to in online Bitcoin forums, to find businesses where bitcoin holders can spend their bitcoins. On online forums, bitcoin enthusiasts express a great desire to develop an extensive network of merchants that accept bitcoins, so it could serve their hope for it to serve as a formidable alternative to fiat currencies.

The data contains coordinates and categories of businesses accepting bitcoins as payment, together with the date and time they were added to CoinMap's online map. The top categories are shopping, food, ATMs, lodging, cafes, nightlife, and sports venues. We geolocate all addresses using the coordinates provided to identify which city, state and country they are located in. As of the end of 2018, the database consists of 14,149 venues. Removing duplicated entries of venues, our final list has 13,741 merchants. Figure 4 shows the monthly frequency of addition of bitcoin merchants over time on CoinMap since its inception. No data is available on the size of transactions.

\footnotetext{
${ }^{26}$ OpenStreetMap is one of the world's largest collaborate mapping projects. Developed as a free editable map of the world in 2004, it is used by large established corporations as well as independent website owners to develop a navigable map with complete business/ institutional venue information. As the world's largest database of buildings, OpenStreetMap covers an extensive database of businesses.
} 


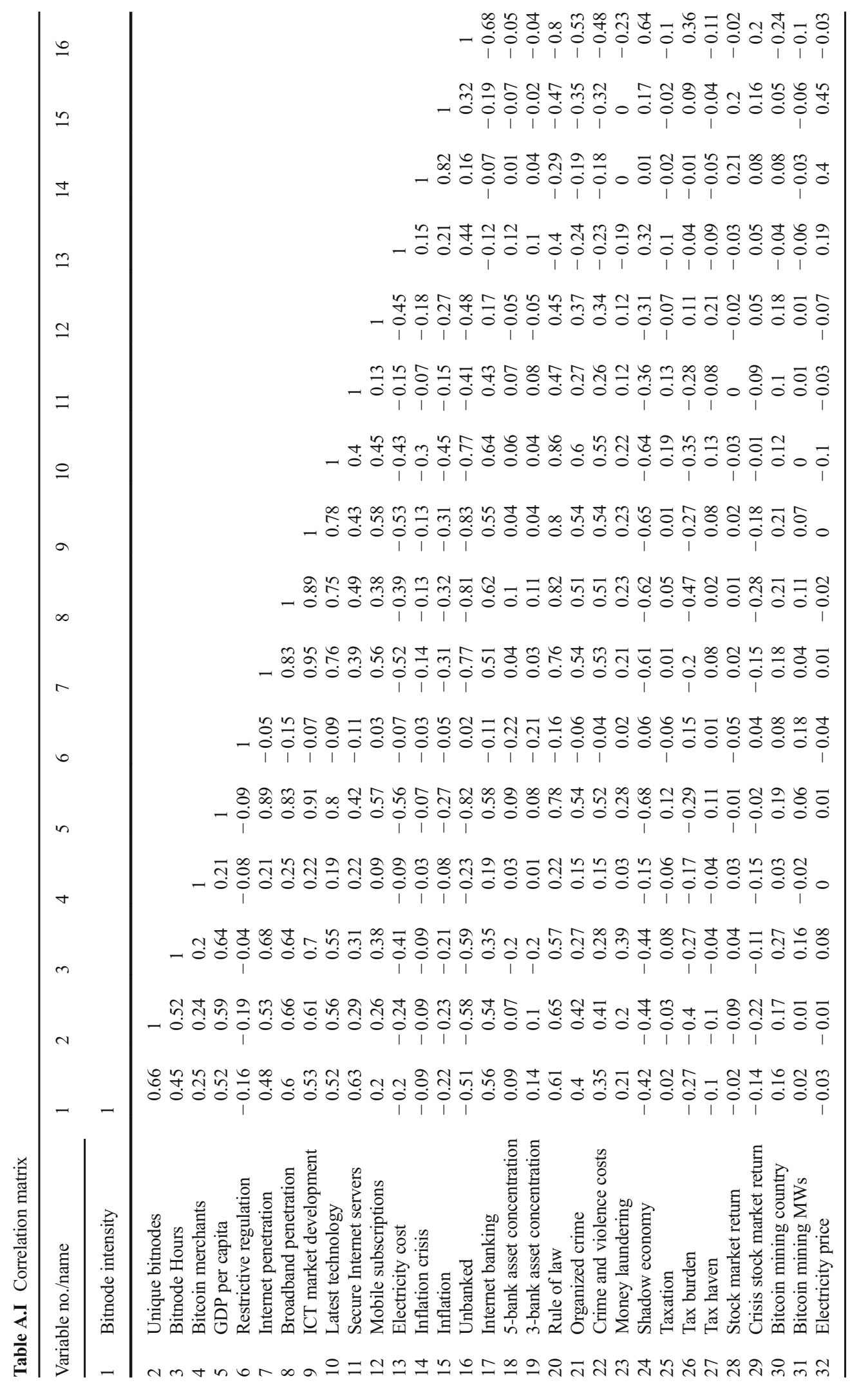

กี

$\bar{m}$

요

๙ิ

$\stackrel{\infty}{\sim}$

$\grave{\sim}$

$\stackrel{\sim}{\sim}$

$\approx$

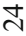

กิ

ก

$\bar{\sim}$

ㄱ

2

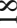

I

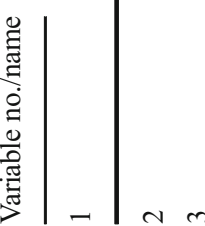




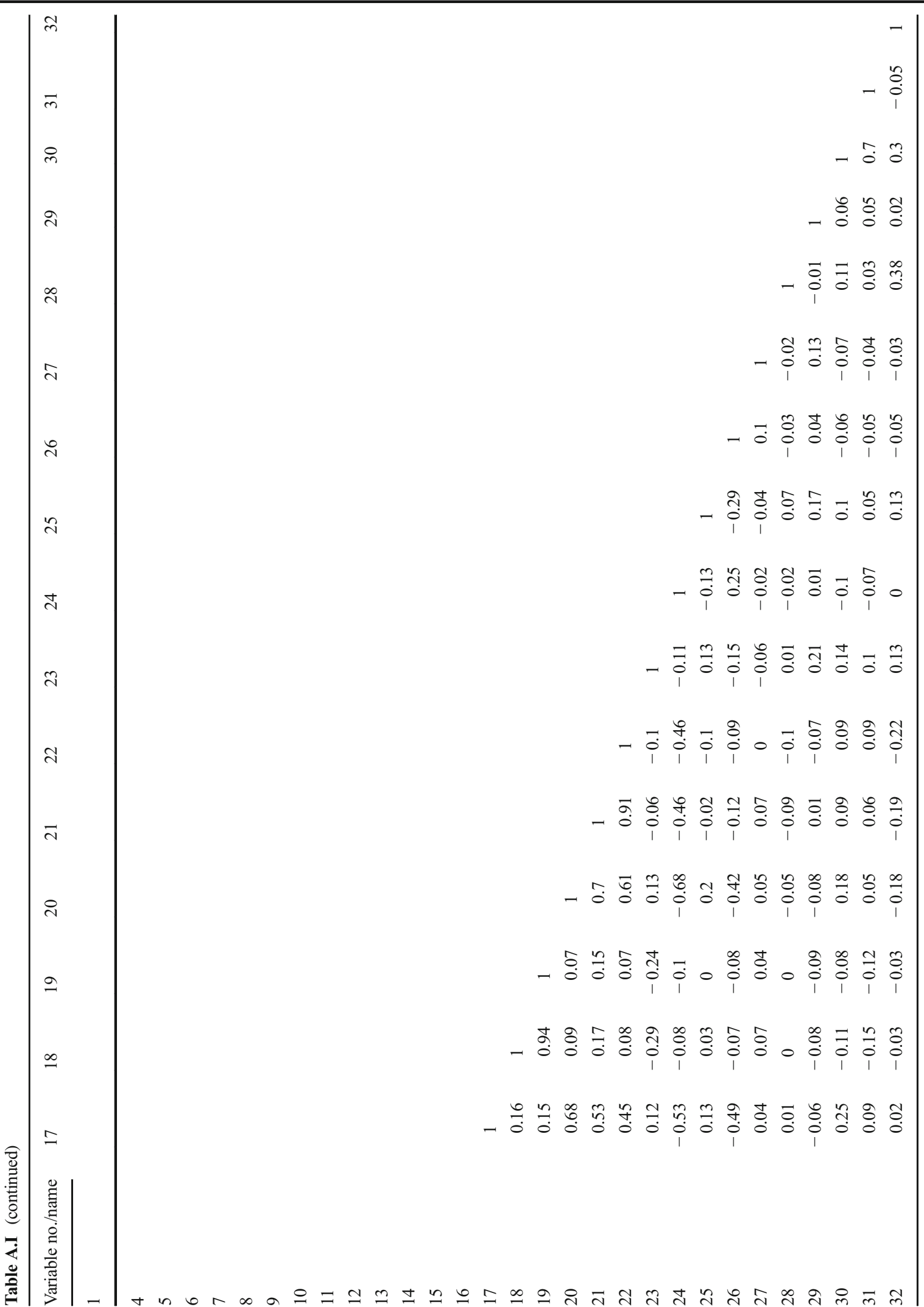




\section{Internet appendix}

Table IA.I Robustness regressions on Bitnode intensity by adding exploratory variables in isolation to baseline regression (Panel A)

(1) (2)

(3)

(4)

(5)

(6)

Dependent variable

Bitnode intensity

Financial characteristics

Inflation crisis

$0.530^{+} \quad 0.654^{*}$

(0.306)

(0.285)

Unbanked

0.008

$-0.006$

$(0.009)$

(0.013)

5-bank asset concentration

0.003

(0.013)

0.000

(0.015)

Criminality characteristics

Money laundering

$1.347^{*}$

$1.156^{+}$

(0.604)

(0.610)

Rule of law

$1.445^{* *}$

$1.267^{*}$

$(0.474)$

$(0.508)$

Baseline characteristics

GDP per capita

$\begin{array}{llllll}0.681 & 1.428^{* * *} & 1.339^{* *} & 1.424^{* * * *} & 1.335^{* * * *} & 0.761^{+} \\ (0.457) & (0.337) & (0.499) & (0.320) & (0.356) & (0.395) \\ -0.529 & -0.574 & -0.584^{+} & -0.573^{+} & -0.586^{+} & -0.541 \\ (0.324) & (0.377) & (0.332) & (0.329) & (0.343) & (0.354) \\ -6.624 & -11.482^{* * *} & -10.492^{*} & -11.482^{* * *} & -11.358^{* * *} & -5.935^{+} \\ (4.347) & (2.827) & (4.802) & (3.012) & (3.132) & (3.434) \\ \text { Yes } & \text { Yes } & \text { Yes } & \text { Yes } & \text { Yes } & \text { Yes } \\ \text { Yes } & \text { Yes } & \text { Yes } & \text { Yes } & \text { Yes } & \text { Yes } \\ \text { Yes } & \text { Yes } & \text { Yes } & \text { Yes } & \text { Yes } & \text { Yes } \\ \text { Tobit } & \text { Tobit } & \text { Tobit } & \text { Tobit } & \text { Tobit } & \text { Tobit } \\ 685 & 685 & 685 & 685 & 685 & 685 \\ 137 & 137 & 137 & 137 & 137 & 137 \\ 0.41 & 0.36 & 0.36 & 0.36 & 0.37 & 0.40 \\ -1306.1 & -1314.8 & -1314.8 & -1314.9 & -1312.9 & -1309.4 \\ 0.72 & 0.74 & 0.74 & 0.74 & 0.74 & 0.73\end{array}$

Restrictive regulation

Constant

$-6.624$

$-11.482^{* * *}$

$-10.492^{*}$

$-11.482^{* * * *}$

$-11.358^{* * *}$

$-5.935^{+}$

Year FEs

World region FEs

Year-world region FEs

Panel data specification

Observations

Number of countries

Pseudo $R$-Squared

Log-likelihood

$-1314.8$

0.74

$-1314.9$

$-1309.4$

$\mathrm{RHO}$

All models are Tobit random effects models lower-censored at 0 and their associated pseudo R-squared are reported. Panel-data adjusted bootstrapped standard errors, clustered at the country level, are reported in parentheses. The symbols $* * *, * *, *,+$ mean that the reported coefficients are statistically different from zero, respectively, at the $0.1,1,5$, and $10 \%$ level 
Table IA.II Robustness regressions on unique bitnodes by adding exploratory variables in isolation to baseline regression (Panel A)

\begin{tabular}{|c|c|c|c|c|c|c|}
\hline Dependent variable & $\begin{array}{l}(1) \\
\text { Unique bi }\end{array}$ & $(2)$ & (3) & (4) & $(5)$ & (6) \\
\hline \multicolumn{7}{|l|}{ Financial characteristics } \\
\hline Inflation crisis & $\begin{array}{l}7.038^{* * *} \\
(2.596)\end{array}$ & $\begin{array}{l}5.875^{*} \\
(2.445)\end{array}$ & & & & \\
\hline Unbanked & $\begin{array}{l}-0.189^{*} \\
(0.078)\end{array}$ & & $\begin{array}{l}-0.288^{* * *} \\
(0.070)\end{array}$ & & & \\
\hline 5-bank asset concentration & $\begin{array}{l}0.011 \\
(0.069)\end{array}$ & & & $\begin{array}{l}0.013 \\
(0.082)\end{array}$ & & \\
\hline \multicolumn{7}{|l|}{ Criminality characteristics } \\
\hline Money laundering & $\begin{array}{l}6.916^{* * *} \\
(2.381)\end{array}$ & & & & $\begin{array}{l}5.853^{*} \\
(2.770)\end{array}$ & \\
\hline Rule of law & $\begin{array}{l}9.323^{\text {*** }} \\
(2.557)\end{array}$ & & & & & $\begin{array}{l}9.845^{\text {**** }} \\
(2.332)\end{array}$ \\
\hline \multicolumn{7}{|l|}{ Baseline characteristics } \\
\hline GDP per capita & $\begin{array}{l}0.039 \\
(2.209)\end{array}$ & $\begin{array}{l}8.946^{\text {**** }} \\
(1.536)\end{array}$ & $\begin{array}{l}4.292^{*} \\
(1.749)\end{array}$ & $\begin{array}{l}8.903^{\text {*** }} \\
(1.376)\end{array}$ & $\begin{array}{l}8.446^{* * *} \\
(1.198)\end{array}$ & $\begin{array}{l}3.342^{+} \\
(1.784)\end{array}$ \\
\hline Restrictive regulation & $\begin{array}{l}3.069^{*} \\
(1.347)\end{array}$ & $\begin{array}{l}3.384^{*} \\
(1.365)\end{array}$ & $\begin{array}{l}2.708^{*} \\
(1.354)\end{array}$ & $\begin{array}{l}3.386^{*} \\
(1.341)\end{array}$ & $\begin{array}{l}3.188^{*} \\
(1.596)\end{array}$ & $\begin{array}{l}3.663^{* *} \\
(1.265)\end{array}$ \\
\hline Constant & $\begin{array}{l}19.808 \\
(20.597)\end{array}$ & $\begin{array}{l}-58.362^{\text {**** }} \\
(12.931)\end{array}$ & $\begin{array}{l}-6.835 \\
(16.692)\end{array}$ & $\begin{array}{l}-58.966^{\text {**** }} \\
(14.654)\end{array}$ & $\begin{array}{l}-57.456^{* * *} \\
(10.462)\end{array}$ & $\begin{array}{l}-11.338 \\
(14.818)\end{array}$ \\
\hline Year FEs & Yes & Yes & Yes & Yes & Yes & Yes \\
\hline World region FEs & Yes & Yes & Yes & Yes & Yes & Yes \\
\hline Year-world region FEs & Yes & Yes & Yes & Yes & Yes & Yes \\
\hline Panel data specification & Tobit & Tobit & Tobit & Tobit & Tobit & Tobit \\
\hline Observations & 685 & 685 & 685 & 685 & 685 & 685 \\
\hline Number of countries & 137 & 137 & 137 & 137 & 137 & 137 \\
\hline Pseudo $R$-squared & 0.62 & 0.58 & 0.58 & 0.58 & 0.58 & 0.61 \\
\hline Log-likelihood & -2266.7 & -2294.4 & -2284.1 & -2294.6 & -2292.0 & -2279.5 \\
\hline RHO & 0.54 & 0.58 & 0.58 & 0.58 & 0.57 & 0.56 \\
\hline
\end{tabular}

All models are Tobit random effects models lower-censored at 0 and their associated pseudo R-squared are reported. Panel-data adjusted bootstrapped standard errors, clustered at the country level, are reported in parentheses. The symbols $* * *, * *, *,+$ mean that the reported coefficients are statistically different from zero, respectively, at the $0.1,1,5$ and $10 \%$ level 
Table IA.VII Robustness regressions on Bitnode hours by adding exploratory variables in isolation to baseline regression (Panel A)

\begin{tabular}{|c|c|c|c|c|c|c|}
\hline Dependent variable & $\begin{array}{l}\text { (1) } \\
\text { Bitnode hours }\end{array}$ & $(2)$ & (3) & (4) & $(5)$ & (6) \\
\hline \multicolumn{7}{|l|}{ Financial characteristics } \\
\hline Inflation crisis & $\begin{array}{l}50.642 \\
(65.208)\end{array}$ & $\begin{array}{l}21.316 \\
(75.872)\end{array}$ & & & & \\
\hline Unbanked & $\begin{array}{l}-2.309 \\
(1.421)\end{array}$ & & $\begin{array}{l}-2.883^{*} \\
(1.316)\end{array}$ & & & \\
\hline 5-bank asset concentration & $\begin{array}{l}-5.080^{* *} \\
(1.676)\end{array}$ & & & $\begin{array}{l}-5.709^{* * *} \\
(1.583)\end{array}$ & & \\
\hline \multicolumn{7}{|l|}{ Criminality characteristics } \\
\hline Money laundering & $\begin{array}{l}176.344^{\text {**** }} \\
(53.490)\end{array}$ & & & & $\begin{array}{l}214.910^{\text {**** }} \\
(55.422)\end{array}$ & \\
\hline Rule of law & $\begin{array}{l}88.669^{+} \\
(45.858)\end{array}$ & & & & & $\begin{array}{l}78.177 \\
(53.565)\end{array}$ \\
\hline \multicolumn{7}{|l|}{ Baseline characteristics } \\
\hline GDP per capita & $\begin{array}{l}72.001^{*} \\
(34.734)\end{array}$ & $\begin{array}{l}163.076^{\text {**** }} \\
(30.603)\end{array}$ & $\begin{array}{l}117.830^{\text {**** }} \\
(32.456)\end{array}$ & $\begin{array}{l}173.152^{\text {*** }} \\
(27.254)\end{array}$ & $\begin{array}{l}145.646^{\text {**** }} \\
(23.679)\end{array}$ & $\begin{array}{l}119.839^{* *} \\
(40.040)\end{array}$ \\
\hline Restrictive regulation & $\begin{array}{l}32.565 \\
(39.446)\end{array}$ & $\begin{array}{l}47.150 \\
(34.713)\end{array}$ & $\begin{array}{l}43.588 \\
(44.952)\end{array}$ & $\begin{array}{l}30.404 \\
(47.014)\end{array}$ & $\begin{array}{l}45.289 \\
(47.311)\end{array}$ & $\begin{array}{l}51.749 \\
(54.152)\end{array}$ \\
\hline Constant & $\begin{array}{l}382.419 \\
(431.859)\end{array}$ & $\begin{array}{l}-762.920^{*} \\
(328.849)\end{array}$ & $\begin{array}{l}-259.390 \\
(417.735)\end{array}$ & $\begin{array}{l}-415.942 \\
(355.106)\end{array}$ & $\begin{array}{l}-740.771^{*} \\
(330.463)\end{array}$ & $\begin{array}{l}-400.660 \\
(384.618)\end{array}$ \\
\hline Year FEs & Yes & Yes & Yes & Yes & Yes & Yes \\
\hline World region FEs & Yes & Yes & Yes & Yes & Yes & Yes \\
\hline Year-world region FEs & Yes & Yes & Yes & Yes & Yes & Yes \\
\hline Panel data specification & Tobit & Tobit & Tobit & Tobit & Tobit & Tobit \\
\hline Observations & 685 & 685 & 685 & 685 & 685 & 685 \\
\hline Number of countries & 137 & 137 & 137 & 137 & 137 & 137 \\
\hline Log-likelihood & -2386.8 & -2402.9 & -2397.6 & -2397.4 & -2403.4 & -2405.2 \\
\hline $\mathrm{RHO}$ & 0.62 & 0.69 & 0.69 & 0.65 & 0.66 & 0.69 \\
\hline
\end{tabular}

All models are Tobit random effects models lower-censored at 0 and upper censored at 750 (upper limit of active Bitnode hours in a month) and their associated pseudo R-squared are reported. Panel-data adjusted bootstrapped standard errors, clustered at the country level, are reported in parentheses. The symbols $* * *, * * *,+$ mean that the reported coefficients are statistically different from zero, respectively, at the $0.1,1,5$, and $10 \%$ level 
Table IA.IV Robustness regressions substituting Inflation crisis with a $15 \%$ or $25 \%$ min inflation (Panel A)

\begin{tabular}{|c|c|c|c|c|c|c|}
\hline Dependent Variables: & $\begin{array}{l}\text { (1) } \\
\text { Bitnode intensity }\end{array}$ & $\begin{array}{l}\text { (2) } \\
\text { Unique bitnodes }\end{array}$ & $\begin{array}{l}(3) \\
\text { Bitnode hours }\end{array}$ & $\begin{array}{l}\text { (4) } \\
\text { Bitnode intensity }\end{array}$ & $\begin{array}{l}\text { (5) } \\
\text { Unique bitnodes }\end{array}$ & $\begin{array}{l}(6) \\
\text { Bitnode hours }\end{array}$ \\
\hline \multicolumn{7}{|l|}{ Financial characteristics } \\
\hline $25 \%$ Min Inflation & $\begin{array}{l}0.677 \\
(0.490)\end{array}$ & $\begin{array}{l}8.580^{* *} \\
(3.202)\end{array}$ & $\begin{array}{l}74.911 \\
(97.863)\end{array}$ & & & \\
\hline $15 \%$ Min Inflation & & & & $\begin{array}{l}0.775^{*} \\
(0.334)\end{array}$ & $\begin{array}{l}8.038^{* *} \\
(2.452)\end{array}$ & $\begin{array}{l}121.690^{+} \\
(64.821)\end{array}$ \\
\hline Unbanked & $\begin{array}{l}0.008 \\
(0.009)\end{array}$ & $\begin{array}{l}-0.189^{* *} \\
(0.073)\end{array}$ & $\begin{array}{l}-2.320 \\
(1.623)\end{array}$ & $\begin{array}{l}0.008 \\
(0.009)\end{array}$ & $\begin{array}{l}-0.190^{*} \\
(0.081)\end{array}$ & $\begin{array}{l}-2.376^{+} \\
(1.353)\end{array}$ \\
\hline 5-bank asset concentration & $\begin{array}{l}0.003 \\
(0.016)\end{array}$ & $\begin{array}{l}0.013 \\
(0.067)\end{array}$ & $\begin{array}{l}-5.071^{* *} \\
(1.555)\end{array}$ & $\begin{array}{l}0.004 \\
(0.013)\end{array}$ & $\begin{array}{l}0.015 \\
(0.072)\end{array}$ & $\begin{array}{l}-5.035^{* *} \\
(1.679)\end{array}$ \\
\hline \multicolumn{7}{|l|}{ Criminality characteristics } \\
\hline Money laundering & $\begin{array}{l}1.348^{* *} \\
(0.491)\end{array}$ & $\begin{array}{l}6.945^{* *} \\
(2.532)\end{array}$ & $\begin{array}{l}176.610^{* * *} \\
(53.588)\end{array}$ & $\begin{array}{l}1.331^{* *} \\
(0.510)\end{array}$ & $\begin{array}{l}6.825^{* *} \\
(2.263)\end{array}$ & $\begin{array}{l}175.268^{* *} \\
(59.596)\end{array}$ \\
\hline Rule of law & $\begin{array}{l}1.469^{* *} \\
(0.503)\end{array}$ & $\begin{array}{l}9.634^{* * *} \\
(2.649)\end{array}$ & $\begin{array}{l}92.375^{*} \\
(46.450)\end{array}$ & $\begin{array}{l}1.470^{* *} \\
(0.458)\end{array}$ & $\begin{array}{l}9.513^{\text {*** }} \\
(2.301)\end{array}$ & $\begin{array}{l}96.620^{+} \\
(53.552)\end{array}$ \\
\hline \multicolumn{7}{|l|}{ Baseline characteristics } \\
\hline GDP per capita & $\begin{array}{l}0.656 \\
(0.475)\end{array}$ & $\begin{array}{l}-0.238 \\
(2.095)\end{array}$ & $\begin{array}{l}68.815^{+} \\
(38.871)\end{array}$ & $\begin{array}{l}0.679 \\
(0.466)\end{array}$ & $\begin{array}{l}0.009 \\
(1.860)\end{array}$ & $\begin{array}{l}68.917^{+} \\
(39.943)\end{array}$ \\
\hline Restrictive regulation & $\begin{array}{l}-0.534 \\
(0.357)\end{array}$ & $\begin{array}{l}3.016^{+} \\
(1.549)\end{array}$ & $\begin{array}{l}32.214 \\
(38.786)\end{array}$ & $\begin{array}{l}-0.479 \\
(0.372)\end{array}$ & $\begin{array}{l}3.572^{*} \\
(1.518)\end{array}$ & $\begin{array}{l}40.662 \\
(37.398)\end{array}$ \\
\hline Constant & $\begin{array}{c}-6.412 \\
(4.460)\end{array}$ & $\begin{array}{l}22.056 \\
(19.682)\end{array}$ & $\begin{array}{l}409.386 \\
(420.884)\end{array}$ & $\begin{array}{l}-6.618 \\
(4.342)\end{array}$ & $\begin{array}{l}19.767 \\
(18.050)\end{array}$ & $\begin{array}{l}406.150 \\
(403.880)\end{array}$ \\
\hline Year FEs & Yes & Yes & Yes & Yes & Yes & Yes \\
\hline World Region FEs & Yes & Yes & Yes & Yes & Yes & Yes \\
\hline Year-World Region FEs & Yes & Yes & Yes & Yes & Yes & Yes \\
\hline Observations & 685 & 685 & 685 & 685 & 685 & 685 \\
\hline Pseudo R-Squared & 0.42 & 0.63 & 0.32 & 0.41 & 0.67 & 0.32 \\
\hline Number of Countries & 137 & 137 & 137 & 137 & 137 & 137 \\
\hline
\end{tabular}

All models are Tobit random effects models lower censored at 0 and their associated overall R-squared is reported. Panel-data bootstrapped standard errors, clustered at the country level, are reported in parentheses. The symbols $* * *, * *, *,+$ mean that the reported coefficients are statistically different from zero, respectively, at the $0.1,1,5$ and 10\% level. Models 3 and 6 are in addition upper-censored at 750 (upper limit of active Bitnode hours in a month) 
Table IA.V Disentangling the effect of Rule of law on Bitcoin infrastructure adoption (Panel A; Country-year level)

\begin{tabular}{|c|c|c|c|c|}
\hline Dependent variables & $\begin{array}{l}\text { (1) } \\
\text { Bitnode intensity }\end{array}$ & $\begin{array}{l}\text { (2) } \\
\text { Bitcoin merchants }\end{array}$ & $\begin{array}{l}\text { (3) } \\
\text { Bitnode intensity }\end{array}$ & $\begin{array}{l}\text { (4) } \\
\text { Bitcoin merchants }\end{array}$ \\
\hline Organized crime & $\begin{array}{l}0.152 \\
(0.188)\end{array}$ & $\begin{array}{l}-0.419 \\
(0.373)\end{array}$ & & \\
\hline Crime and violence costs & & & $\begin{array}{l}-0.016 \\
(0.221)\end{array}$ & $\begin{array}{l}-0.656 \\
(0.486)\end{array}$ \\
\hline Money laundering & $\begin{array}{l}0.992 \\
(0.656)\end{array}$ & $\begin{array}{l}0.516 \\
(0.724)\end{array}$ & $\begin{array}{l}1.117^{+} \\
(0.596)\end{array}$ & $\begin{array}{l}0.554 \\
(0.718)\end{array}$ \\
\hline Inflation crisis & $\begin{array}{l}0.395 \\
(0.447)\end{array}$ & $\begin{array}{l}-0.241 \\
(0.993)\end{array}$ & $\begin{array}{l}0.285 \\
(0.418)\end{array}$ & $\begin{array}{l}-0.783 \\
(5.133)\end{array}$ \\
\hline Unbanked & $\begin{array}{l}0.009 \\
(0.011)\end{array}$ & $\begin{array}{l}-0.050 \\
(0.035)\end{array}$ & $\begin{array}{l}-0.004 \\
(0.012)\end{array}$ & $\begin{array}{l}-0.050^{+} \\
(0.030)\end{array}$ \\
\hline Five-bank asset concentration & $\begin{array}{l}0.008 \\
(0.019)\end{array}$ & $\begin{array}{l}-0.011 \\
(0.026)\end{array}$ & $\begin{array}{l}0.008 \\
(0.014)\end{array}$ & $\begin{array}{l}-0.023 \\
(0.028)\end{array}$ \\
\hline GDP per capita & $\begin{array}{l}1.696^{\text {**** }} \\
(0.480)\end{array}$ & $\begin{array}{l}0.786 \\
(0.690)\end{array}$ & $\begin{array}{l}1.278^{* *} \\
(0.443)\end{array}$ & $\begin{array}{l}0.742 \\
(0.515)\end{array}$ \\
\hline Restrictive bitcoin regulation & $\begin{array}{l}-0.603^{+} \\
(0.316)\end{array}$ & $\begin{array}{l}-0.588 \\
(0.680)\end{array}$ & $\begin{array}{l}-0.612^{+} \\
(0.335)\end{array}$ & $\begin{array}{l}-0.558 \\
(0.859)\end{array}$ \\
\hline Constant & $\begin{array}{l}-16.043^{* * * *} \\
(4.393)\end{array}$ & $\begin{array}{l}-1.822 \\
(6.132)\end{array}$ & $\begin{array}{l}-11.075^{*} \\
(4.367)\end{array}$ & $\begin{array}{l}0.523 \\
(4.174)\end{array}$ \\
\hline Year FEs & Yes & Yes & Yes & Yes \\
\hline World Region FEs & Yes & Yes & Yes & Yes \\
\hline Year-World Region FEs & Yes & Yes & Yes & Yes \\
\hline Observations & 665 & 665 & 685 & 685 \\
\hline Log-likelihood & -1231.9 & -1393.8 & -1279.6 & -1400.4 \\
\hline Number of countries & 133 & 133 & 137 & 137 \\
\hline RHO & 0.75 & 0.20 & 0.73 & 0.22 \\
\hline
\end{tabular}

All models are Tobit random effects models lower-censored at 0 and their associated pseudo R-squared are reported. Panel-data adjusted bootstrapped standard errors, clustered at the country level, are reported in parentheses. The symbols $* * *, * *, *,+$ mean that the reported coefficients are statistically different from zero, respectively, at the $0.1,1,5$ and $10 \%$ level. Models 1 and 2 exclude the 4 countries of Belize, Bermuda, Cayman Islands and Syria, as no value was reported for the variable organized crime from the data source 
Table IA.VI Variable description and data sources of variables for alternative explanation analysis

\begin{tabular}{|c|c|c|c|}
\hline Variable & Description & Source & Source variable name \\
\hline \multicolumn{4}{|l|}{ Panel A } \\
\hline $\begin{array}{l}\text { Shadow } \\
\text { econo- } \\
\text { my }\end{array}$ & $\begin{array}{l}\text { Size estimates of the shadow economy as a percentage } \\
\text { of a nation's GDP, based on last available year } \\
\text { reported }\end{array}$ & Elgin and Öztunalı (2012) & \\
\hline Tax haven & $\begin{array}{l}\text { Indicator variable equal to } 1 \text { for countries either } \\
\text { black-listed or gray-listed by the EU as } \\
\text { non-cooperative tax jurisdictions }\end{array}$ & $\begin{array}{l}\text { ec.europa.eu/taxation_- } \\
\text { customs/tax-common-eu-list_en, } \\
\text { accessed on December } 6,2018\end{array}$ & \\
\hline Taxation & $\begin{array}{l}\text { Taxes on income, profits, and capital gains are levied } \\
\text { on the actual or presumptive net income of } \\
\text { individuals, on the profits of corporations and } \\
\text { enterprises, and on capital gains, whether realized or } \\
\text { not, on land, securities, and other assets. } \\
\text { Intragovernmental payments are eliminated in } \\
\text { consolidation. }\end{array}$ & $\begin{array}{l}\text { International Monetary Fund, Government } \\
\text { Finance Statistics Yearbook and data } \\
\text { files }\end{array}$ & GC.TAX.YPKG.RV.ZS \\
\hline $\begin{array}{l}\text { Tax } \\
\text { burden }\end{array}$ & $\begin{array}{l}\text { Composite index of the tax burden, including direct } \\
\text { taxes, in terms of the top marginal tax rates on } \\
\text { individual and corporate incomes, and overall taxes, } \\
\text { consisting of all forms of direct and indirect taxation } \\
\text { at all governmental levels, as a percentage of GDP. } \\
\text { This variable is defined on a 100-tax burden scale, } \\
\text { such that highest values correspond to lower tax } \\
\text { burden and vice versa. The variable is standardized } \\
\text { in regression analyses. }\end{array}$ & The Heritage Foundation, 2014-2018 & $\begin{array}{l}\text { Tax burden (or Fiscal } \\
\text { Freedom from 2016) }\end{array}$ \\
\hline $\begin{array}{l}\text { Bitcoin } \\
\text { mining } \\
\text { country }\end{array}$ & $\begin{array}{l}\text { Indicator variable equal to } 1 \text { for countries identified as } \\
\text { having high levels of activity of bitcoin or } \\
\text { crypto-asset mining facilities }\end{array}$ & $\begin{array}{l}\text { Hileman and Rauchs (2017) and Rauchs } \\
\text { et al. (2018) }\end{array}$ & \\
\hline $\begin{array}{l}\text { Bitcoin } \\
\text { mining } \\
\text { MWs }\end{array}$ & $\begin{array}{l}\text { National aggregated capacity of facilities used for } \\
\text { crypto-asset mining measured in megawatts (MW) }\end{array}$ & Hileman and Rauchs (2017) & \\
\hline $\begin{array}{l}\text { Electricity } \\
\text { price }\end{array}$ & $\begin{array}{l}\text { Price of electricity in US cents per kWh. A monthly } \\
\text { electricity consumption is assumed, for which a bill } \\
\text { is then computed for a warehouse based in the largest } \\
\text { business city of the economy for the month of March }\end{array}$ & $\begin{array}{l}\text { World Bank Doing Business Reports } \\
\text { (2014-2018); "Getting Electricity" } \\
\text { section }\end{array}$ & \\
\hline $\begin{array}{l}\text { Stock } \\
\quad \text { market } \\
\text { return }\end{array}$ & $\begin{array}{l}\text { The percentage U.S. dollar price change in the } \\
\text { country-specific stock markets covered by the } \\
\text { S\&P/IFCI and S\&P/Frontier BMI country indices } \\
(2014-2018)\end{array}$ & $\begin{array}{l}\text { World Bank obtained from: Standard \& } \\
\text { Poor's, Global Stock Markets Factbook } \\
\text { and supplemental S\&P data. }\end{array}$ & CM.MKT.INDX.ZG \\
\hline $\begin{array}{l}\text { Crisis } \\
\text { stock } \\
\text { market } \\
\text { return }\end{array}$ & $\begin{array}{l}\text { The percentage U.S. dollar price change in the } \\
\text { country-specific stock markets covered by the } \\
\text { S\&P/IFCI and S\&P/Frontier BMI country indices } \\
\text { for the years of } 2008-2009\end{array}$ & $\begin{array}{l}\text { World Bank obtained from: Standard \& } \\
\text { Poor's, Global Stock Markets Factbook } \\
\text { and supplemental S\&P data. }\end{array}$ & CM.MKT.INDX.ZG \\
\hline
\end{tabular}


Table IA.VII Robustness tests of financial and criminality drivers excluding countries without Bitcoin infrastructure (Panel A; Countryyear level)

\begin{tabular}{|c|c|c|c|c|}
\hline Dependent variables & $\begin{array}{l}\text { (1) } \\
\text { Bitnode intensity }>0\end{array}$ & $\begin{array}{l}\text { (2) } \\
\text { Unique bitnodes }>0\end{array}$ & $\begin{array}{l}(3) \\
\text { Bitnode hours }>0\end{array}$ & $\begin{array}{l}\text { (4) } \\
\text { Bitcoin merchants }>0\end{array}$ \\
\hline \multicolumn{5}{|l|}{ Financial characteristics } \\
\hline Inflation crisis & $\begin{array}{l}0.656^{*} \\
(0.331)\end{array}$ & $\begin{array}{l}8.508^{* *} \\
(3.109)\end{array}$ & $\begin{array}{l}63.253 \\
(80.025)\end{array}$ & $\begin{array}{l}1.690 \\
(1.276)\end{array}$ \\
\hline Unbanked & $\begin{array}{l}0.011 \\
(0.011)\end{array}$ & $\begin{array}{l}-0.176^{*} \\
(0.088)\end{array}$ & $\begin{array}{l}-2.069 \\
(1.515)\end{array}$ & $\begin{array}{l}-0.035^{+} \\
(0.018)\end{array}$ \\
\hline Five-bank asset concentration & $\begin{array}{l}0.009 \\
(0.014)\end{array}$ & $\begin{array}{l}0.040 \\
(0.064)\end{array}$ & $\begin{array}{l}-4.496^{* *} \\
(1.659)\end{array}$ & $\begin{array}{l}-0.014 \\
(0.027)\end{array}$ \\
\hline \multicolumn{5}{|l|}{ Criminality characteristics } \\
\hline Money laundering & $\begin{array}{l}1.392^{*} \\
(0.607)\end{array}$ & $\begin{array}{l}7.231^{* *} \\
(2.443)\end{array}$ & $\begin{array}{l}181.439^{* *} \\
(57.945)\end{array}$ & $\begin{array}{l}0.475 \\
(0.595)\end{array}$ \\
\hline Rule of law & $\begin{array}{l}1.538^{* *} \\
(0.482)\end{array}$ & $\begin{array}{l}10.075^{* * *} \\
(2.493)\end{array}$ & $\begin{array}{l}99.385^{+} \\
(51.276)\end{array}$ & $\begin{array}{l}0.860^{+} \\
(0.513)\end{array}$ \\
\hline \multicolumn{5}{|l|}{ Baseline Controls } \\
\hline GDP per capita & $\begin{array}{l}0.557 \\
(0.512)\end{array}$ & $\begin{array}{l}-0.709 \\
(1.749)\end{array}$ & $\begin{array}{l}58.254 \\
(43.641)\end{array}$ & $\begin{array}{l}0.048 \\
(0.435)\end{array}$ \\
\hline Restrictive regulation & $\begin{array}{l}-0.543^{*} \\
(0.257)\end{array}$ & $\begin{array}{l}3.012^{*} \\
(1.472)\end{array}$ & $\begin{array}{l}31.062 \\
(45.992)\end{array}$ & $\begin{array}{l}-1.027 \\
(0.756)\end{array}$ \\
\hline Constant & $\begin{array}{l}-6.048 \\
(4.790)\end{array}$ & $\begin{array}{l}23.508 \\
(18.356)\end{array}$ & $\begin{array}{l}446.380 \\
(438.980)\end{array}$ & $\begin{array}{l}2.214 \\
(5.210)\end{array}$ \\
\hline Year FEs & Yes & Yes & Yes & Yes \\
\hline World Region FEs & Yes & Yes & Yes & Yes \\
\hline Year-World Region FEs & Yes & Yes & Yes & Yes \\
\hline Panel Data Specifications & Tobit & Tobit & Tobit & Tobit \\
\hline Observations & 650 & 650 & 650 & 565 \\
\hline Number of Countries & 130 & 130 & 130 & 113 \\
\hline Pseudo R-Squared & 0.44 & 0.65 & 0.23 & $<0$ \\
\hline Log-likelihood & -1301.6 & -2262.9 & -2382.4 & -1386.3 \\
\hline RHO & 0.71 & 0.53 & 0.61 & 0.16 \\
\hline
\end{tabular}

All models are Tobit random effects models and their associated overall R-squared is reported. Panel-data bootstrapped standard errors, clustered at the country level, are reported in parentheses. The symbols ***,**,*, + mean that the reported coefficients are statistically different from zero, respectively, at the 0.1, 1, 5 and 10\% level. Model (3) is upper-censored at 750 (upper limit of active Bitnode hours in a month) 
Table IA.VIII Robustness tests of social drivers excluding regions without Bitcoin infrastructure (Panel B; Region-year level)

\begin{tabular}{|c|c|c|c|c|c|c|}
\hline Dependent variables & $\begin{array}{l}(1) \\
\text { Bitnode } \\
\text { intensity }>0\end{array}$ & $\begin{array}{l}(2) \\
\text { Unique } \\
\text { bitnodes }>0\end{array}$ & $\begin{array}{l}(3) \\
\text { Bitcoin } \\
\text { merchants }>0\end{array}$ & $\begin{array}{l}(4) \\
\text { Bitnode } \\
\text { intensity >0 }\end{array}$ & $\begin{array}{l}(5) \\
\text { Unique } \\
\text { bitnodes }>0\end{array}$ & $\begin{array}{l}(6) \\
\text { Bitcoin } \\
\text { merchants }>0\end{array}$ \\
\hline \multicolumn{7}{|l|}{ Social characteristics } \\
\hline High risk willingness & $\begin{array}{l}4.414 \\
(3.631)\end{array}$ & $\begin{array}{l}20.920 \\
(23.771)\end{array}$ & $\begin{array}{l}14.357^{*} \\
(6.367)\end{array}$ & $\begin{array}{l}5.974 \\
(3.670)\end{array}$ & $\begin{array}{l}34.322 \\
(24.362)\end{array}$ & $\begin{array}{l}20.175^{* *} \\
(6.985)\end{array}$ \\
\hline $\begin{array}{l}\text { High risk willingness } \mathrm{x} \\
\text { Bitcoin price }\end{array}$ & & & & $\begin{array}{l}-0.605^{* *} \\
(0.211)\end{array}$ & $\begin{array}{l}-5.402^{*} \\
(2.168)\end{array}$ & $\begin{array}{l}-2.012^{*} \\
(0.991) \\
0.292 \\
(0.178)\end{array}$ \\
\hline Bitcoin price & & & & $\begin{array}{l}0.013 \\
(0.039)\end{array}$ & $\begin{array}{l}-2.999^{* * * *} \\
(0.397)\end{array}$ & $\begin{array}{l}0.292 \\
(0.178)\end{array}$ \\
\hline Trust in others & $\begin{array}{l}1.949 \\
(1.219)\end{array}$ & $\begin{array}{l}19.573^{*} \\
(9.458)\end{array}$ & $\begin{array}{l}-2.093 \\
(2.656)\end{array}$ & $\begin{array}{l}2.062^{+} \\
(1.216)\end{array}$ & $\begin{array}{l}20.139^{*} \\
(9.449)\end{array}$ & $\begin{array}{l}-1.981 \\
(2.653)\end{array}$ \\
\hline $\begin{array}{l}\text { Distrust in banks \& financial } \\
\text { system }\end{array}$ & $\begin{array}{l}4.309^{* *} \\
(1.603)\end{array}$ & $\begin{array}{l}24.170^{*} \\
(12.305)\end{array}$ & $\begin{array}{l}2.876 \\
(2.864)\end{array}$ & $\begin{array}{l}4.302^{* *} \\
(1.599)\end{array}$ & $\begin{array}{l}24.117^{*} \\
(12.294)\end{array}$ & $\begin{array}{l}2.836 \\
(2.861)\end{array}$ \\
\hline Distrust in other institutions & $\begin{array}{l}-3.376 \\
(2.279)\end{array}$ & $\begin{array}{l}-24.477 \\
(16.552)\end{array}$ & $\begin{array}{l}-6.207 \\
(3.900)\end{array}$ & $\begin{array}{l}-3.409 \\
(2.275)\end{array}$ & $\begin{array}{l}-24.462 \\
(16.543)\end{array}$ & $\begin{array}{l}-6.181 \\
(3.897)\end{array}$ \\
\hline \multicolumn{7}{|l|}{ Baseline characteristics } \\
\hline GDP per capita & $\begin{array}{l}-1.911^{*} \\
(0.842)\end{array}$ & $\begin{array}{l}-33.624^{* * *} \\
(8.510)\end{array}$ & $\begin{array}{l}-6.408 \\
(4.470)\end{array}$ & $\begin{array}{l}-1.919^{*} \\
(0.837)\end{array}$ & $\begin{array}{l}-33.743^{* * *} \\
(8.473)\end{array}$ & $\begin{array}{l}-6.181 \\
(4.453)\end{array}$ \\
\hline Restrictive regulation & $\begin{array}{l}-0.059 \\
(0.406)\end{array}$ & $\begin{array}{l}4.217 \\
(4.108)\end{array}$ & $\begin{array}{l}-0.480 \\
(2.246)\end{array}$ & $\begin{array}{l}0.058 \\
(0.407)\end{array}$ & $\begin{array}{l}5.220 \\
(4.126)\end{array}$ & $\begin{array}{l}0.190 \\
(2.266)\end{array}$ \\
\hline Constant & $\begin{array}{l}17.323^{*} \\
(8.220)\end{array}$ & $\begin{array}{l}307.839^{* * *} \\
(76.940)\end{array}$ & $\begin{array}{l}48.074 \\
(38.258)\end{array}$ & $\begin{array}{l}17.229^{*} \\
(8.183)\end{array}$ & $\begin{array}{l}308.580^{* * *} \\
(76.645)\end{array}$ & $\begin{array}{l}45.291 \\
(38.128)\end{array}$ \\
\hline Year FEs & Yes & Yes & Yes & Yes & Yes & Yes \\
\hline Country FEs & Yes & Yes & Yes & Yes & Yes & Yes \\
\hline Panel data specifications & Tobit & Tobit & Tobit & Tobit & Tobit & Tobit \\
\hline Observations & 1210 & 1210 & 1000 & 1210 & 1210 & 1000 \\
\hline Number of Regions & 242 & 242 & 200 & 242 & 242 & 200 \\
\hline Number of Countries & 34 & 34 & 31 & 34 & 34 & 31 \\
\hline Log-likelihood & -2771.9 & -5182.3 & -2652.4 & -2767.7 & -5179.1 & -2650.3 \\
\hline Rho & 0.77 & 0.55 & 0.08 & 0.77 & 0.55 & 0.08 \\
\hline
\end{tabular}

All models are Tobit random effects models and their associated overall R-squared is reported. Panel-data bootstrapped standard errors, clustered at the country level, are reported in parentheses. The symbols $* * *, * *, *,+$ mean that the reported coefficients are statistically different from zero, respectively, at the $0.1,1,5$ and $10 \%$ level 
Open Access This article is licensed under a Creative Commons Attribution 4.0 International License, which permits use, sharing, adaptation, distribution and reproduction in any medium or format, as long as you give appropriate credit to the original author(s) and the source, provide a link to the Creative Commons licence, and indicate if changes were made. The images or other third party material in this article are included in the article's Creative Commons licence, unless indicated otherwise in a credit line to the material. If material is not included in the article's Creative Commons licence and your intended use is not permitted by statutory regulation or exceeds the permitted use, you will need to obtain permission directly from the copyright holder. To view a copy of this licence, visit http://creativecommons.org/licenses/by/4.0/.

\section{References}

Acquisti, A., Taylor, C., \& Wagman, L. (2016). The economics of privacy. Journal of Economic Literature, 54(2), 442-492 https://doi.org/10.1257/jel.54.2.442.

Akins, B. W., Chapman, J. L., \& Gordon, J. M. (2015). A whole new world: income tax considerations of the bitcoin economy. Pittsburgh Tax Review. https://doi.org/10.5195 /taxreview.2014.32.

Albrecht, C., Duffin, K. M., Hawkins, S., \& Morales Rocha, V. M. (2019). The use of cryptocurrencies in the money laundering process. Journal of Money Laundering Control, 22(2), 210 216 https://doi.org/10.1108/JMLC-12-2017-0074.

Aldridge, J., \& Décary-Hétu, D. (2016a). Hidden wholesale: the drug diffusing capacity of online drug cryptomarkets. International Journal of Drug Policy, 35, 7-15 https://doi. org/10.1016/j.drugpo.2016.04.020.

Aldridge, J., \& Décary-Hétu, D. (2016b). Cryptomarkets and the future of illicit drug markets. In The internet and drug markets (European Monitoring Centre for Drugs and Drug Addiction: Insights 21) (pp. 23-30). Luxembourg: Publications Office of the European Union.Available at: https://daviddhetu.openum.ca/files/sites/39/2018/12/Future. pdf. Accessed 27 November 2019.

Arnold, S., \& Auer, B. R. (2015). What do scientists know about inflation hedging? The North American Journal of Economics and Finance, 34, 187-214 https://doi. org/10.1016/J.NAJEF.2015.08.005.

Athey, S., Parashkevovz, I., Sarukkai, V., \& Jing, X. (2016). Bitcoin Pricing, Adoption, and Usage: Theory and Evidence. Stanford University Graduate School of Business Research Paper no. 16-42. Available at: https://ssrn. com/abstract $=2826674$

Athey, S., Catalini, C., \& Tucker, C. E. (2017). The digital privacy paradox: small money, small costs, small talk. SSRN Working Paper. https://doi.org/10.2139/ssrn.2916489.

Audretsch, D. B., Heger, D., \& Veith, T. (2015). Infrastructure and entrepreneurship. Small Business Economics, 44(2), 219230 https://doi.org/10.1007/s11187-014-9600-6.

Ba, S., \& Pavlou, P. A. (2002). Evidence of the effect of trust building technology in electronic markets: price premiums and buyer behavior. MIS Quarterly, 26(3), 243-268 https://doi.org/10.2307/4132332.
Baek, C., \& Elbeck, M. (2015). Bitcoins as an investment or speculative vehicle? A first look. Applied Economics Letters, 22(1), 30-34 https://doi.org/10.1080 /13504851.2014.916379.

Bain \& Company (2019). Many consumers trust technology companies more than banks. 9 January. Available at: https://www. bain.com/insights/many-consumers-trust-technologycompanies-morethan-banks-snap-chart/. Accessed 30 August 2019.

Bank of International Settlements. (2019). BIS triennial central bank survey - foreign exchange turnover in April 2019. Available at: https://www.bis.org/statistics/rpfx19_fx.pdf. Accessed 27 November 2019.

Barratt, M. J., Ferris, J. A., \& Winstock, A. R. (2016). Safer scoring? Cryptomarkets, social supply and drug market violence. International Journal of Drug Policy, 35, 24-31 https://doi.org/10.1016/j.drugpo.2016.04.019.

Bashir, M., Strickland, B., \& Bohr, J. (2016). What motivates people to use bitcoin? In E. Sprio \& Y. Ahn (Eds.), Social Informatics. In SocInfo 2016. Lecture notes in computer science (Vol. 10047, pp. 347-367). Cham: Springer https://doi.org/10.1007/978-3-319-47874-6_25.

Baur, D. G., Dimpfl, T., \& Kuck, K. (2018a). Bitcoin, gold and the US dollar - a replication and extension. Finance Research Letters, 25, 103-110 https://doi.org/10.1016/J. FRL.2017.10.012.

Baur, D. G., Hong, K. H., \& Lee, A. D. (2018b). Bitcoin: medium of exchange or speculative assets? Journal of International Financial Markets, Institutions and Money, 54, 177-189 https://doi.org/10.1016/j.intfin.2017.12.004.

Beck, T., \& Martínez pería, M. S. (2011). What explains the price of remittances? An examination across 119 country corridors. World Bank Economic Review, 25(1), 105-131 https://doi. org/10.1093/wber/lhr017.

Bertsch, C., Hull, I., Qi, Y., \& Zhang, X. (2017). Bank misconduct, trust, and online lending. Sveriges Riksbank working paper series no. 346. http://www.christophbertsch. com/data/TrustOnlineLending_BertschHullQiZhang.pdf. Accessed 27 November 2019.

Blau, B. M. (2018). Price dynamics and speculative trading in Bitcoin. Research in International Business and Finance, 43, 15-21 https://doi.org/10.1016/j.ribaf.2017.07.183.

Block, J. H., Colombo, M. G., Cumming, D. J., \& Vismara, S. (2018). New players in entrepreneurial finance and why they are there. Small Business Economics, 50(2), 239-250. https://doi.org/10.1007/s11187-016-9826-6.

Bohannon, J. (2016). The bitcoin busts. Science, 351(6278), 1144-1146. https://doi.org/10.1126/science.351.6278.1144.

Böhme, R., Christin, N., Edelman, B., \& Moore, T. (2015). Bitcoin: economics, technology, and governance. Journal of Economic Perspectives, 29(2), 213-238. https://doi. org/10.1257/jep.29.2.213.

Borio, C., Claessens, S., Cohen, B., Domanski, D., Halaburda, H., Hughes, K., et al. (2017). Central bank cryptocurrencies. BIS quarterly review. Available at: https://www.bis. org/publ/qtrpdf/r_qt1709f.pdf. Accessed 11 November 2019.

Bouoiyour, J., \& Selmi, R. (2015). What does Bitcoin look like? Annals of Economics and Finance, 16(2), 449-492 Available at: https://ideas.repec.org/a/cuf/journl/y2015v16i2bouoiyour. html. 
Bouri, E., Gupta, R., Tiwari, A. K., \& Roubaud, D. (2017a). Does Bitcoin hedge global uncertainty? Evidence from waveletbased quantile-in-quantile regressions. Finance Research Letters, 23, 87-95. https://doi.org/10.1016/j.frl.2017.02.009.

Bouri, E., Molnár, P., Azzi, G., Roubaud, D., \& Hagfors, L. I. (2017b). On the hedge and safe haven properties of Bitcoin: is it really more than a diversifier? Finance Research Letters, 20, 192-198 https://doi.org/10.1016/j.frl.2016.09.025.

Bouri, E., Lucey, B., \& Roubaud, D. (2019a). Cryptocurrencies and the downside risk in equity investments. Finance Research Letters, in press. https://doi.org/10.1016/j. frl.2019.06.009.

Bouri, E., Shahzad, S. J. H., \& Roubaud, D. (2019b). Cryptocurrencies as hedges and safe-havens for US equity sectors. In Quarterly review of economics and finance, in press. https://doi.org/10.1016/j.qref.2019.05.001.

Campbell, J. Y. (2006). Household finance. The Journal of Finance, 61(4), 1553-1604 https://doi.org/10.1111/j.15406261.2006.00883.x.

Cheah, E.-T., \& Fry, J. (2015). Speculative bubbles in Bitcoin markets? An empirical investigation into the fundamental value of Bitcoin. Economics Letters, 130, 32-36 https://doi. org/10.1016/j.econlet.2015.02.029.

Choo, K. K. R. (2015). Cryptocurrency and virtual currency: corruption and money laundering/terrorism financing risks? In Handbook of digital currency: bitcoin, innovation, financial instruments, and big data. https://doi.org/10.1016/B9780-12-802117-0.00015-1.

CipherTrace (2018). Cryptocurrency anti-money laundering report. Available at: https://ciphertrace.com/wpcontent/uploads/2018/10/crypto_aml_report_2018q3.pdf. Accessed 27 November 2019.

Cœuré, B. (2018). The new frontier of payments and market infrastructure: on cryptos, cyber and CCPs. BIS. Available at: https://www.bis.org/review/r181115a.htm. Accessed 27 November 2019.

Cohen, B. (2017). The rise of alternative currencies in post-capitalism. Journal of Management Studies, 54(5), 739-746 https://doi.org/10.1111/joms.12245.

Cohn, A., Engelmann, J., Fehr, E., \& Maréchal, M. A. (2015). Evidence for countercyclical risk aversion: an experiment with financial professionals. American Economic Review, 105(2), 860-885. https://doi.org/10.1257/aer.20131314.

Conti-Brown, P., Lastra, R., Raskin, M., \& Yermack, D. (2018). Digital currencies, decentralized ledgers and the future of central banking. In Research handbook on central banking. https://doi.org/10.4337/9781784719227.00028.

Corbet, S., Cumming, D. J., Lucey, B. M., Peat, M., \& Vigne, S. A. (2019). The destabilising effects of cryptocurrency cybercriminality. Economics letters, in press. https://doi. org/10.1016/j.econlet.2019.108741.

Correia, S. (2017). GEOCODE_IP: Stata module to geocode IP addresses. Statistical Software Components, (S458333). Available at: https://ideas.repec.org/c/boc/bocode/s458333. html. Accessed 27 November 2019.

Czernich, N., Falck, O., Kretschmer, T., \& Woessmann, L. (2011). Broadband infrastructure and economic growth. Economic Journal, 121(552), 505-532 https://doi.org/10.1111/j.14680297.2011.02420.x.

Demant, J., Munksgaard, R., Décary-Hétu, D., \& Aldridge, J. (2018). Going local on a global platform: a critical analysis of the transformative potential of cryptomarkets for organized illicit drug crime. International Criminal Justice Review, 28(3), 255-274 https://doi.org/10.1177 /1057567718769719.

Demirguc-Kunt, A., Klapper, L., Singer, D., Ansar, S., \& Hess, J. (2018). The global findex database 2017: measuring financial inclusion and the fintech revolution. The World Bank. https://doi.org/10.1596/978-1-4648-1259-0.

Dierksmeier, C., \& Seele, P. (2018). Cryptocurrencies and business ethics. Journal of Business Ethics, 152(1), 1-14. https://doi.org/10.1007/s10551-016-3298-0.

Dodd, N. (2018). The social life of bitcoin. Theory, Culture \& Society, 35(3), 35-56 https://doi.org/10.1177 /0263276417746464.

Dodgson, M., Gann, D., Wladawsky-Berger, I., Sultan, N., \& George, G. (2015). Managing digital money. Academy of Management Journal, 58(2), 325-333 https://doi. org/10.5465/amj.2015.4002.

Duarte, J., Siegel, S., \& Young, L. (2012). Trust and credit: the role of appearance in peer-to-peer lending. Review of Financial Studies, 25(8), 2455-2484 https://doi.org/10.1093 $/ \mathrm{rfs} / \mathrm{hhs} 071$.

Dwyer, G. P. (2015). The economics of bitcoin and similar private digital currencies. Journal of Financial Stability, 17, 81-91 https://doi.org/10.1016/j.jfs.2014.11.006.

Dyhrberg, A. H. (2016). Bitcoin, gold and the dollar - a GARCH volatility analysis. Finance Research Letters, 16, 85-92 https://doi.org/10.1016/j.frl.2015.10.008.

Elgin, C., \& Öztunal1, O. (2012). Shadow economies around the world: model based estimates. Working papers 2012/05, Bogazici University, 1-48. Available at: http://www.econ. boun.edu.tr/public_html/RePEc/pdf/201205.pdf. Accessed 27 November 2019.

Elliott, F., \& Duncan, G. (2009). Chancellor Alistair Darling on brink of second bailout for banks. The Times, p. 1,2 and 6 . London, UK. Available at: https://www.thetimes.co. uk/article/chancellor-alistair-darling-on-brink-of-secondbailout-for-banks-n91382mn62h. Accessed 27 November 2019.

Engert, W., \& Fung, B. S. C. (2017). Central bank digital currency: motivations and implications. Bank of Canada. Available at: https://www.bankofcanada.ca/wp-content/uploads/2017/11 /sdp2017-16.pdf. Accessed 27 November 2019.

Ermakova, T., Fabian, B., Baumann, A., Izmailov, M., \& Krasnova, H. (2017). Bitcoin: drivers and impediments. SSRN Working Paper. https://doi.org/10.2139/ssrn.3017190.

Estrin, S., Gozman, D., \& Khavul, S. (2018). The evolution and adoption of equity crowdfunding: entrepreneur and investor entry into a new market. Small Business Economics, 51(2), 425-439. https://doi.org/10.1007/s11187-018-0009-5.

European Central Bank. (2019). Banknotes and coins circulation. https:/www.ecb.europa.eu/stats/policy and exchange rates/banknotes+coins/circulation/html/index.en.html. Accessed 11 November 2019.

Evans-Pughe, C., Novikov, A., \& Vitaliev, V. (2014). To bit or not to bit? [Bitcoin cryptocurrency]. Engineering \& Technology, 9(4), 82-85. https://doi.org/10.1049/et.2014.0411.

Eyal, I., \& Sirer, E. G. (2014). Majority is not enough: Bitcoin mining is vulnerable. In Lecture notes in computer science (including subseries lecture notes in artificial intelligence 
and lecture notes in bioinformatics). https://doi.org/10.1007 1978-3-662-45472-5 28.

Fanusie, Y. J., \& Robinson, T. (2018). Bitcoin laundering: an analysis of illicit flows into digital currency services. Washington, DC. Available at: https://cdn2.hubspot. net/hubfs/3883533/downloads/Bitcoinlaundering.pdf. Accessed 27 November 2019.

Fatás, A., \& Weder, B. (2019). Initial coin offerings: fundamentally different but highly correlated. Available at: https://voxeu.org/article/initial-coin-offeringsfundamentally-different-highly-correlated. Accessed 27 November 2019.

FATF (2014). Virtual currencies - key definitions and potential AML/CFT risks. FATF report. Available at: https://www.fatfgafi.org/media/fatf/documents/reports/Virtual-currency-keydefinitions-and-potential-aml-cft-risks.pdf. Accessed 27 November 2019.

Fisch, C. (2019). Initial coin offerings (ICOs) to finance new ventures. Journal of Business Venturing, 34(1), 1-22. https://doi.org/10.1016/J.JBUSVENT.2018.09.007.

Fisch, C., Masiak, C., Vismara, S., \& Block, J. (2019). Motives and profiles of ICO investors. Journal of Business Research, in press. https://doi.org/10.1016/j.jbusres.2019.07.036.

Foley, S., Karlsen, J. R., \& Putniņš, T. J. (2019). Sex, drugs, and bitcoin: how much illegal activity is financed through cryptocurrencies? The Review of Financial Studies, 32(5), 1798-1853. https://doi.org/10.1093/rfs/hhz015.

Folkinshteyn, D., Lennon, M., \& Reilly, T. (2015). A tale of twin tech: bitcoin and the WWW. Journal of Strategic and International Studies, X(2), 82-89 Available at: https://ssrn. com/abstract $=2601617$.

Forbes (2015). Americans trust tech firms more than banks for finance. 24 June. Available at https://www.forbes. com/sites/niallmccarthy/2015/06/24/americans-trust-techfirms-more-than-banks-for-finance-infographic/\#583802874 e94. Accessed 30 August 2019.

Fry, J. (2018). Booms, busts and heavy-tails: the story of bitcoin and cryptocurrency markets? Economics Letters, 171, 225229. https://doi.org/10.1016/j.econlet.2018.08.008.

Gandal, N., \& Halaburda, H. (2014). Competition in the cryptocurrency market. CEPR discussion paper no. DP10157. Available at: https://ssrn.com/abstract=2501640

Gazel, M., \& Schwienbacher, A. (2018). Entrepreneurial fintech clusters. SSRN Working Paper. https://doi.org/10.2139 /ssrn.3309067.

Giannetti, M., \& Wang, T. Y. (2016). Corporate scandals and household stock market participation. Journal of Finance, 71(6), 2591-2636. https://doi.org/10.1111/jofi.12399.

Glaser, F., Zimmermann, K., Haferkorn, M., Weber, M. C., \& Siering, M. (2014). Bitcoin - asset or currency? Revealing users' hidden intentions. In Twenty second european conference on information systems (ECIS). https://doi.org/10.1007 1978-3-319-42448-4_6.

Goldfarb, A., \& Tucker, C. (2019). Digital economics. Journal of Economic Literature, 57(1), 3-43. https://doi.org/10.1257 /jel.20171452.

Greenstein, S. M., \& Spiller, P. T. (1996). Estimating the welfare effects of digital infrastructure. In National Bureau of Economic Research Working Paper No. 5770. https://doi. org/10.3386/w5770.
Griffin, J. M., \& Shams, A. (2019). Is bitcoin really un-tethered? Journal of Finance, forthcoming. https://doi.org/10.2139 /ssrn.3195066.

Grohmann, A., Klühs, T., \& Menkhoff, L. (2018). Does financial literacy improve financial inclusion? Cross country evidence. World Development, 111, 84-96. https://doi.org/10.1016/j. worlddev.2018.06.020.

Gross, M., Hogarth, J., \& Schmeiser, M. (2012). Use of financial services by the unbanked and underbanked and the potential for mobile financial services adoption. Federal Reserve Bulletin, 98(4), 20. Available at: https://www.federalreserve. gov/pubs/bulletin/2012/pdf/mobile_financial_ services 201209.pdf. Accessed 24 December 2018.

Guiso, L., Sapienza, P., \& Zingales, L. (2018). Time varying risk aversion. Journal of Financial Economics, 128(3), 403-421. https://doi.org/10.1016/j.jfineco.2018.02.007.

Haddad, C., \& Hornuf, L. (2019). The emergence of the global fintech market: economic and technological determinants. Small Business Economics, 53(1), 81-105. https://doi. org/10.1007/s11187-018-9991-x.

Heilman, E., Kendler, A., \& Zohar, A. (2015). Eclipse attacks on bitcoin's peer-to-peer network. In Proceedings of the 24th USENIX Security Symposium (pp. 129-144). Available at: https://www.usenix.org/system/files/conference/usenixsecurity15 /sec15-paper-heilman.pdf. Accessed 9 December 2018.

Henfridsson, O., \& Bygstad, B. (2013). The generative mechanisms of digital infrastructure evolution. MIS Quarterly, 37(3; special issue: Critical realism in IS research), 907931. Available at: https://www.jstor.org/stable/43826006. Accessed 20 August 2019.

Henry, C. S., Huynh, K. P., \& Nicholls, G. (2018). Bitcoin awareness and usage in Canada. Journal of Digital Banking, 2(4), 311-337 Available at: https://www.ingentaconnect. com/content/hsp/jdb001/2018/00000002/00000004 /art00004.

Higgins, S. (2018). Financial technology adoption. Available at: https://seankhiggins.com/assets/pdf/higgins_jmp.pdf. Accessed 27 November 2019.

Hileman, G., \& Rauchs, M. (2017). Global cryptocurrency benchmarking study. https://doi.org/10.2139/ssrn.2965436.

Hoffman, P. T., Postel-Vinay, G., \& Rosenthal, J.-L. (2009). The role of trust in the long-run development of french financial markets. In K. S. Cook, M. Levi, \& R. Hardin (Eds.), Who can we trust? How groups, networks and institutions make trust possible (pp. 249-285). New York: Russell Sage Foundation.

Holt, T. J., Smirnova, O., Chua, Y. T., \& Copes, H. (2015). Examining the risk reduction strategies of actors in online criminal markets. Global Crime, 16(2), 81-103. https://doi. org/10.1080/17440572.2015.1013211.

Hornuf, L., Klus, M. F., Lohwasser, T. S., \& Schwienbacher, A. (2018). How do banks interact with fintechs? Forms of strategic alliance and their economic impact. SSRN working paper. Available at: https://ssrn.com/abstract=3252318

$\mathrm{Hu}$, A., Parlour, C. A., \& Rajan, U. (2018). Cryptocurrencies: stylized facts on a new investible instrument. SSRN Working Paper. https://doi.org/10.2139/ssrn.3182113.

Huang, W., Meoli, M., \& Vismara, S. (2019). The geography of initial coin offerings. Small Business Economics, 1-26. https://doi.org/10.1007/s11187-019-00135-y. 
Iansiti, M., \& Lakhani, K. R. (2017). The truth about blockchain. Harvard Business Review. Available at: https://hbr.org/2017 /01/the-truth-about-blockchain

Ingram Bogusz, C., \& Morisse, M. (2018). How infrastructures anchor open entrepreneurship: the case of Bitcoin and stigma. Information Systems Journal, 28(6), 1176-1212. https://doi. org/10.1111/isj.12204.

Iyidogan, E. (2018). An equilibrium model of blockchain-based cryptocurrencies. SSRN Working Paper. https://doi. org/10.2139/ssrn.3152803.

J5. (2018). Tax enforcement authorities unite to combat international tax crime and money laundering. In Montreal https://www.irs.gov/pub/irs-utl/j5-media-release-7-2-18.pdf.

Kahn, C. M., \& Roberds, W. (2008). Credit and identity theft. Journal of Monetary Economics, 55(2), 251-264. https://doi. org/10.1016/j.jmoneco.2007.08.001.

Kahn, C. M., McAndrews, J., \& Roberds, W. (2005). Money is privacy. International Economic Review, 46(2), 377-399. https://doi.org/10.1111/j.1468-2354.2005.00323.x.

Kamps, J., \& Kleinberg, B. (2018). To the moon: defining and detecting cryptocurrency pump-and-dumps. Crime Science, 7(1), 18. https://doi.org/10.1186/s40163-018-0093-5.

Kaskaloglu, K. (2014). Near zero bitcoin transaction fees cannot last forever. In The International Conference on Digital Security and Forensics (DigitalSec2014). Available at: http://sdiwc.net/digital-library/near-zero-bitcoin-transactionfees-cannot-last-forever.html. Accessed 27 November 2019.

Kethineni, S., \& Cao, Y. (2019). The rise in popularity of cryptocurrency and associated criminal activity. International Criminal Justice Review, 1-20. https://doi. org/10.1177/1057567719827051.

Kewell, B., Adams, R., \& Parry, G. (2017). Blockchain for good? Strategic Change, 26(5), 429-437. https://doi.org/10.1002 jjsc. 2143 .

Killeen, A. (2015). The confluence of bitcoin and the global sharing economy. In Handbook of digital currency (pp. 485-503). D. L. K: Elsevier. Edited by Chuen. https://doi. org/10.1016/B978-0-12-802117-0.00024-2.

Kim, T. (2017). On the transaction cost of bitcoin. Finance Research Letters, 23, 300-305. https://doi.org/10.1016/j. frl.2017.07.014.

Kliber, A., Marszałek, P., Musiałkowska, I., \& Świerczyńska, K. (2019). Bitcoin: safe haven, hedge or diversifier? Perception of bitcoin in the context of a country's economic situation A stochastic volatility approach. Physica A: Statistical Mechanics and its Applications. https://doi.org/10.1016/j. physa.2019.04.145.

Klus, M., Lohwasser, T., Holotiuk, F., \& Moormann, J. (2019). Strategic alliances between banks and Fintechs for digital innovation: Motives to collaborate and types of interaction. The Journal of Entrepreneurial Finance, 21(1), 1-23. Available at: https://digitalcommons.pepperdine. edu/jef/vol21/iss1/1/. Accessed 2 September 2019.

Komosny, D., Voznak, M., \& Rehman, U. S. (2017). Location accuracy of commercial IP address geolocation databases. Journal of Information Technology and Control, 46(3), 333344. https://doi.org/10.5755/j01.itc.46.3.14451.

Krause, M. J., \& Tolaymat, T. (2018). Quantification of energy and carbon costs for mining cryptocurrencies. Nature Sustainability, 1(11), 711-718. https://doi.org/10.1038 /s41893-018-0152-7.
Lagarde, C. (2018). Winds of change: the case for new digital currency. Singapore: International Monetary Fund. Available at: https:/www.imf.org/en/News/Articles/2018/11/13 /sp111418-winds-of-change-the-case-for-new-digitalcurrency. .

Larios-Hernández, G. J. (2017). Blockchain entrepreneurship opportunity in the practices of the unbanked. Business Horizons, 60(6), 865-874 https://doi.org/10.1016/j. bushor.2017.07.012.

Lavorgna, A. (2014). Internet-mediated drug trafficking: towards a better understanding of new criminal dynamics. Trends in Organized Crime, 17(4), 250-270. https://doi.org/10.1007 /s12117-014-9226-8.

Law Library of Congress. (2018). Regulation of cryptocurrency around the world. Available at: https://www.loc. gov/law/help/cryptocurrency/cryptocurrency-world-survey. pdf. Accessed 27 November 2019.

Li, T., Shin, D., \& Wang, B. (2018). Cryptocurrency pump-anddump schemes. SSRN Working Paper. https://doi. org/10.2139/ssrn.3267041.

Liang, T.-P., Wu, S. P.-J., \& Huang, C. (2019). Why funders invest in crowdfunding projects: role of trust from the dual-process perspective. Information \& Management, 56(1), 70-84. https://doi.org/10.1016/J.IM.2018.07.002.

Libra Association. (2019). An introduction to libra. Available at: https://libra.org/en-us/whitepaper. Accessed 30 August, 2019.

Luther, W. J. (2016). Cryptocurrencies, network effects, and switching costs. Contemporary Economic Policy, 34(3), 553-571. https://doi.org/10.1111/coep.12151.

Marian, O. (2013). Are cryptocurrencies super tax havens? Mich. L. Rev. First Impressions, 112(1), 38-48. https://ssrn. com/abstract $=2305863$.

Martino, P., Bellavitis, C., \& DaSilva, C. M. (2019). Blockchain and initial coin offerings (ICOs): a new way of crowdfunding. SSRN Working Paper. https://doi. org/10.2139/ssrn.3414238.

Masiak, C., Block, J. H., Masiak, T., Neuenkirch, M., \& Pielen, K. N. (2019). Initial coin offerings (ICOs): market cycles and relationship with bitcoin and ether. Small Business Economics, 1-18. https://doi.org/10.1007/s11187-01900176-3.

Maurer, B., Nelms, T. C., \& Swartz, L. (2013). "When perhaps the real problem is money itself!": the practical materiality of bitcoin. Social Semiotics, 23(2), 261-277. https://doi. org/10.1080/10350330.2013.777594.

McGinn, D., Birch, D., Akroyd, D., Molina-Solana, M., Guo, Y., \& Knottenbelt, W. J. (2016). Visualizing dynamic bitcoin transaction patterns. Big Data, 4(2), 109-119. https://doi. org/10.1089/big.2015.0056.

Miller, A., Litton, J., Pachulski, A., Gupta, N., Levin, D., Spring, N., \& Bhattacharjee, B. (2018). Discovering bitcoin's public topology and influential nodes. Available at: https://cs.umd. edu/projects/coinscope/coinscope.pdf. Accessed 27 November 2019.

Moser, M., Bohme, R., \& Breuker, D. (2013). An inquiry into money laundering tools in the bitcoin ecosystem. In 2013 $A P W G$ eCrime researchers summit (pp. 1-14). San Fransisco: IEEE. https://doi.org/10.1109 /eCRS.2013.6805780. 
Nair, S. (2019). Trust in tech is wavering and companies must act. In Edelman. https://www.edelman.com/research/2019-trusttech-wavering-companies-must-act.

Nakamoto, S. (2008). Bitcoin: a peer-to-peer electronic cash system. https://bitcoin.org/bitcoin.pdf. Accessed 9 December 2018.

NDIC. (2008). Money laundering in digital currencies. Washington, DC. Available at: https://www.justice. gov/archive/ndic/pubs28/28675/28675p.pdf. Accessed 27 November 2019.

Niepelt, D. (2020). Reserves for all? Central bank digital currency, deposits, and their (non)-equivalence. International Journal of Central Banking, forthcoming. Available at: https://ssrn. com/abstract=3254206

Ormsby, E. (2016). Silk road: insights from interviews with users and vendors. In J. Mounteney, A. Oteo, \& P. Griffiths (Eds.), The Internet and drug markets (European monitoring Centre for Drugs and Drug Addiction: Insights 21) (pp. 61-67). Luxembourg: Publications Office of the European Union.

Philippon, T. (2016). The fintech opportunity. NBER working paper no. 22476. Available at: http://pages.stern.nyu. edu/ tphilipp/papers/FinTech.pdf. Accessed 6 March 2019.

Poese, I., Uhlig, S., Kaafar, M. A., Donnet, B., \& Gueye, B. (2011). IP geolocation databases. ACM SIGCOMM Computer Communication Review, 41(2), 53. https://doi. org/10.1145/1971162.1971171.

Rau, P. R. (2017). Law, trust, and the development of crowdfunding. Available at: https://ssrn.com/abstract=2989056

Rauchs, M., Blandin, A., Klein, K., Pieters, G., Recanatini, M., \& Zhang, B. (2018). 2nd global cryptoasset benchmarking study. Available at: https://www.jbs.cam.ac. uk/fileadmin/user_upload/research/centres/alternativefinance/downloads/2018-12-ccaf-2nd-global-cryptoassetbenchmarking.pdf. Accessed 2 May 2019.

Raymaekers, W. (2015). Cryptocurrency bitcoin: disruption, challenges and opportunities. Journal of Payments Strategy \& Systems, 9(1), 30-46 Available at: https://www. ingentaconnect.com/content/hsp/jpss/2015/00000009 /00000001/art00005.

Reinhart, C. M., \& Rogoff, K. S. (2011). From financial crash to debt crisis. American Economic Review, 101(5), 1676-1706. https://doi.org/10.1257/aer.101.5.1676.

Sadhya, V., \& Sadhya, H. (2018). Barriers to adoption of blockchain technology. Available at: https://aisel.aisnet. org/amcis2018/AdoptionDiff/Presentations/20/. Accessed 27 February 2019.

Saiedi, E., Mohammadi, A., \& Broström, A. (2017). Distrust in banks and fintech adoption: the case of P2P loans. Swedish House of Finance research paper no. 18-6. https://doi. org/10.2139/ssrn.3124301

Sameeh, T. (2018). ICO basics - The difference between security tokens and utility tokens. Coinintelligence. Available at: https://www.cointelligence.com/content/ico-basics-securitytokens-vs-utility-tokens/.

Schuh, S., \& Shy, O. (2016). US consumers' adoption and use of bitcoin and other virtual currencies. Federal Reserve Bank of Boston Working Paper. Available at: https://www. banqueducanada.ca/wp-content/uploads/2015/12/usconsumers-adoption.pdf. Accessed 8 January 2019.

Shahzad, S. J. H., Bouri, E., Roubaud, D., Kristoufek, L., \& Lucey, B. (2019). Is bitcoin a better safe-haven investment than gold and commodities? International Review of Financial Analysis, 63, 322-330. https://doi.org/10.1016/j. irfa.2019.01.002.

Shavitt, Y., \& Zilberman, N. (2011). A geolocation databases study. IEEE Journal on Selected Areas in Communications, 29(10), 2044-2056. https://doi.org/10.1109 /JSAC.2011.111214.

Shiller, R. (2019). Bitcoin narratives. In Narrative economics: how stories go viral and drive major economic events (1st ed., pp. 3-11). Princeton, NJ, USA: Princeton University Press.

Shin, L. (2017). Here's the man who created ICOs and this is the new token he's backing. Forbes. https://www.forbes. com/sites/laurashin/2017/09/21/heres-the-man-who-createdicos-and-this-is-the-new-token-hes-backing.

Smith, K. (2019). Darknet transactions up 70\% — with BTC still the currency of choice. Available at: https://bravenewcoin. com/insights/darknet-transactions-up-70-with-btc-still-thecurrency-of-choice. Accessed 27 November 2019.

Soska, K., \& Christin, N. (2015). Measuring the longitudinal evolution of the online anonymous marketplace ecosystem. In Proceedings of the 24th USENIX security symposium Available at: https://www.usenix.org/system/files/conference/usenixsecurity15 /sec15-paper-soska-updated.pdf.

Spigel, B. (2017). The relational organization of entrepreneurial ecosystems. Entrepreneurship Theory and Practice, 41(1), 49-72. https://doi.org/10.1111/etap.12167.

Stigler, G. J. (1971). The theory of economic regulation. The Bell Journal of Economics and Management Science, 2(1), 3. https://doi.org/10.2307/3003160.

$\mathrm{Su}, \mathrm{J}$. (2019). Hackers stole over $\$ 4$ billion from crypto crimes in 2019 so far, up from $\$ 1.7$ billion in all of 2018 . Forbes. https://www.forbes.com/sites/jeanbaptiste/2019/08/15 /hackers-stole-over-4-billion-from-crypto-crimes-in-2019so-far-up-from-1-7-billion-in-all-of-2018/

Subramanian, R., \& Chino, T. (2015). The state of cryptocurrencies, their issues and policy interactions. Journal of International Technology and Information Management, 24(3), 25-40 Available at: https://scholarworks.lib.csusb.edu/jitim/vol24/iss $3 / 2$.

Sussan, F., \& Acs, Z. J. (2017). The digital entrepreneurial ecosystem. Small Business Economics, 49(1), 55-73. https://doi. org/10.1007/s11187-017-9867-5.

Svetlana, S., Kokkinaki, A., \& Ifigenia, G. (2017). In which distributed ledger do we trust? A comparative analysis of cryptocurrencies. In MCIS 2017 proceedings, 21. (p. 13). Available at: http://aisel.aisnet.org/mcis2017/21

Swartz, L. (2018). What was bitcoin, what will it be? The technoeconomic imaginaries of a new money technology. Cultural Studies, 32(4), 623-650. https://doi.org/10.1080 /09502386.2017.1416420.

Tasca, P. (2015). Digital currencies: principles, trends, opportunities, and risks. SSRN Working Paper. https://doi.org/10.2139 /ssrn.2657598.

Teo, E. G. S. (2015). Emergence, growth, and sustainability of bitcoin. In D. L. K. Chuen (Ed.), Handbook of digital currency (pp. 191-200). Elsevier. https://doi.org/10.1016/B9780-12-802117-0.00009-6.

Thakor, A. V. (2019). Fintech and banking. Journal of Financial Intermediation, in press. https://doi.org/10.2139 /ssrn.3332550. 
Thakor, R., \& Merton, R. (2018). Trust in lending. In NBER working paper no. 24778. https://doi.org/10.3386/w24778.

The Economist (2018). Chips off the block: from one cryptocurrency to thousands. The Economist's technology quarterly. Available at: https://www.economist. com/technology-quarterly/2018/09/01/fromonecryptocurrency-to-thousands. Accessed 27 November 2019.

Tilson, D., Lyytinen, K., \& Sørensen, C. (2010). Digital infrastructures: the missing IS research agenda. Information Systems Research, 21(4), 748-759. https://doi.org/10.1287 /isre.1100.0318.

U.S. Federal Reserve Board. (2019). How much U.S. currency is in circulation? Available at: https://www.federalreserve. gov/faqs/currency_12773.htm. Accessed 11 November 2019.

UNODC. (2019). World drug report 2019: global overview of drug demand and supply. https://doi.org/10.18356/bdc264 f4-en.

Van Alstyne, M. (2014). Why bitcoin has value. Communications of the ACM, 57(5), 30-32. https://doi.org/10.1145/2594288.

Van Hout, M. C., \& Bingham, T. (2014). Responsible vendors, intelligent consumers: silk road, the online revolution in drug trading. International Journal of Drug Policy, 25(2), 183189. https://doi.org/10.1016/j.drugpo.2013.10.009.

van Rooij, M., Lusardi, A., \& Alessie, R. (2011). Financial literacy and stock market participation. Journal of Financial Economics, 101(2), 449-472. https://doi.org/10.1016/j. jifineco.2011.03.006.

van Rooij, M. C. J., Lusardi, A., \& Alessie, R. J. M. (2012). Financial literacy, retirement planning and household wealth. The Economic Journal, 122(560), 449-478. https://doi. org/10.1111/j.1468-0297.2012.02501.x.

van Slobbe, J. (2016). The drug trade on the deep web: a law enforcement perspective. In J. Mounteney, A. Oteo, \& P. Griffiths (Eds.), The Internet and drug markets (European Monitoring Centre for Drugs and Drug Addiction: Insights 21) (pp. 77-83). Publications Office of the European Union. van Wegberg, R., Oerlemans, J.-J., \& van Deventer, O. (2018). Bitcoin money laundering: mixed results? An explorative study on money laundering of cybercrime proceeds using bitcoin. Journal of Financial Crime, 25(2), 419-435. https://doi.org/10.1108/JFC-11-2016-0067.

Vigna, P., \& Casey, M. J. (2015). The age of cryptocurrency: how bitcoin and digital money are challenging the global economic order. New York, N.Y: St. Martin's Press.

Wang, L., \& Pustogarov, I. (2017). Towards better understanding of bitcoin unreachable peers. Available at: https://arxiv. org/pdf/1709.06837.pdf. Accessed 27 November 2019.

Wang, K., Bellavitis, C., \& Da Silva, C. M. (2019). An introduction to blockchain, cryptocurrency and initial coin offerings. In A. Quas, Y. Alperovych, C. Bellavitis, I. Paeleman, \& D. S. Kamuriwo (Eds.), New frontiers in entrepreneurial finance research (pp. 1-21). Singapore: World Scientific. https://doi. org/10.1142/11344.

Wei, W. C. (2018). Liquidity and market efficiency in cryptocurrencies. Economics Letters, 168, 21-24. https://doi.org/10.1016/J.ECONLET.2018.04.003.

Winstock, A., Barratt, M., Maier, L., \& Ferris, J. (2018). Global drug survey (GDS) 2018. Key findings report. Available at: https://www.globaldrugsurvey.com/gds-2018/. Accessed 21 February 2019.

Xue, M., Hitt, L. M., \& Chen, P. (2011). Determinants and outcomes of Internet banking adoption. Management Science, 57(2), 291-307. https://doi.org/10.1287/mnsc.1100.1187.

Yermack, D. (2015). Is bitcoin a real currency? An economic appraisal. In D. L. K. Chuen (Ed.), Handbook of digital currency (pp. 31-43). Amsterdam: Elsevier. https://doi. org/10.1016/B978-0-12-802117-0.00002-3.

Yermack, D. (2018). FinTech in sub-saharan Africa: what has worked well, and what hasn't. In NBER working paper no. 25007. https://doi.org/10.3386/w25007.

Publisher's note Springer Nature remains neutral with regard to jurisdictional claims in published maps and institutional affiliations. 